Andrews University

Digital Commons @ Andrews University

2020

\title{
The Use of Differentiated Instruction by Teachers of the Columbia Union Seventh-day Adventists
}

Jennifer Jill Bianco

Andrews University, bianco@andrews.edu

Follow this and additional works at: https://digitalcommons.andrews.edu/dissertations

Part of the Teacher Education and Professional Development Commons

\section{Recommended Citation}

Bianco, Jennifer Jill, "The Use of Differentiated Instruction by Teachers of the Columbia Union Seventhday Adventists" (2020). Dissertations. 1731.

https://digitalcommons.andrews.edu/dissertations/1731

https://dx.doi.org/10.32597/dissertations/1731

This Thesis is brought to you for free and open access by the Graduate Research at Digital Commons @ Andrews University. It has been accepted for inclusion in Dissertations by an authorized administrator of Digital Commons @ Andrews University. For more information, please contact repository@andrews.edu. 


\title{
ABSTRACT \\ THE USE OF DIFFERENTIATED INSTRUCTION BY TEACHERS OF THE COLUMBIA UNION OF SEVENTH-DAY ADVENTISTS
}

\author{
By
}

Jennifer Jill Bianco

Chair: Janet Ledesma 


\title{
ABSTRACT OF GRADUATE STUDENT RESEARCH \\ Dissertation
}

\author{
Andrews University \\ School of Education
}

\section{Title: THE USE OF DIFFERENTIATED INSTRUCTION BY TEACHERS OF THE COLUMBIA UNION OF SEVENTH-DAY ADVENTISTS}

Name of researcher: Jennifer Jill Bianco

Name and degree of faculty chair: Janet Ledesma Ph.D.

Date completed: April 2020

The Problem

Teachers in the Columbia Union of Seventh-day Adventists were provided training in differentiated instruction training during the summers of 2013-2016. However, there were no formal follow-up communications to report or to share their experiences with implementing the newly learned method of instruction. The purposes of this study were (a) to describe the teachers' beliefs and levels of practice of differentiated instruction after completing the training; (b) to determine if there are differences in beliefs and practice; and (c) to describe methods of support for implementation of differentiated instructions. 


\section{Method}

This study used a mixed-method design. The quantitative section used an online survey which was emailed to the 93 teachers of the Columbia Union who completed the differentiated instruction training. Fifty-four (54) competed and returned the surveys. The qualitative section involved eight teachers who indicated their willingness to be interviewed regarding their experiences with teaching using differentiated instruction after they had completed the training. Items for the online survey and interview protocol were developed based on the differentiated instruction innovation configuration by Kirner (2009).

The quantitative data was. analyzed using descriptive statistics, Chi-square tests of association and a Z-test. The qualitative data analysis was conducted by identifying shared themes, patterns, characteristics and indicators present on the innovation configuration map and in the interviews. Coding of the transcribed interviews was completed by matching similar themes such as strategies, assessments, time, and collaboration. These codes were used to recognize noteworthy data that matched the categories of the innovation configuration categories of differentiated instruction.

\section{Findings}

Overall, between $84 \%$ to $91 \%$ of teachers believe in features of differentiated instruction in the areas of content, process and assessment. For the practice of these features, only $46 \%$ reported practicing the assessment statements, $69 \%$ for content the content statements, and $71 \%$ for the process statements. Wilcoxon signed rank tests indicated that there are statistically significant $(\mathrm{p}<.05)$ differences between beliefs and 
frequency of practice. Interviews with the eight teachers indicated that most teachers shared with and received ideas from other teacher concerning differentiated instruction. Most teachers also self-reflect and observe other teachers implement differentiated instruction.

\section{Conclusion}

The results indicate that teachers' level of practice is not consistent with their level of beliefs about differentiated instruction. Fewer teachers practice differentiated instruction, especially in the areas of assessment. There appears to be high levels of interactions among teachers in the implementation of differentiated instruction. Future staff developments should focus on ways to narrow the gap between beliefs and practice as well as include teachers beyond the Columbia Union with and without the training. 
Andrews University

School of Education

\title{
THE USE OF DIFFERENTIATED INSTRUCTION BY TEACHERS OF THE COLUMBIA UNION OF SEVENTH-DAY ADVENTISTS
}

\author{
A Research Study \\ Presented in Partial Fulfillment \\ of the Requirements for the Degree \\ Doctor of Philosophy
}

By

Jennifer Jill Bianco

April 2020 


\title{
THE USE OF DIFFERENTIATED INSTRUCTION BY TEACHERS OF THE COLUMBIA UNION OF SEVENTH-DAY ADVENTISTS
}

\author{
A Dissertation \\ Presented in Partial Fulfillment \\ Of the Requirements for the Degree \\ Doctor of Philosophy
}

By

Jennifer Jill Bianco

APPROVAL BY THE COMMITTEE:

Chair: Janet Ledesma

Dean, College of Education and

International Services, School of Graduate Studies Andrews

University

Alayne Thorpe

Member: Shirley Freed

Member: Jimmy Kijai

External: Ruth Horton

Date approved 
TABLE OF CONTENTS

LIST OF FIGURES …………………………….................................... vi

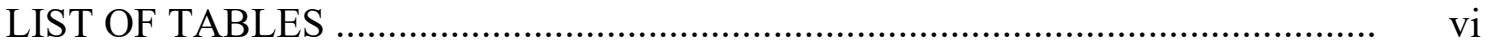

LIST OF ABBREVIATIONS ................................................................... vii

ACKNOWLEDGEMENTS ...................................................................... viii

\section{Chapter}

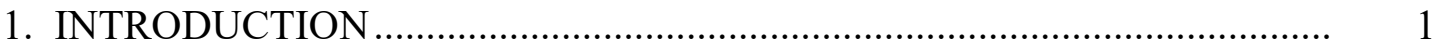

Background of the Problem........................................................................ 1

Context of the Study ................................................................................. 8

Statement of the Problem ...................................................................... 9

The Purpose of the Study ......................................................................... 11

Research Questions ........................................................................ 11

Research Design .............................................................................. 11

Conceptual Framework …………………………............................ 12

Definitions of Terms …………………………………………...... 14

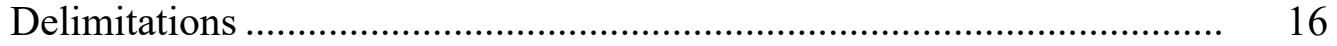

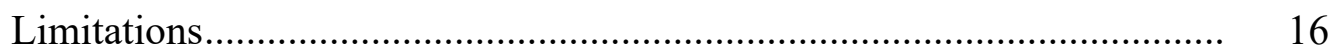

Significance of the Study .................................................................... 17

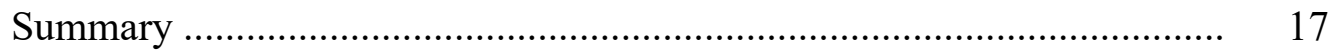

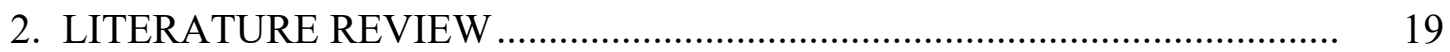

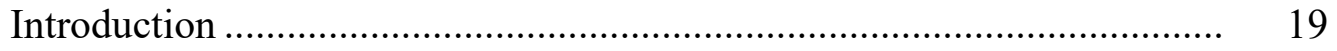

Professional Development and Learning ............................................... 19

Professional Development.............................................................. 20

Professional Learning ................................................................... 21

Concerns-Based Adoption Model (CBAM) ............................................. 24

Professional Support.......................................................................... 29

Peer-Coaching .......................................................................... 29

Professional Learning Communities ................................................. 32

Self-Reflection.................................................................... 34

Differentiated Instruction ..................................................................... 35 
Critical Elements of Differentiated Instruction .................................... $\quad 37$

Implementation Models ................................................................. 40

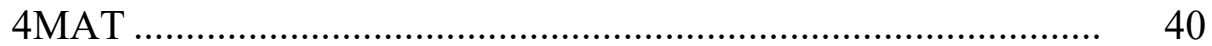

Gardner's Multiple Intelligence Theory ......................................... 41

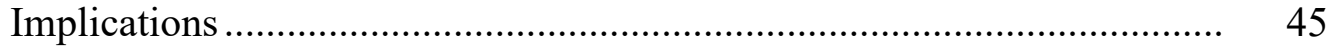

Summary of Literature ................................................................... 45

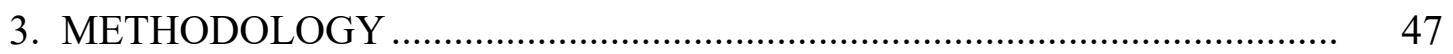

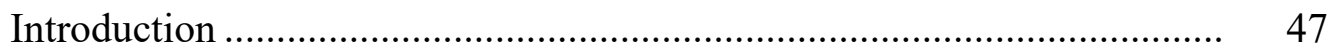

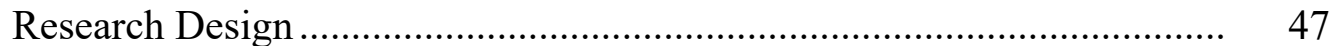

Description of Training ........................................................................ 49

Data Collection ................................................................................ 52

Innovation Configuration ............................................................. 53

Quantitative ............................................................................ 55

Convenience Sample ................................................................. 55

Quantitative Data Collection ........................................................ 55

Quantitative Data Analysis............................................................. 57

Reliability ................................................................... 58

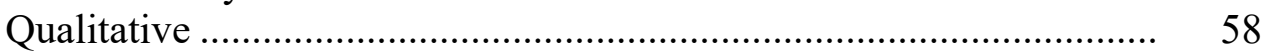

Purposeful Sample .................................................................. 58

Qualitative Data Collection ........................................................ 58

Qualitative Data Analysis............................................................. 59

Trustworthiness of Qualitative Data....................................................... 60

Generalizability of Qualitative Data........................................................... 61

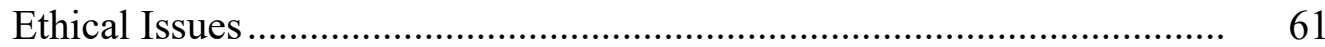

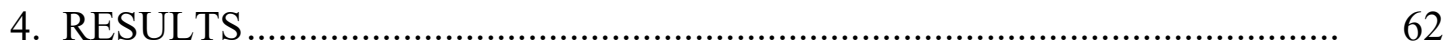

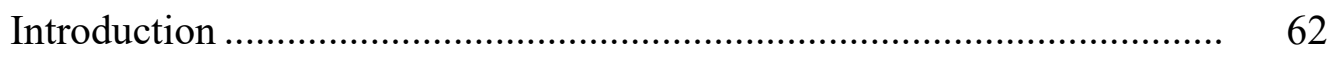

Participant Characteristics ..................................................................... 62

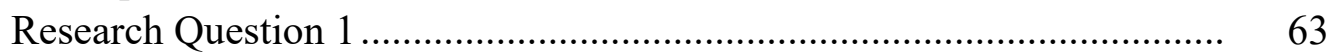

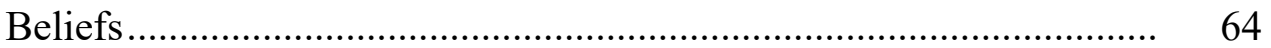

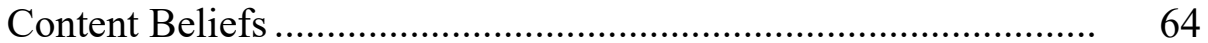

Process Beliefs....................................................................... 69

Assessment Beliefs ...................................................................... 74

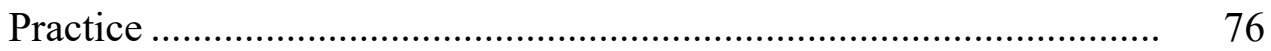

Content Practice........................................................................ 78

Process Practice ........................................................................ 81

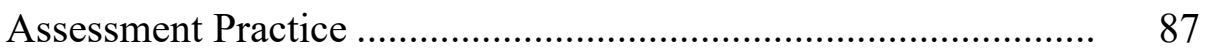

Research Question 1 Summary …………………………………...... 89

Research Question 2 .......................................................................... 91

Content Belief and Practice Statement Pairs ....................................... 91

Process Beliefs and Practice Statement Pairs .................................... 95

Assessment Practice and Belief Statement Pairs............................... 100

Research Question 2 Summary ........................................................ 104 
Research Question 3 …….............................................................. 105

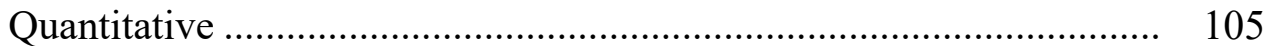

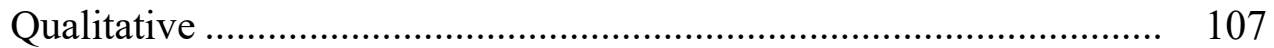

Research Question \#3 Summary ………………….......................... 108

Summary of Major Findings ............................................................... 109

5. KEY FINDINGS, DISCUSSION AND FUTURE CONSIDERATIONS ....... 113

Description of the Study ........................................................................ 113

Findings and Discussion................................................................... 114

Recommendations for Practice.......................................................... 128

Suggestions for Future Research ........................................................... 128

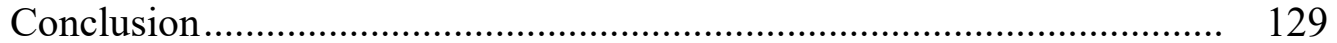

Appendix

A. Differentiated Instruction Beliefs/Practice Survey ………………………..... 131

B. Interview Questions............................................................................ 136

C. The Innovation Configuration (IC) Map for Differentiated

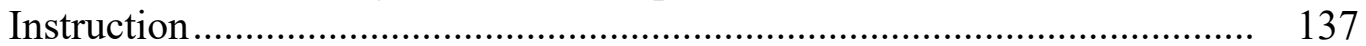

D. Innovation Configuration/Beliefs/Practice Correlation Chart....................... 142

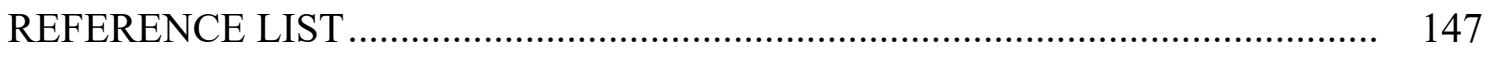

VITA 


\section{LIST OF FIGURES}

1. A Visual Representation of the Construct of an Innovation

Configuration Map

\section{LIST OF TABLES}

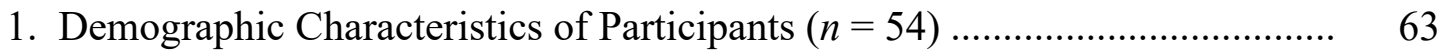

2. Content Area Survey Belief Statements …………………………………….... 65

3. Process Belief Statements.......................................................................... 70

4. Assessment Belief Statements ...................................................................... 75

5. Content Practice Statements ......................................................................... 77

6. Process Practice Statements …………………………………………….... 82

7. Assessment Practice Statements .................................................................... 88

8. Content Belief/Practice Statement Pairs ........................................................... 92

9. Process Belief/Practice Statement Pair............................................................ 96

10. Assessment Belief/Practice Statement Pairs ................................................... 101

11. Wilcox on Signed Rank Test for Comparing Overall Beliefs and

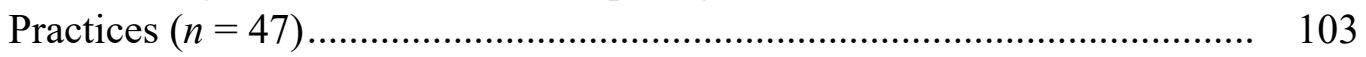

12. Support Statements .......................................................................... 106

13. Key Finding Overview of Categories Teachers Believe/Practice............. 110 


\section{LIST OF ABBREVIATIONS}

CBAM Concerns-Based Adoption Model

IC Innovation Configuration

NAD North American Division 


\section{ACKNOWLEDGEMENTS}

The journey to the completion of my dissertation has been a long one. I'm tremendously thankful for those who have stuck with me along this journey. I am extremely thankful for the support of my family- my husband and daughters who have lost much "wife and mommy time", have been my biggest cheerleaders and have encouraged me each and every time I was feeling discouraged and defeated. My parents and extended family who never wavered in their faith in my completion of this project. Their sideline support meant more than I could ever express.

My committee chair, Dr. Ledesma, and members Dr. Freed and Dr. Kijai, for their tireless work and continuous thoughtful feedback and suggestions. Their kindness spurred me to keep writing and working. They all promised to see me through and that has finally come to fruition. I cannot thank you enough for your time, energy, support and patience.

To the Columbia Union for sponsoring me to complete this research. It is my sincere hope that this study is useful to the office of education moving forward as we strive to do our very best for the children of God's kingdom.

And finally, and most importantly, to our Maker and King. Thank-you God for giving me all of the tools needed to complete this research. From the sponsorship, to the time, determination and individuals, each one was imperative in the completion of this journey. It is my desire to continue working and leading in the field of education for the purpose of bringing children to You. 


\section{CHAPTER 1}

\section{INTRODUCTION}

This study describes professional learning, differentiated instruction, and the support methods used when differentiated instruction was newly implemented. According to Knapp (2003), professional learning refers to "changes in the thinking, knowledge, skills, and approaches to instruction that form practicing teacher's repertoire" (p. 112-113). Professional development and professional learning opportunities are provided for educators to positively impact their teaching. In order for these opportunities to be capitalized upon, the information and methods learned must be utilized properly.

\section{Background of the Problem}

Stewart (2014) discussed the process of teacher learning and how it has progressed through a "reform" movement over the past decade as the fundamental belief links "high-quality professional development to higher-quality teaching and highquality teaching to student achievement" (p. 28). This movement has changed the way we look at professional development.

Professional development, as it has been generally practiced, consisted mainly

of one-time workshops. Teachers who attended these workshops were given information within a specific content area or teaching method and then they were expected to go back to their classroom to implement their newly gained knowledge with 
their students. While they may have had all of the necessary information and materials, they were not equipped with an arrangement for immediate feedback and support.

According to Taton (2015), "Consequently, the traditional approach to professional development replicates problems with traditional approaches to teaching and learning; - teachers inevitably became passive, disengaged, and struggled to apply what is being taught to their classrooms" (p. 4). Therefore, it can be said according to Taton (2015), that traditional, “professional development does not address the teacher's questions about their classrooms, or their students' specific needs" (p. 4).

In the past decade, administrators have realized there has been a missing component. Clark and Hollingsworth (2002) argued that it is imperative for teachers to be continually involved in professional development programs as they are "active learners" who individually shape their own professional growth through reflective participation and practice (p. 948). Grierson (2011) discussed that while professional development workshops and training are essential and necessary to obtain information, content, and experience, it is likely another component is crucial in order for the professional development content to become a reality in individual classrooms and in an individual teacher's repertoire.

Clark \& Hollingsworth (2002) stated: "there is little doubt that supporting teacher's abilities to construct professional knowledge is critically important to fostering educational improvement" (p. 5 as cited in Fullan, Hill \& Crevola 2006). The reform movement of this past decade of thought and practice has generated new strategies and support methods in the field of education. 
Professional development has become connected with a model of training from the "top-down." According to Hargreaves (2014), this model of professional development in-servicing is based on "the assumption that teachers need direct instruction about how to improve their skills and master new strategies" (p. 7).

While professional development is necessary, most schools and districts have recognized that teachers need to be engaged in authentic, valuable, learning experiences which will enable the teachers to grow professionally and improve academic instruction. When teachers buy into this position, there may be more cooperation and desire to maintain high standards and further their individual practice and repertoire after attending professional development training sessions.

Hargreaves (2014) discussed the cooperation of teachers when involved in professional development. He urged, "ownership over compliance, conversation over transmission, deep understanding over enacting rules and routines, and goal-directed activity over content coverage" (p. 147). Enabling the teachers to have intentional conversations with their colleagues regarding classroom practice and encouraging support methods such as peer-coaching, self-reflection, and others, are important professional learning methods for administrators to consider as on-going in the practice of professional development.

Professional development and professional learning are two separate entities in the field of education. (Gusky, 1994) stated that "research on professional development in education is quite extensive. For the most part, however, this research has documented the inadequacies of professional development" (p. 4). Current literature highlights the reality of the shortcomings of professional development conducted 
without the informal process of professional learning. It needs to be understood that professional learning is more than professional development.

Knapp (2003) viewed professional learning as a variety of activities which are both formal and informal. These activities engaged teachers and administrators in innovative learning about their profession. Beatrice Avalos (2011) notes:

Teacher professional learning is a complex process which requires cognitive and emotional involvement of teachers individually and collectively, the capacity and willingness to examine where each one stands in terms of convictions and beliefs and the perusal and enactment of appropriate alternatives for improvement or change. (p. 12)

Distinguishing between professional development and professional learning is key for administrators as they provide opportunities for both of these essential training tools for their teachers.

Directly applying knowledge and new practice techniques in the classroom and allowing teachers to engage in critical inquiry through professional practice and part of a professional learning community can lead teachers to "feel empowered, less isolated, more effective, and more confident when implementing new strategies" (Grierson (2011) p.7 as cited in Fullan, Hill, \& Crevola (2006).

According to Fullan (2007) when teachers work with each other on problems in their classrooms professional learning takes place. Collaboration, unstructured voluntary opportunities, and learning in a professional learning community of teachers would then be more effective to the growth of the teacher than participating in a professional development one-day activity without any follow-up support or collaboration. Thus, it may be understood that teachers who collaborate and are active members of a professional learning community, would more positively affect the students and their learning than those who lacked collaboration with colleagues. 
According to Stewart (2014) "learning communities thrive well when all participants are invested in the work they are doing” (p. 28). Intentionally creating professional learning communities to work together on new learning techniques and problems, as well as classroom practice, would be beneficial for administrators in helping their teachers to be competent and confident in their practice.

If professional learning is fundamentally about teachers being trained, learning, implementing new ideas into their classrooms, and collaborating with their peers, the question may be asked, how do we know teachers are implementing these new ideas with understanding and integrity? While a group of teachers may be trained professionally in the same content and method, there are several factors which may allow for differences between the curriculum or method design and the actual implementation. According to Kauchak \& Eggen (1993), these factors may be attributed to teacher and student characteristics, motivation, curriculum content, time, and resources (p. 20).

Educational leaders introduce ideas and methods to their teachers with the hope that the implementation will result in increased learning among students. However, successfully implementing new ideas and programs involves much more than training, materials, and resources. One of the overlooked factors is the human element. People are actually doing the work and each one will respond to a new idea and program with their own set of beliefs and attitudes. Therefore, each individual will interpret the implementation in somewhat of a different way.

There are various strategies used to foster professional learning. The strategy used in this study to examine the advancement and progression of change in the 
implementation of a new method or curriculum in a classroom is the Concerns-Based Adoption Model (CBAM). The CBAM model has been used extensively to examine the advancement and progression of change, the concerns, levels of use and the perceptions of teachers participating in professional development and professional learning activities and classroom implementation. The CBAM model acknowledges that learning brings change. Self-oriented questions such as "What is it?" and "How will it affect me?" are asked. After these questions are addressed and resolved, more task-oriented questions such as "How do I do it?", "How can I use these materials more efficiently?", "How can I organize myself?" and "Why is it taking so much time?" emerge. Finally, when all these concerns are largely resolved, the teacher can focus on impact. Teachers may ask "Is this change working for my students?" and "Is there something that I could do that would work better?" (Loucks-Horsley, 1996).

A component of the CBAM, an innovation configuration map (IC), is an effective way to facilitate a change process within an educational setting. Hall and Hord (Ceedar Center, 2011) recognized innovation configurations as the big picture of what administrators who are implementing the change are visualizing. Individuals can look at an IC so they can clearly see and understand what is expected.

According to the Appalachia Regional Educational Laboratory (2016), an IC map answers the questions "What is the innovation?", "How is it used?", and "What does it look like when implemented?" It provides a common language and "establishes a continuum of acceptable and unacceptable variations of a practice" giving an idea of what the innovation should look like before any implementation occurs. 
An IC map will assist in moving from "less than ideal, to ideal" in the implementation of an innovation (p. 50). An innovation configuration has been used extensively to determine the extent to which educational professional development procedures are implemented in different teaching methods, such as differentiated instruction.

Differentiated instruction is not a new way of teaching. Dixon, Yssel, McConnell \& Hardin (2014) state:

Diversity in learning abilities, the idea that students learn differently from one another, is not a new concept. One size does not fit all when instructing students because they differ in a number of ways. To meet student needs, teachers must adjust both curriculum and instruction for various groups of students. (p. 112)

Even in classes where there is one grade, there are several different levels of academic achievement, student interest, and learning needs. According to Latz, Neumester, Adams, and Pierce (2009), most classrooms contain a group of students who perform academically with a variety of grade levels; therefore, the teachers cannot always "teach to the middle" and have academic success with all of their students.

Teaching with the differentiated instruction method is challenging and is often supported with professional development and professional learning opportunities such as one-day in-services, workshops as well as a variety of support methods such as peercoaching, self-reflection, and professional learning groups. In a study of teachers being required to implement differentiated instruction, Jewett and MacPhee (2012) write:

They (the teachers) share their experiences, stories, tools, and methods, and through these kinds of interactions, they learn how to do their work better. This collaborative sharing of knowledge about teaching and learning- as well as the ensuing questions that were generated- served as the core of the peer-coaching experiences. (p. 106) 
In summary, professional development should lead to professional learning, which includes support methods. Giving teachers support they need to acquire this outcome is paramount in obtaining a program in which teachers are learning, engaging, and stimulating their students with professional knowledge and professional practice. One way for administrators to provide support to their teachers is to create a professional learning environment, which will allow collaboration, reflection, peercoaching, and other support methods.

\section{Context of the Study}

According to Greenleaf (2005) Seventh-day Adventist (SDA) schools began in the nineteenth century when the church was first being organized as a denomination. In 1853, the very first church school began in Buck's Bridge, New York. Five families sent their children to this school. It existed for only three years. However, during this time, two other small church schools were organized in both Michigan and Vermont. It became the norm to begin a church school with every Seventh-day Adventist church that was opened. With the support of both the churches and the Seventh-day Adventist Headquarters, there were 220 church schools connected with churches in North America. Now there are over 8,800 SDA schools, colleges, and universities worldwide (Adventist Archives-Educational Program, N.D.).

According to the 2018-2019 statistical data on the Adventist Archives website, there are 712 elementary schools in North America. (Adventist Education-Statistics, N.D.) The majority of these schools are considered "small" schools and have multiple grade levels of students in each classroom. The term "multi-grade" is commonly

defined as a classroom where there is more than one grade level taught in the same 
classroom by the same teacher. The teachers are responsible for teaching different grades as well as various academic levels within each grade. Often the ability levels of individual students cross-grades enabling the teachers to group them differently according to their interests and their academic levels. Seventh-day Adventist classrooms and curriculums also lend themselves to being able to teach to different learning styles and preferences. This fits directly with the concept of differentiated instruction.

In the summer of 2013, the Columbia Union of Seventh-day Adventists began to train their teachers in a series of three trainings of differentiated instruction. There were three cohorts for a two-year, three-day per summer training for a combined total of 6 days of training for each participant. A total of 93 teachers completed the training. The Columbia Union has not formally collected data on the understanding, implementation and support methods following the training of the teachers in differentiated instruction.

This study explored three concepts: professional development, professional learning, and support methods and how they relate to the differentiated instruction training, beliefs, and practice of the teachers of the Columbia Union.

\section{Statement of the Problem}

Educational organizations spend valuable money on training teachers in bestpractice techniques. They often make assumptions that because the teachers have been trained, they return to the classroom and implement the newly-learned strategies with confidence. According to Birman, Desimone, Porter, and Garet (2000) the research on teacher professional development is limited and there is "relatively little systematic research about the effect of professional development on improving teaching or on improving student outcomes" (p.6) after training events. However, teachers may 
actually be frustrated, or they may not fully know how to implement the new material into their current routines. They also may not feel comfortable with the material, or the need for ongoing support when implementing new materials and strategies. Are educational organizations using resources not just on training teachers, but also ensuring the newly trained teachers are obtaining the support they need to be successful?

According to the research designed to understand the process of change in teacher practice as a result of professional development experiences, Henry and Opfer (2004) and Neville and Robinson (2003) discuss that there continues to be a lingering notion that the practice of teachers is changed by professional development, yet it is not clear what specifically influences the change. Also, according to Armour and Yelling (2004), Desimone, Porter, Garet, Yoon, and Birman (2002) Garet, Porter, Desimone, Birman, and Yoon (2001), Hiebert (1999), Birman et al. (2000) and Tolbert (2001) there is not a lot of direct proof that has been linked to both teacher practices and student learning that has been used to look at the success of professional development opportunities.

Similarly, at the conclusion of the differentiated instruction training provided by the Columbia Union of Seventh-day Adventists from 2013-2016, the teachers that were trained did not have formal follow-up communications to report or to share their experiences with implementing the newly learned method of instruction. It may not have been clear to administrators if the teachers understood differentiated instruction, if they actually implemented it into their classrooms, or how they may have felt during this process. 
While there was a tremendous amount of money and resources spent on this professional development endeavor, there was no research on how the training impacted teacher professional development. In addition, there was no study on how differentiated instruction was implemented into the classroom. Most importantly, there was no way of identifying the type of support or assistance that was needed for a meaningful and worthwhile training effort.

\section{The Purpose of the Study}

The purpose of this study is to describe how teachers of the Columbia Union of Seventh-day Adventists implemented differentiated instruction in their classrooms after completing the training. The purpose also is to determine if the teachers used any type of on-going support during their implementation.

\section{Research Questions}

This study was guided by the following research questions:

1. How do teachers who have attended differentiated instruction workshops describe their beliefs and practices concerning the use of differentiated instruction in their classrooms?

2. How do their beliefs of differentiated instruction compare with their classroom practices?

3. How do teachers report and describe various methods of support on their implementation of differentiated instruction?

\section{Research Design}

This is a mixed-methods study that used data collected from teachers in the Columbia Union who were in one of the cohorts of the two-year summer training of 
differentiated instruction from 2013-2106. The ninety-three teachers who completed the training were invited to complete the survey. There were fifty-three surveys returned.

A mixed-methods approach was chosen for this research as it gives a complete understanding and picture of the beliefs and practices of differentiated instruction by using both quantitative and qualitative data. Teddlie and Tashakkori (2003) state "a mixed-methods approach is helpful in that one is able to conduct in-depth research and it provides a more meaningful interpretation of the data being examined."

\section{Conceptual Framework}

The conceptual framework for this study was built on teacher's beliefs and practices, professional development and professional learning, differentiated instruction, which consists of the teacher differentiating content, process, and the assessment of the curriculum being taught in the classroom, and support methods. Smylie (1988) discusses that the beliefs of the teacher is the biggest predictor of the change of their individual professional practice. According to Avalos (2011), the understanding of professional development of teachers is about "teachers learning, learning how to learn, and transforming their knowledge into practice for the benefit of student growth" ( $p$. 10). Buxton, Allexsaht-Snider, Kayumova, Aghasaleh, Choi \& Cohen (2015) discussed that "while professional development, content, active learning, coherence, duration, and collective participation" may "be necessary for effective teacher professional learning, they are not sufficient to ensure enactment of professional learning goals" (p. 500).

Knapp (2003) claimed that professional learning may be defined as changes in “one's capacity for practice (i.e. changes in professional relevant thinking, knowledge, skills, and habits of mind) and/or changes in the practice itself" (p. 113). 
Differentiated instruction is an approach to instruction and curriculum that takes into account student differences, strengths, and preferences. According to Tomlinson \& Jarvis (2009) "it provides a framework for responding to differences in student's current and developing levels of readiness, their learning profiles, and their interests, to optimize the match between students and learning opportunities" (p. 113). When using this method, teachers will differentiate the curriculum content, classroom process, and student assessment to meet the individual needs of the students.

According to Dixon et al (2014) "teachers are the ones who take charge of these modifications, and their skill in understanding the characteristics of student learning and then using this knowledge in adapting lessons is paramount to success in this complex process" (p. 113). It is the responsibility of the trained teacher, who understands the characteristics of their students, to use their knowledge in adapting lessons in order to use differentiated instruction to better the learning environment, process, and to provide any adjustments to curriculum and content to meet the needs of individual students.

Implementing any new method, such as differentiated instruction, can be a difficult, time-consuming endeavor. According to Dixon et al. (2014) "allowing teachers to observe each other differentiate lessons, providing feedback to each other after the observation, and giving time for them to collaborate on shared lessons also provide reinforcement for actually practicing what they have learned" (p. 125). Joyce and Showers (2002), reported that teachers benefit from this cycle of simulation, practice, and feedback to enhance their own growth and development and enrich their instruction (p. 2, 3). Stover, Kissel, Haag \& Shoniker (2011) discussed that coaching provides self-reflection, a form of professional learning, with a differentiated approach 
to meet the diverse needs of teachers (p. 498). Busher (1994) found that peer coaching positively increased students' perceptions of their teacher's effectiveness (p. 3).

Another form of support is teacher self-reflection. There are many ways for a teacher to perform self-reflection. These include, but are not limited to, videos, journals, observation records, and artifacts. The type of self-reflection will vary from teacher to teacher, but all will be helpful, if used properly, in the professional growth of the teacher.

\section{Definitions of Terms}

The following terms and definitions provide clarity and context for this study: Assessment: $a$ product that reflects student understanding- tends to be tangible e.g. report, test, brochure, PowerPoint, performance, etc.

Concerns-Based Adoption Model (CBAM): a model used to monitor and guide the change process within education (Hall, Wallace, \& Dossett, 1973). The CBAM consists of three diagnostic tools: SoCQ, Levels of Use, and Innovation Configuration

Content: includes curriculum topics, concepts or themes which reflect standards and presents facts and skills

Columbia Union Conference: an Adventist organization that provides

administrative leadership, governance and support services to eight Mid-Atlantic States and their respective conferences for ministries, including education.

Differentiated Instruction: an approach of teaching where teachers proactively

plan varied approaches to what students need to learn, how they will learn it, or how they will show what they have learned in order to increase the likelihood that each student will learn as much as he or she can, as efficiently as possible. (Tomlinson, 1999, p.5) 
Innovation Configuration: a tool used in this study that helped to identify the understanding and fidelity of teachers using differentiated instruction in their classrooms. It allows for deciphering observable behaviors and noted understanding of concepts.

$N A D$ : Abbreviation for North American Division, the sub-entity of the General Conference of Seventh-day Adventists.

Peer Coaching: a "confidential process through which two or more professional colleagues work together to reflect on current practices; expand, refine, and build new skills; share ideas; teach one another; conduct classroom research; or solve problems in the workplace" (Robbins, 1991, p.1).

Process: suggests how students make sense of and understand information and ideas being studied; reflects specific student learning styles as well as their learning preferences

Professional Development: Generally, a one-time workshop or training within a specific content area or teaching method, attended by teachers to give them information and then to return to their classroom to implement.

Professional Learning: "coherent, sustained, and evidence-based strategies that improve educator effectiveness and student achievement, including job-embedded coaching or other forms of assistance to support educator's transfer of new knowledge and skills to their work" (New Jersey Education, n.d.)

Professional Learning Community: "a place in which teachers and administrators of a school continually seek and share learning and act on that learning" (Astuto, Clark, Read, McGree, \& Fernandez, 1993, p. 2) 


\section{Self-Reflection:}

involves thinking about and critically analyzing one's actions with the goal of improving one's professional practice. Engaging in reflective practice requires individuals to assume the perspective of an external observer in order to identify the assumptions and feelings underlying their practice and then to speculate about how these assumptions and feelings affect practice. (Imel, 1992, p. 2)

\section{Seventh-day Adventist School:}

Adventist education imparts more than academic knowledge. It fosters a balanced development of the whole person spiritually, intellectually, physically and socially. Its tune dimensions span eternity. It seeks to develop a life of faith in God and respect for the dignity of all human beings; to build character akin to that of the Creator; to nurture thinkers rather than mere reflectors of others' thoughts; to promote loving service rather than selfish ambition; to ensure maximum development of each individual's potential; and to embrace all that is true, good, and beautiful. (Adventist Education-About, N.D.)

\section{Delimitations}

This study was delimited to Seventh-day Adventist elementary teachers in the Columbia Union Conference who completed the training in the differentiated instruction method of teaching. The information and data collected in this study investigated only the teacher's and the researcher's perceptions of how they described their beliefs and practices concerning the use of differentiated instruction in their classroom and how they described methods of on-going support. It is also delimited to the understanding of the researcher on the fidelity of implementation, as shown by the innovative configuration.

\section{Limitations}

The limitations of this study were the participant's willingness to participate in the interviews. It was also limited by the ability of the participating teachers to reflect and report accurately their thoughts on their differentiated instruction efforts. Some teachers did not complete every question on the survey given by the researcher which 
limited accurate data and the interpretation of such data. An additional limitation would be that the data collected in this study was self-reported from the teachers on their practice and not personally observed by the researcher. Some educators may have been prohibited from implementing a new method or to practice it with integrity due to not understanding the method, time to prepare, or other various factors.

Another limitation could have been the inhibition of the individual teachers to report negatively about the Columbia Union training as it is a relatively small group and they may have had a fear of being identified.

\section{Significance of the Study}

This study is significant because it shows the beliefs and practices of teachers who try to implement differentiated instruction following professional development training. This study is also significant to show that ongoing support in various ways is paramount for the success of teachers after professional development training. It will contribute to the professional practices of educators and administrators in the Columbia Union as well as other educational circles.

The study may also be significant in understanding how increased professional learning of the teacher takes place in the classroom after professional learning development trainings. The information gleaned from this study also gives school administrators insight on how to reach and support their teachers in the best way possible to improve instruction.

\section{Summary}

Chapter 1 provided an introduction, overview, context, and background of the problem for the research study. It also explained the research questions as they related 
to the problem and purpose. The key definitions relating to the study, the research design and delimitations, and limitations are also included in Chapter 1. Chapter 2 includes a review of the literature on professional development and professional learning, the concerns-based adoption model (CBAM), and professional support methods. It also includes the differentiated instruction method of teaching as well as implementation models.

The methodology of the research study is described in Chapter 3 including a description of the interviews and data collection procedures. Chapter 4 discusses in detail the analysis, themes and the overall results of the study. Chapter 5 describes the results of the study with a discussion and analysis of the findings, including suggestions and recommendations for further research in this field. 


\section{CHAPTER 2}

\section{LITERATURE REVIEW}

\section{Introduction}

This literature review provided the framework and context for the study. Professional development and professional learning were described in detail to set the foundation for the basis of this research. Differentiated instruction is the method of instruction the participants of this study were professionally trained in. Some theoretical frameworks and the three main areas: content, process, and assessment, of differentiated instruction were researched and explored.

The literature examined also focused on various support methods as a tool for teachers implementing a new method in their classroom. Two components of the CBAM model of the measurement of beliefs and attitudes of change, the innovation configuration and the stages of concern, were also reviewed.

\section{Professional Development and Learning}

For many years educators have been encouraged, or even coerced, into participating in various forms of training. It was expected that after the training, their beliefs, as well as their practices, would change so that student achievement would improve. There is some research showing that there is a relationship between beliefs and practices. According to Good (1987), teacher's beliefs are linked to student

performance. The beliefs of teachers are key forces in decisions that teachers make and 
actions that influence the achievement of their students. But what is that relationship, and what kinds of professional development result in the professional practice that will result in the needed changes in the classrooms? This section differentiates between professional development and professional learning.

\section{Professional Development}

According to Desimone (2009), most professional development opportunities for educators rely on a field expert to model and distribute the information and techniques to the teachers. Generally, this is an in-service that takes place one time where the participants receive the newest information and best-practice techniques. McLesky \& Waldron (2002) suggest that this method relies completely on the participants to then implement their new knowledge, as well as practice the new techniques on their own. This method of instruction does not take into account individual experience of the teacher, prior knowledge, or the specific setting or subject matter. Instead, it assumes all participants are on the same level of knowledge and will be returning to very comparable classrooms with similar students.

Van Harpen (2015) discussed that professional learning is more than professional development. She described seven standards that professional learning is focused on. They include "learning communities, leadership, resources, data, learning designs, implementation, and outcomes" (p.11). These standards provide a framework for a "multi-dimensional working definition of professional growth opportunities, which include seeking, accessing, and acquiring knowledge, skills, and dispositions for effective and continuous self-improvement" (p. 11). 
These seven standards are described by Mizell, Hord, Killion \& Hirsh (2011) as professional learning that increased educator effectiveness and results for all students:

1. Learning Communities: "Occurs within learning communities committed to continuous improvement, collective responsibility, and goal alignment."

2. Resources: "Requires prioritizing, monitoring, and coordinating resources for educator learning."

3. Learning Designs: "Integrates theories, research, and models of human learning to achieve its intended outcomes."

4. Leadership: "Requires skillful leaders who develop capacity, advocate, and create support systems for professional learning."

5. Data: "Uses a variety of sources and types of student, educator, and system data to plan, assess, and evaluate professional learning."

6. Implementation: "Applies research on change and sustains support for the implementation of professional learning for long-term change."

7. Outcomes: "Aligns its outcomes with educator performance and student curriculum standards" (p. 41)

\section{Professional Learning}

Knapp (2003) describes professional learning as "changes in the thinking, knowledge, skills, and approaches to instruction that form practicing teacher's or administrator's repertoire" (p. 112-113). Hirsch (2009) wrote that "improving professional learning for educators is a crucial step in transforming schools and improving academic achievement" (p. 3). 
Dixon et al. (2014) noted that professional learning opportunities should "not only introduce the topic, but they should also allow teachers to practice the strategy in a workshop setting in which the coach helps them write and review their own lessons, assuring them of greater success in the classroom" (p. 114).

Joyce \& Showers (2002) proposed that effective professional learning comprises of continued modeling and practice, feedback from colleagues and administrators, as well as reflection over a period of time. Roach (1996) discusses that professional learning in education allows for problem solving where the teachers are able to collaborate to identify resources and strategies that meet their students' needs.

There is much research on what constructs meaningful and effective professional learning qualities. Desimone (2009), discussed four powerful professional learning qualities. The first quality examined is the need to be "individualized and school-based." Teachers learn best when they are applying and learning within their own classrooms through "practice and self-reflection." Problem-solving will focus directly on the individual needs to the teachers and will provide ongoing support (p. 76).

The second professional learning quality is to "utilize coaching and other follow-up procedures." According to Desimone (2009), it is essential for professional learning to engage teachers in observations, peer support, and ongoing meaningful feedback in order to increase confidence in teachers (p. 76).

The third professional learning quality is to "engage in collaboration." When teachers meet regularly to discuss, plan and differentiate lessons, outcomes will allow for professional growth as well as increased student achievement. According to Kennedy \& Shiel (2010) frequent meetings lead to "an open and collaborative 
atmosphere where teachers can feel safe to share their concerns and brainstorm freely with their colleagues, which leads to practice that is more successful" (p. 376).

Finally, the fourth professional learning quality is to "embed practices into the daily lives of teachers." Successful collaboration is a process that requires ongoing dialog, practice, and reflection. Cochran-Smith and Lytle (1999) state that "collecting and analyzing data of daily life in schools is critical to professional development" ( $p$. 22). This can take the form of various activities from as simple as a journal entry, to a formal problem-solving session. The most important takeaway from the analyzation of data is to look carefully at the "change process throughout the stages of implementation" (p. 76).

According to Nishimura (2014), this form of intimate professional learning can sometimes be daunting to teachers because they are used to being secluded in their own personal classrooms; however, the positive results of peer coaching and colleague collaboration can easily outweigh uncertainty. Desimone (2009) discusses "the most powerful teacher learning and application occur inside individual teacher's classrooms through practice and self-reflection" (p. 76).

The staff at the Research and Development Center for Teacher Education at the University of Texas at Austin began an investigation as to what actually would happen when teachers were asked to "change their practices or adopt an innovation." This process resulted in the Concerns-Based Adoption Model (CBAM) (Hall et al., 1973). This is now one of the widely-used models for change innovations. 


\section{Concerns-Based Adoption Model (CBAM)}

The concerns-based adoption model (CBAM) originated from a 1969 study by Fuller and Case. Their study reviewed the satisfaction of teacher-education students for teacher preparation, as well as a three-stage developmental model that was related to their concerns. The CBAM system developed statements about their concerns as well as being able to score those concerns. Fuller and Case (1969) could identify feelings and perceptions using this system. After this study was complete, Hall (1974) used Fuller and Cases' (1969) concern levels into a scoring system manual.

The concerns-based adoption model (CBAM) provides a technique that allows educational administrators and leaders to give individuals in a program or training, supports which will allow for the best possible level of success. CBAM is the measurement of beliefs and attitudes over a period of time instead of during a single event. As discussed by (Anderson, 1977), the concerns-based adoption model (CBAM) is a framework and methodology for the "measurement, description, and explanation" of various phases of the implementation of instruction and curriculum innovation. There are five assumptions of this model.

The first assumption is that change is a process, not an event that will take place immediately. It takes three to five years to completely implement and make changes in classroom practice.

Second, change is individual. When an institution wants to facilitate change, it must first focus on the change of individual members. Different people have different needs. If something is going to be fully implemented, the type of assistance and help needed is going to vary depending on individuals and their specific needs. 
Third, change is extremely personal. Giving attention to the individual feelings

of individuals is crucial in influencing the successful implementation and overall outcome of change. Often, personal concerns can be perceived as being resistant.

However, resistance to change is a natural phenomenon as individuals want and need to know how something will affect them personally.

Fourth, as teachers progress through the stages their perceptions of capability and level of skill will change regarding the innovation. As they begin to grow through the process, assistance needs will also vary and need to be adjusted accordingly.

Finally, the fifth assumption is the facilitators of change must be available to individuals, proceed systematically with regular and consistent assessment while providing support (Hall \& Loucks, 1978) (as cited by Tunks \& Weller, 2009). This can look like professional learning groups, coaching, formal observations, conversations, or any other variety of assessment. The important factor is that it is consistent and supportive to meet the needs of the individuals.

Three components of CBAM are considered diagnostic dimensions. They assist in assessing and guiding the process of effective implementation of a new teaching method. According to Hord, Stiegelbaur, Hall, \& George (2006), they are:

(1) Innovation Configurations: An Innovation Configuration Map provides a clear picture of what constitutes high-quality implementation. It serves as an exemplar to guide and focus staff efforts.

(2) Stages of Concern: The Stages of Concern process, which includes a questionnaire, interview, and open-ended statements, enables leaders to identify staff members' attitudes and beliefs toward a new program or initiative. With this knowledge, leaders can take actions to address individuals' specific concerns.

(3) Levels of Use: The Levels of Use interview tool helps determine how well staff, both individually and collectively, are using a program. Levels range from nonuse to advanced use. When combined with the Innovation 
Configuration and first-hand observations, this information can help staff effectively implement a new program. (p. 236)

When these components are used regularly, it helps determine problems or issues teachers may have when implementing a new method. These tools will help administrators or leaders problem-solve on how to help the teachers for the most positive outcome. When individual comfort and competence increases, they can move past their personal concerns to work towards achieving desired outcomes. Also, it needs to be understood that the beliefs and practice of teachers influence each other. Beliefs do not occur without practice and vice versa. According to Ertmer (2005), teacher attitudes or beliefs are the dominant factors in innovation integration.

In the 1970s and 1980s, the innovation configuration component was developed by researchers at the Research and Development Center for Teacher Education at the University of Texas at Austin. "Since its development, researchers have tested CBAM for reliability and validity" (Hord, et al., 2006). Currently, CBAM components are used in educational, organizational, and research settings.

Various studies have been conducted using CBAM. A study by Roach, Kratochwill \& Frank (2009) used CBAM to support the implementation of researchbased practices. They found that evaluators "may be able to impact teacher's implementation and enhance the effectiveness of the teacher" (p. 317). They also found that by "analyzing the innovation configuration map, evaluators might determine which intervention components are being used successfully and which are being implemented with less integrity" (p. 316).

From the earliest studies used to validate CBAM and its approach, to the most recent, they all add insight, validity, and reliability to educational research. According 
to Hall, Dirksen, \& George (2013) evaluators have found CBAM to be "an excellent tool to support formative program evaluations" (p. 31). My study will contribute to the existing literature on the use of CBAM in research on differentiated instruction by focusing on the beliefs and perceptions of teachers and support methods they use. Figure 1 shows the relationship between the components of CBAM.

The innovation configuration construct is one of the diagnostic dimensions of CBAM. Administrators or leaders use this component of CBAM to develop and/or analyze specific actions or behaviors related to the process or program. According to Hord, et al., (2006), the Innovation Configuration Process "provides clear, specific, and shared descriptions of what a new program or practice should look like; focuses on the key components of a program or practice; describes variations for each component of a new program in terms of the actions and behaviors that are ideal, acceptable, and unacceptable; differs from rubrics in that innovation configurations describe rather than rate a new practice; produces flexible documents that can change as the use of a new program or practice matures; and helps teachers who are new to a school understand program expectations.” 


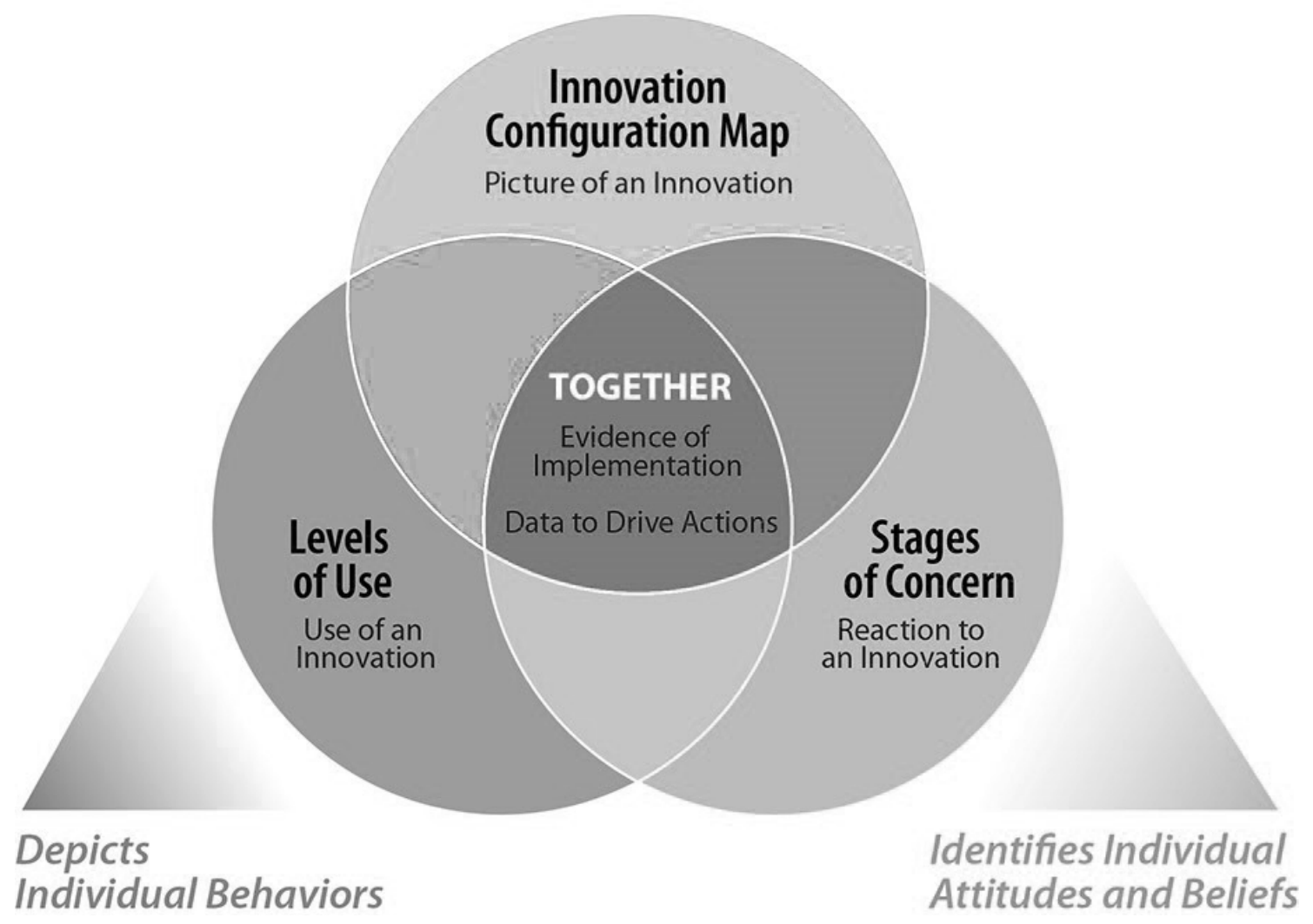

Figure 1. A visual representation of the construct of an innovation configuration map.

Hall \& George (2000) state that "IC mapping is an approach for assessing the extent of implementation of a program" (p. 2). An IC map can be compared to a road map as it shows different ways of getting from point A to point B. IC maps are useful in a variety of situations including self-reflection, peer observation, staff development, and evaluation personnel. According to (Hall \& George, 2000) four of the most popular applications for the innovation configuration (IC) map in education are: 1) SelfReflection, where teachers can review what has just been done in their classroom and 
self-assess by circling each component that has been completed. When this is complete, they can look back and begin adding other components. 2) Guide Peer Observations, this is when a colleague could use specific components, or the entire IC map depending on the needs and what was discussed prior to the observation. After the observation, the two would meet and discuss what had been observed using the IC map as a guide. 3) Observational Guide, administrators, coaches and others who are expected to observe, can use an IC map to focus on particular areas. An IC map can also guide to meaningful feedback, and 4) Staff Diagnostic Tool: An IC map can be influential in deciding the content of professional development and training.

An innovation configuration map will provide credible information regarding current practice. It can be used as the validation for program or policy changes in "teacher preparation and professional development programs at the district, state, and university levels" (Ceedar Center, 2011). In short, the tool components of an innovation configuration map are used to assist administrators, leaders, and researchers to understand and assist in the process of implementing the new practice.

\section{Professional Support}

\section{Peer-Coaching}

Dixon et al. (2014) note that professional learning activities should not just introduce the topic but should also permit the teachers to engage and practice the strategy in a practice setting where the coach assists them while they write and review their own lessons. This would assure them greater achievement in the classroom.

Little and Paul (2011) recommend that educators be allowed time to "discuss, reflect on, and plan" for professional learning, and they expounded on the significance 
of sustainability teacher supports such as peer collaboration or mentor coaching. The concept of teacher collegiality and collaboration is becoming widely recognized by staff developers in the form of peer coaching. Peer coaching may help effect needed changes in the school and stimulate greater productivity in the classroom and higher achievement. According to Busher (1994), peer coaching programs do not evaluate the teacher based on the observation. Instead, the observation is followed by constructive feedback which is aimed at improving instructional techniques.

Typically, in a coaching model, coaches and teachers would engage in a cycle of “demonstration, observation, and reflection" (Mraz, Algozzine, \& Kissel, 2009). Robbins (1991) defined peer coaching as a "confidential process through which two or more professional colleagues work together to reflect on current practices; expand, refine, and build new skills; share ideas; teach one another; conduct classroom research, or solve problems in the workplace" (p. 1). Following this description, teachers would have the opportunity to improve their professional practice.

According to Tschannen-Moran and Tschannen-Moran (2010), peer coaching has become an integral part of professional development which leads to transformative changes in the classroom. Peer coaching delivers a safe setting for the teachers to try new strategies and skills while they reflect on and improve their practice (Kohler, Good, Crilley, \& Shearer, 2001).

Peer coaching should be centered on the individual teacher and their personal strengths and goals. (Tschannen-Moran \& Tschannen-Moran, 2011). In research conducted by Shields (2007) the outcomes of peer-coaching include creating positive support networks, opportunities for meaningful conferencing which impact and 
confirms both classroom instruction and management practices (p. 53-54). Showers \& Joyce (1996) indicate that "educators who participated in more intensive, sustained professional development, such as peer-coaching, practiced new skills and strategies more frequently and applied them more appropriately than did their counterparts who worked alone to expand their repertories" (p. 14).

Teachers have different backgrounds, experiences, and needs. During coaching conversations in which teachers reflect on their beliefs and attitudes, their teaching is transformed. According to Stover, Kissel, Haag, and Shoniker (2011) in order for meaningful transformation to happen, teachers need to have a say in their own learning. Furthermore, a fundamental part of professional development is a relationship that includes trust (Stover, et al., 2011). Stover, et al, indicate that the process of constructing learning through ongoing interaction in the form of discourse and reflection provides opportunities for collaboration. This professional development stance frees teachers from their classrooms and creates a learning environment where teachers have a stake in what they learn themselves. With this approach, the teachers' voices are heard and valued. (p. 500

Differentiated instruction coaching promotes a culture of ongoing learning for the professional and will inspire teachers to be reflective, and to make changes in order to be a more effective and engaged teacher with their students and with colleagues. According to Bean, Belcastro, Hathaway, Risko, Rosemary \& Roskos (2008), teachers who work with coaches to improve their practice incorporate higher-level thinking activities and questions, encourage active engagement from their students, and their ability to differentiate instruction and instruction materials is increased. 


\section{Professional Learning Communities}

Astuto et al. (1993) define a professional learning community as "a place in which teachers and administrators of a school continuously seek and share learning and act on that learning" (p. 2). Professional learning communities have been used recently in schools to assist the teachers and administrators in engaging teachers pedagogically and to aid collaborative decisions about how to help their students achieve the goals set for them (DuFour, 2004).

According to Mitchell (2013), "Professional learning communities are believed to be necessary to sustain improvement in teacher practices" (p. 2). Extensive research has been conducted on professional learning communities (DuFour, DuFour, Eaker, \& Many, 2006; Eaker, DuFour, \& Eaker, 2006). According to Eaker (2002), “A school cannot function as a professional learning community until its staff has grappled with the questions that provide direction both for the school as an organization and individuals with it" (p. 3).

Hord (1997) discusses that student learning increases when teachers engage in authentic professional learning communities. Other benefits of professional learning communities are the "reduction of isolation of teachers, increased commitment to the mission and goals of the school, shared responsibilities, and collaborate professionally. Overall, professional learning communities are a platform to cultivate professional growth and student achievement" (p. 33).

Vygotsky (1980) proposes that "human learning is largely a social process." This social process is acutely applicable to professional learning communities in that they emphasize collaboration as an essential avenue to increase the knowledge and efficacy of teachers. Attard (2012) discusses that in professional learning communities, 
teachers learn from and with each other. Eventually, they will begin to see each other as a community of teachers who emphasize the implementation of new ideas. They will discuss and practice these ideas, observe, reflect and communicate with each other to grow and build upon their individual strengths and capacities (p. 55).

A professional learning community (PLC) has been defined by Astuto et al. (1993) as a "place in which teachers and administrators of a school continually seek and share learning and act on that learning." Oftentimes, schools use professional learning communities to organize teachers into professional working groups.

According to Eaker (2002), there are three major themes used to develop the conceptual framework for professional learning communities: (a) a foundation of collaborative development that consists of shared mission, vision, values, and goals, (b) collaborative teams that are working together for a common goal, and (c) a focus on outcomes as proof of an assurance of continuous improvement. According to DuFour et al. (2006), teachers are often asked to keep three general questions in mind: "What do we want students to learn?", "How will we know if they have learned it?", and "What are we going to do if they do not learn?"

It is important to understand that a crucial part of professional learning communities is that there is not so much a focus on teaching, but of learning. It is anticipated that all students have an elevated level of learning. Collaboration is a significant aspect of professional learning communities. Without collaboration and sharing among teachers, there will not be the needed time dedicated to discussing important issues of learning (DuFour et al, 2006). 
In order for professional learning communities to be effective, teachers must have a desire and willingness to change their professional practices. The combined knowledge of professionals should be used to guide decisions, and all need to have an open sense of new possibilities (DuFour et al., 2006).

Teachers will work together to accomplish goals set by the group. It may become apparent that a particular teacher is more proficient in one area than others and for that reason, this teacher would show the others how to improve their skill in this teaching area. New strategies are not always the answer but creating conditions for continuous improvement for student learning is always the goal (DuFour et al., 2006; Hord, 2004; Schmoker, 2006; Stiggins, 2005).

In educational settings, professional learning communities will help teachers better understand teaching practices and improve their overall teaching performances by analyzing what students have and have not learned. In professional learning communities, teaching practices are adjusted and modified to meet the needs of the students (DuFour et al., 2006). Professional learning communities help connect the gap between research and practice at the school level as they assist teachers to focus on student learning.

\section{Self-Reflection}

According to Gusky (1986), change will occur when teachers are able to observe their own practice. Teacher coaching can assist both change and professional growth. Both the teacher and the coach "demonstrate, observe, reflect, and consider how teaching decisions influence students" (p. 6). Teacher coaching should also be differentiated so that the experience will be relevant to both the needs and interests of 
the teachers. Every teacher has their own teaching style, experiences, and knowledge base to bring to their classroom.

Therefore, a "one-size-fits-all approach" to professional learning is not relevant to the needs of each individual. Neither does it lead to maintainable change (Stover, et al., 2011). Zeichner and Liston (1996) state:

If a teacher never questions the goals and the values that guide his or her work, the context in which he or she teaches, or never examines his or her assumptions, then it is our belief that this individual is not engaged in reflective teaching. (p. 61)

According to Fattig \& Taylor (2008), differentiated instruction is defined as a reflective and responsive style of teaching. Differentiated instruction is "responsive" teaching rather than a "one-size-fits-all" approach to teaching (Tomlinson \& McTighe, 2006). When the teacher is able to reflect on their teaching and lessons, and then react and respond by improving their practice, they will grow professionally, and their students will benefit as well. These are characteristics of an engaged and reflective teacher.

\section{Differentiated Instruction}

Teachers and administrators are always looking for best practices related to differentiated instruction in order to respond to the different student needs and to increase their achievement. According to Lawrence-Brown (2004), "if we are to maximize achievement in general curriculum standards, we should increase our efforts to differentiate instruction" (p. 47). For differentiated instruction inclusion to be successful, all students should show academic improvement. Providing a range of learning opportunities that lend to individual needs and interests of the students that will challenge and give practice for success is a goal of differentiated instruction. Lawrence- 
Brown (2004) state "All students benefit from the availability of a variety of methods and supports and an appropriate balance of challenge \& success" (p. 47).

"Differentiation provides a framework for responding to differences in student's current and developing levels of readiness, their learning profiles, and their interests, to optimize the match between students and learning opportunities" (p. 56). The process of differentiated instruction begins with activities which allow students to begin to think, work and personalize the content. According to Dixon et al. (2014),

teachers who differentiate their instruction respond to learner needs in the way content is presented, the way content is learned, and the way students respond to content. All these adaptations are designed to meet the individual characteristics of learners and to maximize their time in school. (p. 113)

According to Hall (2002), it is common knowledge that not all students are alike. Differentiated instruction is based on the premise that instruction should vary and be adapted to better meet the needs of diverse students in the classroom. It may be believed by untrained individuals that differentiating instruction is merely giving different assignments to students on individual levels. Hall (2009) notes that differentiation is not about creating an individualized daily lesson plan for each and every student. "Differentiated instruction means changing the pace, level, or kind of instruction teachers provide in response to individual learners' needs, styles, or interests" (Heacox, 2002).

Therefore, a technique of teaching to a diverse group of students should be implemented in each classroom with a teacher who is able to give instruction meeting the individual learning needs and styles to advance learning for each student. The greatest learning occurs when a student is challenged with material that is neither too easy nor too difficult. 
Berliner and Biddle (1995) discuss that because classrooms have more than one student, that there is already a wide-range of learning needs. Teachers may struggle to give each individual student learning activities that is designed just for them. Not all activities work the same for every student. Therefore, teachers need to adjust both the curriculum as well as the activities and instruction for different groups of students (Dixon et al., 2014).

Differentiation allows for diversity in assignments, products, and pacing which gives students opportunities to work at their level of challenge and achieve their own levels of success (Hall, 2009). Differentiated instruction can meet the needs of diverse students by providing them with choices, so students can demonstrate their learning in different ways (Chien, 2012).

According to Furry, Silverstein, Van Vieck (2010), the basic idea of differentiated instruction is that in classrooms that have a greater variety of student learning preferences, more individualized teaching may consequent in increased student achievement. Torgenson (2008) urges teachers to emphasize these four key practices:

1, "increase the quality and consistency of the instruction in every classroom."

2. "conduct timely and valid assessments."

3. "use this data to improve school level and instructional planning", and

4. "provide more intensive intervention to help struggling students catch up to grade-level standards."

\section{Critical Elements of Differentiated Instruction}

According to Tomlinson and Jarvis (2009), differentiation is an approach to teaching which takes student differences into account in creating activities and 
instruction for each student to engage with to develop necessary skills. It is a method of teaching where teachers proactively

plan varied approaches to what students need to learn, how they will learn it, and/or how they will show what they have learned in order to increase the likelihood that each student will learn as much as he or she can, as efficiently as possible. (p.5).

There are several elements in the classroom in which teachers can differentiate based on the individual student's readiness, interest, or learning profile. These are (a) Content, (b) Process, and (c) Assessment. Examples of differentiating content may be to use materials at varying levels of readability, using different levels of spelling or vocabulary lists, or using auditory or visual means. A teacher would also provide a variety of resources and activities that address student interest, learning styles and their prior knowledge. Tomlinson \& McTighe (2006) state that "differentiated teaching means a teacher is attuned to students' varied learning needs.... and will make modifications (to content) as to how students get access to important ideas and skills" (p. 18).

Process differentiation may include using small groups for re-teaching struggling learners or extension of skills for advanced learners. It could also be using tiered activities in which students are working towards the same understanding and skills, but have varying levels of support or challenge, interest centers, manipulatives or other hands-on support, and allowing different lengths of time a student may need to finish an assignment or to allow advanced learners to pursue an area in greater depth. According to the Iris Center (2010) at Vanderbilt, "when teachers differentiate process, they teach the same concept or skill to each student; however, the manner in which each student makes sense of the topic or skill can vary" (p. 6). It can then be said that 
teachers should vary the activities the students use to master the skills and concepts of the content being taught. "They can decide how best to do this by taking into account their students' readiness levels interests or learning profiles" (p. 6).

Grouping students is also an important part of the process segment of differentiated instruction. Teachers should plan instruction so that all students spend time working with a variety of peers. Sometimes they should work with mixedreadiness groups, similar interest groups, randomly, with the class as a whole and sometimes with those who learn as they do. Using a variety of grouping strategies allows students to see themselves "in a variety of contexts" and aides the teacher in “auditioning" students in different settings with different peers and kinds of work (Tomlinson, 1999).

According to Hall, Vue, Strangman, and Meyer (2004) "initial and on-going assessment of student readiness and growth are essential" they go on to say that "meaningful pre-assessment naturally leads to functional and successful differentiation" (p. 7). According to Tomlinson (2001), the assessment portion can be differentiated by giving students different opportunities to show what they have learned, rubrics which extend the varied skill levels of the students and allowing students to create their own assessments which contain required components (p. 13).

Assessment is a teaching tool not just to measure instruction, but to extend teaching. Assessments may be formal or informal and can include a variety of procedures, such as interviews, surveys, performance assessments to name a few. Hall et al. (2004) state that "incorporating pre- and on-going assessments informs teachers so 
that they can better provide a menu of approaches choices, and scaffolds for the varying needs of interests and abilities that exist in classrooms of diverse students” (p. 7).

In a study conducted by Ismaji \& Imam-Morina (2018) differentiated instruction provides opportunities for transitioning traditional knowledge to the active learning process. The study shows that students prefer this form of learning and that it meets their individual needs and learning styles. This type of quality teaching increases the learner's needs for "promotion of individual abilities in learning" which increases overall student achievement (p. 216).

\section{Implementation Models}

There are several models, or frameworks of strategies teachers have used when implementing differentiated instruction. These are briefly described to give the reader the context of a paradigm, teachers may be working under when implementing differentiated instruction in their classroom.

\section{MAT}

The 4MAT Instructional Strategy is the use and practice of the learner's "natural learning cycle" in the classroom as defined by Bernice McCarthy (1996). There are four parts to this cycle. First, the cycle begins with the knowledge and experience a student has previously gained and can relate to. Second, it will then add new information or understanding which is to be learned. Third, the student will manipulate the new information and then take the newly learned material and apply it. The fourth and last point in the cycle is where the learner builds a new base from which to relate information and begin the cycle again. 
The 4MAT strategy, which is considered a natural cycle of learning, suggests that "each learner is more comfortable at one of the four main phases in the cycle." (McCarthy, \& Morris, 1998). According to McCarthy,

the Imaginative Learner perceives by feeling and processes by watching, the Analytical 2 Learner perceives by thinking and processes by watching, the Common-Sense Learner perceives by thinking and doing to process, and the Dynamic Learner feels the way through for perceiving and processes actively by doing. (McCarthy, 1996)

When teachers use the 4MAT system, they will plan their instruction for each of the four learning preferences. Their plans will span several days on a given curriculum topic. Some of the lessons will focus on mastery, will others will focus on the understanding, personal involvement or synthesis. When this approach is used, each learner is given the chance to approach the topic through their preferred method while being able to strengthen weaker areas.

\section{Gardner's Multiple Intelligence Theory}

In 1983 Howard Gardner argued that "reason, intelligence, logic, knowledge are not synonymous" (p. 4). He suggested a view of intelligence that has integrated into classrooms and instructional methods. The Theory of Multiple Intelligences (MI Theory) broadens the concept of intelligence from simple mathematical and linguistic approaches and ability to incorporate areas such as music, spatial relations, and interpersonal knowledge.

According to Sternberg \& Williams (1998), "A closer look at theories of intelligence can provide a middle ground between the idea that there is a single way in which minds work and the notion that every mind is unique" (p. 576). When trying to understand the mind in a classroom, a theory such as Gardner's Multiple Intelligences, 
can assist teachers in understanding and working with students that require different strategies for instruction for understanding and mastery.

Howard Gardner also compiled a list of seven intelligences. He suggested that all humans possess at least seven relatively different faculties. While each human possesses all of the intelligences, the strength and weakness of each vary depending on the individual.

The first intelligence is Logical-Mathematical, "which consists of the ability to detect patterns, reason deductively and think logically" (Brualdi Timmins, 1996, p. 1). Those who learn with this intelligence appreciate abstract relations. Many scientists, accountants, and philosophers possess a strong Logical-Mathematical intelligence.

The second intelligence is Linguistic, "which involves having a mastery of language. This intelligence includes the ability to effectively manipulate language to express oneself. It also allows one to use language as a means to remember information" (Brualdi Timmins, 1996, p. 1). The linguistic intelligence allows individuals to make sense of the world and communicate through language. This intelligence is often connected with scientific and mathematical thinking and typical professions may include anyone in the field of writing (journalist, novelist, etc.) and lawyers who need strong communication skills.

The third intelligence is Spatial. "This intelligence gives one the ability to control and create mental images so they can then solve problems" (Brualdi Timmins, 1996, p. 1). It makes it possible for individuals to see information easily and to re-create and transform this information from memory. Many artists, architects, designers, and mechanics use their Spatial intelligence. 
The fourth intelligence is Musical, which uses the ability to recognize and use musical pitches, tones, and rhythm. This intelligence allows one to compose, understand and communicate through the gift of sound. Typically, composers, conductors, and singers have a strong Musical intelligence.

The fifth intelligence is Bodily-Kinesthetic, "which is the ability to use one's mental abilities to coordinate their own body movements" (Brualdi Timmins, 1996, p. 1). Athletes, dancers, and actors use the intelligence of their physical body to create products or solve problems.

Interpersonal is the sixth intelligence. This is the ability to both understand and discern the feelings, as well as the intentions, of others. Teachers, politicians, and salespeople often use their Interpersonal intelligence to recognize and make distinctions about other people's feelings and their intentions.

Finally, the seventh intelligence is Intrapersonal, which is "the ability to understand your own personal feelings and motivations" (Brualdi Timmins, 1996, p. 1) This helps individuals to separate their own feelings to make decisions about their lives and to assist others as well. Therapists and religious leaders typically have a strong Intrapersonal intelligence.

There are many differentiation strategies educators can use to include the strengths of their students in their classrooms using the base of Gardner's Multiple Intelligence Theory. Some of these strategies are:

Stations: Setting up different areas in the classroom where students can work on different tasks at the same time. Using stations will allow for flexible grouping and interest/strength grouping, as not all students need to complete the tasks at each station. 
Compacting: When teachers assess students prior to a unit of study, the teachers can easily plan activities for students, so they are not continuing to work on what they already know.

Agendas: A personalized list of activities that students will complete in a specified period of time. Some students will have similar activities, while others will be dissimilar depending on strengths and interests.

Complex Instruction: This strategy using materials that are challenging, small instructional groups and tasks that are open-ended. Teachers will rotate between groups and be available to answer questions and probe the thinking of the students.

Orbital Studies: These are independent investigations that revolve around the curriculum. Students are likely to select their own topics and work with the teacher for guidance throughout the project.

Choice Boards: This strategy allows for work assignments to be placed in a series of pockets, or on a chart. The students will choose activities from a particular row. The teacher can target work students' needs, yet each student is allowed choice.

According to Sternberg and Williams (1998) "The theory can become a framework for thinking about the students we teach and how to teach them, helping teachers become more reflective and explicit about the pedagogical choices they make" (p. 576). When these instructional frameworks are considered and used when implementing differentiated instruction in an elementary classroom, the results may have a positive effect on student achievement and overall motivation for the individual learners 


\section{Implications}

There is a need for integrity of implementation of the professional learning opportunities given to teachers during professional development trainings.

Administrators need to consider how they will evaluate the professional development training as well as how they will use this additional information to increase teacher professionalism and student achievement.

\section{Summary of Literature}

The purpose of this literature review has been to examine the research on professional development, professional learning, the use of CBAM, differentiated instruction, and teacher support. 4-MAT and Gardner's Multiple Intelligence Theory were described to give context of the framework of differentiated instruction. Peer coaching, self-reflection, and professional learning communities were discussed as examples of professional learning strategies.

This research will add to the existing literature on the use of CBAM by focusing on the beliefs and practices of the teachers who took this professional development training of differentiated instruction. In this study we will look to see if the teachers that took the training believe what they were introduced to regarding differentiated instruction at the training, and do they practice what they believe? It will be suggested that teachers do not always practice what they believe.

The training was a professional development opportunity with the intent of taking what they had learned back to their respective classrooms and school communities. There the teachers would begin to implement their knowledge into a professional learning experience, with self-reflection, collaboration and adjustments to 
their teaching practice to further develop their professional practice and ultimately increase student achievement.

This study indicates that teachers may put some of their beliefs into practice, as well as look at discrepancies between what teachers believe and what they actually practice. Specific areas within differentiated instruction will be discussed to compare the beliefs and practices. A discussion from the interviews will give insight as to what teachers suggests would be beneficial for them after completing professional development training and the expectation of implementing it successfully in their classroom. 


\section{CHAPTER 3}

\section{METHODOLOGY}

\section{Introduction}

The primary purpose of this study was to describe how teachers in the Columbia Union of Seventh-day Adventists implemented differentiated instruction in their classrooms after completing the differentiated instruction training. This study provided a deeper understanding of teacher's individual understanding and beliefs of differentiated instruction. It also examined how, and if, those beliefs carried over into their practice and if they used any support methods during their initial implementation.

\section{Research Design}

This is a mixed method research design. I chose mixed methods for this research as it was the best approach to answer the research questions in this study. Both quantitative and qualitative research have strengths and weaknesses. While there may be a perception that context and setting may not be shown in quantitative research simply by taking a survey, or that biases may be present in a qualitative research study and may not lend itself to statistical analysis (Ritchie, Lewis, Nicholls, \& Ormston, 2013), I found both methods suitable for the approach to this study.

Using a mixed methods approach gives a complete picture and understanding of the differentiated instruction method, the beliefs, and practices of the teachers, as well as their feelings concerning this teaching approach and support methods. 
The quantitative section of this study has a survey of the beliefs and practices of differentiated instruction. Creswell (2013) says this "provides a quantitative or numeric description of trends, attitudes, or opinions of a population" (p. 145). This method allows the researcher to obtain beliefs and reported practices to answer research questions. The participants answer the questions anonymously and the data can be collected quickly.

Creswell (2013) writes, "It (data collection) means gaining permissions, conducting a good qualitative sampling strategy, developing means of recording information both digitally and on paper, storing the data, and anticipating ethical issues that may arise" (p.145). He also writes that the phases of collection intimately resemble a "circle of interrelated activities. These activities" include "locating a site or individual, gaining access and making rapport, sampling purposefully, collecting data, recording information, exploring field issues, and storing data" (p.145).

The research questions below were used to guide the study:

1. How do teachers who have attended differentiated instruction workshops describe their beliefs and practices concerning the use of differentiated instruction in their classrooms?

2. How do their beliefs of differentiated instruction compare with their classroom practices?

3. How do teachers report and describe various methods of support on their implementation of differentiated instruction? 


\section{Description of Training}

In the summer of 2013, the Columbia Union of Seventh-day Adventists began an initiative to train their teachers in a professional development opportunity of differentiated instruction. There were three cohorts for a two-year, three-day per summer training for a combined total of six days of training for each participant.

The teachers that participated in the training teach a span of students from PreK$12^{\text {th }}$ grade in a variety of subject areas across the curriculum. Some of these teachers have a one-grade classroom, but the majority teach in a multi-grade classroom. A total of 93 teachers completed the training. The Columbia Union has not formally collected data on the understanding, implementation and support methods following the training of the teachers in differentiated instruction.

This training consisted of the teachers meeting at the Columbia Union Office to be instructed by a recognized expert in the field of differentiated instruction. The first year of training included an overall picture of differentiated instruction — what it is, why it is needed, methods to implement, and specific activities to include. The second year of training was based on formative and summative assessments in a differentiated classroom. Both years of training included lectures, hands-on activities, small group discussions, participation, and "take-home" activities, and materials. The teachers were given handouts and materials based on the training, to use, write notes on, and take back to their classrooms to aid in planning and implementation.

The training began with understanding how learners and learning have changed in the $21^{\text {st }}$ century. More emphasis needs to be made in areas of making meaningful connections and solving problems. Tomlinson (2004) says "a differentiated classroom 
provides different avenues for acquiring content, for thinking through or making sense of ideas, and for solving problems" (p. 1).

Four principles of brain compatible learning were explored. Cash, Heacox, Hollas, and Elliot (2009) discuss these principles. The first principle says, "For learning to occur, students must feel safe and welcome in the learning environment." This can include student fears and anxieties whether it be personal or curriculum-related to create brain-compatible conditions for learning (p. 81).

The second principle states "Learning requires stimulating and varied input." This means that the learner needs to be offered information that is interesting and thought provoking. It must be varied in how we offer the information to students. They will then be more likely to recall and remember the information (p. 84).

The third brain compatible learning principle states "Learning must be active and meaningful." The more movement and stimulating blood flow we allow in the classroom, the more engaged the students will likely be. If the tasks are meaningful, the students will want to be successful. Meaningful tasks also create neural connections to prior knowledge, which will ensure a greater retention of material (p. 85).

The final learning principle is "Learning is based on the amount, accuracy, effectiveness, and relevance of the feedback we offer to students." The students will learn best when they are provided specific and descriptive feedback that can help them achieve success (p. 113).

Frameworks such as 4MAT and Gardner's Multiple Intelligence Theory were explored to help participants understand the importance of brain function and variety of cognitive learning preferences. Ways to wake up the brain were introduced- moving vs. 
sitting, talking vs. listening, engagement vs. worksheets, writing vs. watching, different vs. same, and images vs. words.

Numerous strategies were shared to assist teachers in differentiating all areas of content, process, and assessment. Some of the general strategies for content are "Different levels of text and supplemental resource materials: A range of materials and resources appropriate to the range of students' needs.", "Flexible Pacing: Allowing students the time necessary to become proficient in the content", and "Flexible Grouping: Grouping and re-grouping students based on academic need within the content." (Cash, et al., 2009, p. 82).

A sampling of the general strategies to differentiate process shared were "Varied Learning Styles: Instructional strategies and activities that address the different ways students take in information (Gardener's Multiple Intelligences)", "Tiered Activities: Parallel activities varied based on interest, readiness, or learning style.", and "Adjusted Degrees of Sophistication: Students engage in activities that vary the degree of thinking skills, creativity, problem solving or critical reasoning” (Cash, et al.,, 2009, p. 81).

Differentiating assessment strategies included a checklist, quiz, restating, demonstration, drawing, sequencing, compare-contrast, write an opinion, and predictions. These, or a myriad of other strategies, could be either a "quick-check" or a planned culminating assessment, which may be facilitated by the teacher with options for individual learners or groups (Cash, et al., 2009).

Tomlinson (2004) tells us that learning profiles include cognitive preferences and learning modes. An individual's learning profile is neither fixed nor singular. Teachers can use learning profiles to help students know themselves as learners so they 
can approach learning tasks with confidence. It can also help students to understand that brain changes and they can develop as thinkers and learners. Sternberg (2011) suggests that "learning happens best when students are exposed to all kinds of cognitive preferences and modes."

The teachers that took the differentiated instruction training at the Columbia Union were fully trained in the best practice techniques and framework for differentiated instruction. The trained teachers had the research-based knowledge and the experience of the training to assist them in understanding how their students learned. They also had ideas of varied approaches to use when teaching and implementing differentiated instruction in their classrooms.

\section{Data Collection}

For this research, I collected two different types of data; (a) quantitative data - a survey collecting information about the teacher's beliefs and practices, and (b) qualitative data - interviews from the teachers in the field to best answer the research questions. The data collection process is described in more detail under each particular type of data below.

According to Creswell (2013) "it is thought that the combination of quantitative and qualitative methods presents a more enhanced insight into the research problems and questions than using one of the methods independently" (p. 113). Creswell (2003) also says a sequential mixed-method design is "characterized by the collection and analysis of quantitative data followed by a collection and analysis of qualitative data" (p. 211). Using the survey based on the 2008-2009 innovation configuration of differentiated instruction of the Connecticut Study by Kirner \& Bennet, I used the data 
and analysis to initiate a collection of qualitative results to assist in interpreting the findings of the interviews.

The innovation configuration developed by the Connecticut State Education

Resource Center (see Appendix C) was used in both the quantitative and qualitative data collections. According to Hall et al. (2013), an innovation configuration process specifies clearly the shared descriptions of what a new practice, technique or program should look like. It emphasizes the major components of the practice or technique, and describes what it should look like.

\section{Innovation Configuration}

The innovation configuration component of the Concerns-Based Adoption Model was developed by researchers in the 1970s and 1980s. It was developed at the Research and Development Center for Teacher Education at the University of Texas at Austin. Researchers have been testing CBAM for reliability and validity since its development. In 2006, the innovation configuration component was reorganized to verify accurateness. The innovation configuration is a common tool used in educational settings to help administrators and leaders understand, monitor, and guide the process of implementing new practices (Hord, Stiegelbauer, Hall, \& George, 2006).

The innovation configuration defines ways one would implement an innovation. It will include the different components and the variations of their innovations. Teachers, as well as leaders, use the innovation configuration as a guide as they move toward developing skill with a specific innovation. It also can serve as a reflective tool in discussing progress, be used as an evaluation tool for practice or a program. 
The innovation configuration for differentiated instruction created by the Connecticut State Education Research Education Center was used to study the fidelity and integrity to which teachers are implementing this teaching method.

The Connecticut Innovation Configuration for differentiated instruction was developed and validated as a credible source prior to this research study. The Connecticut Innovation Configuration displayed 16 categories of differentiated instruction on a three- or four-point scale to measure the fidelity of teacher practices in differentiated instruction implementation (Kirner, Henley, Bennet, \& Stokes, 2009).

These 16 categories may be divided into the three sub-categories of the differentiated instruction teaching practice of content, process, and assessment. The “content" sub-category includes alignment of content, product alternatives, resource alternatives, differentiation of content, and resources. Next, the "product" sub-category includes introduction, product choice, grouping alternatives, grouping strategies, teaching strategies, learning activities, products, and time. Finally, the sub-category of "assessment" includes pre-assessments, analysis of pre-assessment data and assessments (formative and summative).

These same categories were used in this research study. Using these categories, the survey and interview questions were designed to collect the information which examined the beliefs and practices of teachers who implemented differentiated instruction after completing the training of the Columbia Union. 


\section{Quantitative}

\section{Convenience Sample}

The population used in this research are the ninety-three Seventh-day Adventist teachers in the Columbia Union who completed the differentiated instruction training. The survey was sent via e-mail to each of the ninety-three participants who completed the training. Fifty-four participants returned the survey giving a 58\% return rate. These returned surveys were used to complete this research. The survey questions were quantitatively analyzed and the teachers willing to be interviewed, as indicated on the survey, were contacted to set up an interview to obtain qualitative data.

\section{Quantitative Data Collection}

The first part of the study was a survey I developed based on the 2008-2009 innovation configuration of differentiated instruction of the Connecticut Study by Kirner \& Bennett (see Appendix C). The innovation configuration map was used to determine the extent to which the various components of differentiated instruction had been implemented. The components were broken down into a belief statement with a corresponding practice statement. A chart was constructed (see Appendix D) to show the connection of the Connecticut Study statements with the belief and practice statements used in the survey. The belief and practice statements were divided into two distinct sections on the survey.

A Survey Monkey online survey was used to obtain data regarding the beliefs and understanding of differentiated instruction and the extent of practice as it is being used in the classroom by the classroom teacher. The survey was sent out to all teachers who completed the training via e-mail with addresses provided by the Columbia Union 
Office of Education. The participants were given two weeks to complete the survey with a reminder e-mail sent one week into the allotted time.

The survey, which was aligned with the Connecticut Innovation Configuration, presented self-reported information from the teachers concerning their beliefs and practices of differentiated instruction.

The survey was divided into two distinct sections. The first section asked the survey participants about their beliefs on differentiated instruction after completing the training. The second section asked them about their current practice of implementing differentiated instruction in their classroom.

The belief section was based on a 4-point scale as follows:

1. Strongly Disagree

2. Disagree

3. Agree

4. Strongly Agree

The practice section was based on the following 5-point scale:

1. Never

2. Less than once per month

3. 1-2 times per month

4. 1-2 times per week

5. 3-5 times per week

Each survey question was directly aligned to the innovative configuration of the Connecticut study of differentiated instruction and is either a question related to the "process", "content", or "assessment" areas of differentiated instruction. The Innovation 
Configuration/Beliefs/Practice Relationship Chart shows the relationship of the reference from the innovation configuration, the survey belief questions, and the survey practice questions (see Appendix D).

\section{Quantitative Data Analysis}

Descriptive statistics from the survey reveal the beliefs and understanding of differentiated instruction in the participants of this study. A Chi-Square test was performed to compare the beliefs and practice of the participants who attended differentiated instruction training.

There were three negative belief statements on the survey that needed to be reverse-coded, or the numerical scoring scale was run in the opposite direction, to ensure the data revealed an accurate analysis.

All of the belief and practice statements on the survey were organized and labeled on the tables with more specific and individual categories within content, process and assessment. These groups were based on integral components of differentiated instruction. This was done for both organization and ease of understanding. In the content area, the groups are alignment of content, differentiation of content, product alternatives, resource alternatives, and resources. In process, the groups were broken down into grouping, grouping alternatives, introduction, learning activities, product choice, products, teaching strategies, and time. The assessment area categories are analysis of pre-assessments, assessments, and pre-assessments.

I organized and analyzed all of the data and compared the reported beliefs as they related to the self-reported practice of the teachers in their implementation of differentiated instruction. Fidelity of teacher practice was analyzed and guided by these 
categories derived from the Innovative Configuration of the Connecticut study of differentiated instruction.

\section{Reliability}

Reliability is the length to which research findings can be duplicated. Yin (2014) discusses that when data is collected, the results must make sense and are both consistent and dependable. Yin (2014) states "readability, credibility, and confirmability all matter" (p. 192). The Cronbach's $\alpha$ lpha test was run to determine the internal consistency of the survey instrument. The result was .954 , which is an excellent score, meaning the reliability of the instrument used was sound.

\section{Qualitative}

\section{Purposeful Sample}

The second part of the study were interviews of teachers who volunteered on the survey to participate in the interviews. The interviews were used to gather additional information from teachers who had indicated their involvement in using on-going supports to enhance their implementation of differentiated instruction. The researcher determined individuals who were willing to be interviewed by their indication of willingness on the survey.

\section{Qualitative Data Collection}

The qualitative data included interviews with eight teachers and an analysis of the responses collected. Participants who indicated their willingness to participate were interviewed to learn more about their beliefs and practices of differentiated instruction as well as their thoughts on the training and ideas for continued support. 
Four participants had face-to-face interviews and the other four participated with Zoom. The teachers were interviewed using the questions in Appendix B to try to gain a picture of their belief of differentiated instruction, their experience implementing it into their classroom, as well as what support methods they may have used. I also was interested in their views on what would be helpful to share with administrators regarding the training, their experience with implementation, and on-going support.

\section{Qualitative Data Analysis}

Qualitative studies are flexible and allow for freedom and choice in the research process. Qualitative research also allows the researcher "flexibility to probe initial participant responses" (Mack, 2005).

After the interviews were complete, they were transcribed and coded by pulling out key words that related to the categories of the differentiated instruction innovation configuration. Similar statements and words were assigned to the categories of the innovation configuration of differentiated instruction to assist the researcher in aligning the information.

The qualitative data analysis was conducted by identifying shared themes, patterns, characteristics and indicators present on the innovation configuration map and in the interviews. Coding of the transcribed interviews was completed by matching similar themes such as strategies, assessments, time, and collaboration. These codes were used to recognize noteworthy data that matched the categories of the innovation configuration categories of differentiated instruction. The data gathered would then be connected to the appropriate research question. 


\section{Trustworthiness of Qualitative Data}

Creswell (2012) used the terms "credibility, dependability, conformability, and transferability, arguing that the trustworthiness of qualitative research should be assessed differently from quantitative research" (p. 125). Credibility is established by using techniques that raise the possibility of credible results. The length of time of the data collection, the observation of a sufficient number of classrooms as to differentiate the relevant from the irrelevant, and the triangulation of data all contribute to the credibility of a qualitative study. Credibility in this study was accomplished using consistent discussions, interviews, and feedback from the teachers involved in the research.

To have trustworthiness in a research project you should also have confirmability. Creswell (2012) writes "the findings are the result of the research, rather than an outcome of the biases and subjectivity of the researcher" (p. 126).

Transferability allows someone to recreate the study. Through the rich description of the study, one can imagine the setting and the feelings described. Transferability was achieved by a detailed and descriptive narrative that tells the stories of teachers and their experience with their implementation of differentiated instruction in their classroom.

Creswell (2012) writes "qualitative research usually does not cover enough of an expanse of subjects and experiences to provide a reasonable degree of reliability" ( $\mathrm{p}$. 125). According to Creswell (2012):

The more important question becomes one of whether the findings are consistent and dependable with the data collected. As the researchers understood it, in qualitative research the goal is not to eliminate inconsistencies but to ensure that the researcher understands when they occur. Thus, it becomes 
incumbent on the researcher to document her procedures and demonstrate that coding schemes and categories have been used consistently. (p. 126)

Consistency in this research project provides the dependability of the research.

The elements in the coding of data gleaned from the interviews, discussions, and response sheets are be arranged in a consistent and reliable manner. Reliable and consistent methods collecting data from the surveys and innovation configuration will contribute to the trustworthiness of this study.

\section{Generalizability of Qualitative Data}

There are no two circumstances in which the situation is identical; therefore, generalization must happen. The reader can make connections that tie similarities to their own setting, experiences, and expertise. This study can be used as a resource to guide their thought process in regard to professional learning, differentiated instruction, and support methods.

By looking for patterns, and applying them to individual context, and experiences, generalizations can be made. According to Eisner (1991), when we look for and find a pattern, we learn to generalize and realize the pattern can be trusted (p. 201).

\section{Ethical Issues}

Andrews University IRB approval was obtained. Pseudonyms were used, and all personal information of participating teachers were kept confidential. Personal views, descriptions, and survey results were not shared or tied to the participants in any way. 


\section{CHAPTER 4}

\section{RESULTS}

\section{Introduction}

The purpose of this mixed-method study was to describe how teachers understand and implement differentiated instruction after completing two three-day intensive training workshops on differentiated instruction at the Columbia Union Conference Office under an expert in the field of differentiated instruction. It also looked at support methods that may have been used by the teachers during the initial implementation.

It was the belief of the researcher that a better understanding of what the participants took away from the workshop, how they implemented differentiated instruction and what support methods, if any, would give insight to administrators at the local, conference, and union levels to assist their teachers in implementing new ideas and strategies effectively after a workshop, as well as ensuring needed support. This chapter presents the findings obtained from eight interviews as well as the results from 54 surveys. The results are grouped by categories in each area of content, process, and assessment in both the belief and practice tables.

\section{Participant Characteristics}

The participants of this study were all K-12 teachers who completed the twoyear (6 total days) training of differentiated instruction at the Columbia Union Conference Office. The interviews included 3 males and 5 females who taught from grades K-12. The surveys included 12 males and 41 females, as well as one who 
abstained from answering gender, for a total of 54 teachers with 1-35 years of teaching experience in grades K-12. Table 1 displays the demographic characteristics of the participants in the study.

Table 1

Demographic Characteristics of Participants $(n=54)$

\begin{tabular}{lcr}
\hline Variable & $N$ & $\%$ \\
\hline Gender & & \\
\multicolumn{1}{c}{ Male } & 13 & 24.1 \\
Female & 40 & 74.1 \\
& & \\
Teaching Experience (yrs.) & & \\
\hline $1-5$ & 8 & 14.8 \\
$6-10$ & 6 & 11.1 \\
$11-15$ & 8 & 14.8 \\
$16-20$ & 7 & 13.0 \\
$21-25$ & 9 & 16.7 \\
$26-30$ & 5 & 0.3 \\
$>35$ & 6 & 11.1
\end{tabular}

Grade Level Taught

$\mathrm{K}-2$

$9 \quad 16.7$

$3-5$

17

31.5

6-8

14

25.9

$9-12$

14

25.9

*\% percentages may not add up to $100 \%$ due to no response to question on survey

\section{Research Question 1}

How do teachers who have attended differentiated instruction workshops describe their beliefs and practices concerning the use of differentiated instruction in their classrooms? 


\section{Beliefs}

Belief item statistics (mean, standard deviation, and percent of participants who agree and strongly agree) are reported in Table 2 for Content, Table 3 for Process, and Table 4 for Assessment. Belief items were scaled along a 4-point Likert scale (1 strongly disagree, 2 - disagree, 3 - agree, and 4 - strongly agree). Thus, for the purpose of this study, items with means of approximately 3.0 indicate that teachers believe those statements of differentiated instruction.

After conducting eight interviews with both male and female teachers, teaching a span of Kindergarten through twelfth grade, there were several common findings concerning content, process, and assessment beliefs and practices. These findings are discussed after each quantitative analysis for the areas of content, process, and assessment.

\section{Content Beliefs}

This section discusses the findings in relationship to content beliefs. These beliefs may refer to using materials at varying levels of readability, providing a variety of resources that address student interest and learning styles, or modifying content to match learning rates. First, the quantitative results from the survey will be discussed, followed by the qualitative findings from the interviews.

Quantitative findings

Table 2 shows belief statements in the content area of differentiated instruction. Using the criteria stipulated earlier, it is apparent that the majority of the teachers believe nine of the eleven content statements of differentiated instruction. The 
Table 2

Content Area Survey Belief Statements

\begin{tabular}{|c|c|c|c|c|c|}
\hline Category & Belief Statements & $N$ & $M$ & $S D$ & $* \%$ \\
\hline \multirow{2}{*}{$\begin{array}{l}\text { Alignment of } \\
\text { Content }\end{array}$} & There should be clearly stated learning objectives & 53 & 3.58 & 0.50 & 100.0 \\
\hline & $\begin{array}{l}\text { It is important that learning objectives be aligned } \\
\text { with NAD standards }\end{array}$ & 53 & 3.28 & 0.63 & 94.3 \\
\hline \multirow[t]{2}{*}{$\begin{array}{l}\text { Differentiation of } \\
\text { Content }\end{array}$} & $\begin{array}{l}\text { It is important to match students to assignments } \\
\text { appropriate to their learning rates }\end{array}$ & 52 & 3.08 & 0.33 & 98.1 \\
\hline & $\begin{array}{l}\text { It is important to adjust content to meet each } \\
\text { individual students' prior knowledge }\end{array}$ & 53 & 2.62 & 0.66 & 60.4 \\
\hline \multirow[t]{2}{*}{$\begin{array}{l}\text { Product } \\
\text { Alternatives }\end{array}$} & $\begin{array}{l}\text { There should be alternative activities to } \\
\text { accommodate the range of student learning styles } \\
\text { in a classroom. }\end{array}$ & 53 & 3.34 & 0.48 & 100.0 \\
\hline & $\begin{array}{l}\text { There should be alternative activities to } \\
\text { accommodate the range of student interests in the } \\
\text { classroom }\end{array}$ & 45 & 3.20 & 0.73 & 92.6 \\
\hline \multirow[t]{3}{*}{ Resources } & $\begin{array}{l}\text { Teachers should use resources that vary in } \\
\text { complexity }\end{array}$ & 53 & 3.30 & 0.46 & 100.0 \\
\hline & $\begin{array}{l}\text { Teachers should provide resources that vary in } \\
\text { familiarity }\end{array}$ & 53 & 3.25 & 0.43 & 100.0 \\
\hline & $\begin{array}{l}\text { It is imperative that teachers provide resources } \\
\text { that vary in abstractness }\end{array}$ & 53 & 2.89 & 0.64 & 73.6 \\
\hline \multirow[t]{2}{*}{$\begin{array}{l}\text { Resource } \\
\text { Alternatives }\end{array}$} & $\begin{array}{l}\text { It is important to provide a variety of resources } \\
\text { that address the full range of student learning } \\
\text { styles }\end{array}$ & 52 & 3.25 & 0.52 & 96.2 \\
\hline & $\begin{array}{l}\text { It is important to provide a variety of resources } \\
\text { that address the full range of student interests }\end{array}$ & 52 & 3.13 & 0.53 & 92.3 \\
\hline
\end{tabular}

*\% of respondents who agree/strongly agree

percentage column indicates the percentage of teachers that agree/strongly agree with each statement.

In the alignment of content category, the teachers who have been trained in differentiated instruction believe both of the statements. They believe that there should 
be clear statements of learning objectives $(M=3.58, S D=0.50)$ and that it is important that learning objectives be aligned with NAD standards $(M=3.28, S D=0.63)$.

In the next category, differentiation of content, the teachers believe it is important to match students to assignments appropriate to their learning rates $(M=3.08$, $S D=0.33$ ). Only about $60 \%$ of the teachers tended to believe the statement that it is important to adjust content to meet each individual students' prior knowledge $(M=$ 2.62, $S D=0.66)$.

Both of the statements in the product alternative category had a high percentage of teachers reporting their belief of the statements alternative activities to accommodate both the range of student learning styles $(M=3.34, S D=0.48)$ and student interest $(M=$ $3.20, S D=0.73)$

The teachers reported they believed two of the three the statements in the resources category. The teachers report their high belief that their resources should vary in complexity $(M=3.30, S D=0.46)$ as well as familiarity $(M=3.25, S D=0.43)$. Regarding the third statement, $73.6 \%$ of the teachers tended to not agree that it is imperative that teachers provide resources that vary in abstractness $(M=2.89, S D=$ $0.64)$.

The final category in the content area is resource alternatives. The teachers report their belief of both statements regarding providing a variety of resources that address the full range of student learning styles $(M=3.25, S D=0.52)$ and the full range of student interests $(M=3.13, S D=0.53)$. 


\section{Qualitative findings}

Consistent belief findings in the interviews directly corresponded with the survey content belief data. The survey data, as well as the results from the interviews, showed that the teachers agreed/strongly agreed that assignments should be matched to students' learning rates, alternative activities to accommodate that range of student interests and learning styles should be incorporated, resources should vary in complexity and familiarity, and that a variety of resources that address the full range of student learning styles and interests should be used.

When interviewing teachers, the topic of validation, or confidence, in what they were already doing regarding using alternative activities and a variety of resources emerged. Connie stated that the training helped her to "recognize there (were) basic principles that (she) was already using." These principles were her beliefs of what good teaching should be and made sense to her as she worked with her individual students. Connie shared that she would try to give assignments to her students in ways which would interest them in both their learning preferences as well as topics they enjoyed whenever possible. She shared she would intentionally take the time to learn about her students, their families, what they enjoyed reading about, hobbies, places they visited (or wanted to visit) etc. and try to use these pieces of information when planning learning experiences for her students.

After the training, Kathy believed she needed to find additional ways to "meet them more using Gardner's Intelligences" corresponding with the overall belief of the teachers that resources need to be incorporated that address the full range of student learning styles and interests. Teaching in a one-room, multi-grade school with six grade levels, Kathy also realized to a different level of understanding, that her students could 
indeed study the same content, yet their activities and assignments could be more appropriate to their learning rates by using different resources that varied in complexity for different students. Before the training, while Kathy gave different assignments, she often just had the younger students "helping" the older ones with major projects. While this allowed for some learning to take place, the training showed her that more learning might happen if she allowed each age group of students to complete their own projects some of the time and incorporate the different learning styles and interests in their assignments. She was excited about integrating this idea into her classroom and immediately "began thinking of ways to incorporate this way of thinking and planning."

Prior to the training, Harold felt like he had to stay "true" to the textbook. The training validated his desire to use it more as a resource and seek alternative resources and activities to enhance his teaching, as well as use activities to accommodate student interest and learning styles. Harold shared he would use online resources, visit bookstores, and just use ideas from previous experiences, as well as use suggestions from the students when planning for lessons. He stated that "I was able to take the material and present it in a way that was good for each of the individual students." Harold also shared that the training "gave him the confidence that (he) was doing better for the students" by differentiating the content of assignments.

\section{Content belief summary}

The teachers reported their strong belief ( $92 \%$ or above) of the majority of the statements in all five categories of the content area. The teachers agreed/strongly agreed with nine out of eleven of the statements. The two statements with lower percentages of belief were in the differentiation of content $(60.4 \%)$ and resources (73.6\%) categories. 
In addition, the teachers who were interviewed agreed with the beliefs that teachers should differentiate alignment of content and use of resources in a variety of ways. These ways range from learning rates, student interests, learning styles, complexity, and familiarity.

\section{Process Beliefs}

This section discusses the findings in relationship to process beliefs. These beliefs may refer to the grouping of students, how a concept or skill is taught to an individual student based on learning profiles, rates or readiness levels, or pacing of assignments. Again, the quantitative results from the surveys will be discussed first, followed by the findings from the interviews.

Quantitative findings

Table 3 shows the belief statements in the process area of differentiated instruction. The majority of the teachers reported they agreed with nineteen of the twenty-two process belief statements.

The teachers who have been trained in differentiated instruction believe three of the six grouping category statements. They believe it is important to use a variety of grouping strategies $(M=3.53, S D=0.54)$. The also agreed with the statements grouping students homogeneously by interest may increase motivation $(M=2.96, S D=0.59)$ and grouping students randomly may increase social skills $(M=2.96, S D=0.55)$. Approximately one-half to three-fourths of the teachers tended to not agree with the final three statements in the grouping category. These statements are grouping students heterogeneously may increase achievement and social skills $(M=2.84, S D=0.54)$, it is 


\section{Table 3}

Process Belief Statements

\begin{tabular}{|c|c|c|c|c|c|}
\hline Categories & Belief Statements & $N$ & $M$ & $S D$ & $* \%$ \\
\hline \multirow[t]{6}{*}{$\begin{array}{l}\text { Grouping } \\
\text { Alternatives }\end{array}$} & $\begin{array}{l}\text { It is important to use a variety of grouping } \\
\text { strategies }\end{array}$ & 453 & 3.53 & 0.54 & 98.1 \\
\hline & $\begin{array}{l}\text { Grouping students homogeneously by interest } \\
\text { may increase motivation }\end{array}$ & 53 & 2.96 & 0.59 & 84.9 \\
\hline & $\begin{array}{l}\text { Grouping students randomly may increase social } \\
\text { skills }\end{array}$ & 53 & 2.96 & 0.55 & 83.0 \\
\hline & $\begin{array}{l}\text { Grouping students heterogeneously may increase } \\
\text { achievement and social skills }\end{array}$ & 51 & 2.84 & 0.54 & 76.5 \\
\hline & $\begin{array}{l}\text { It is important to group students according to } \\
\text { learning styles }\end{array}$ & 53 & 2.64 & 0.65 & 54.7 \\
\hline & $\begin{array}{l}\text { Teachers should group students according to their } \\
\text { interests }\end{array}$ & 53 & 2.58 & 0.60 & 56.6 \\
\hline \multirow[t]{4}{*}{ Introduction } & $\begin{array}{l}\text { It is important that lesson introductions engage } \\
\text { the students }\end{array}$ & 54 & 3.57 & 0.60 & 98.1 \\
\hline & $\begin{array}{l}\text { Lesson introductions should communicate } \\
\text { learning objectives }\end{array}$ & 52 & 3.37 & 0.60 & 94.2 \\
\hline & $\begin{array}{l}\text { Lesson introductions should be relevant to the } \\
\text { students }\end{array}$ & 53 & 3.36 & 0.48 & 100.0 \\
\hline & $\begin{array}{l}\text { Lesson introductions should connect with } \\
\text { students' prior knowledge }\end{array}$ & 52 & 3.17 & 0.79 & 84.6 \\
\hline \multirow[t]{3}{*}{ Learning Activities } & $\begin{array}{l}\text { Critical thinking skills should be incorporated } \\
\text { into learning activities }\end{array}$ & 52 & 3.50 & 0.61 & 98.1 \\
\hline & $\begin{array}{l}\text { Learning activities should be adjusted to address } \\
\text { students' learning rates }\end{array}$ & 52 & 3.10 & 0.36 & 98.1 \\
\hline & $\begin{array}{l}\text { Learning activities should be adjusted to address } \\
\text { students' prior knowledge }\end{array}$ & 52 & 2.92 & 0.56 & 80.8 \\
\hline Products & $\begin{array}{l}\text { Teachers should design assignments that result in } \\
\text { products that vary in complexity }\end{array}$ & 52 & 3.13 & 0.53 & 92.3 \\
\hline Product Choice & $\begin{array}{l}\text { Teachers should provide opportunities for } \\
\text { students to choose their learning activities }\end{array}$ & 53 & 3.17 & 0.47 & 96.2 \\
\hline
\end{tabular}


Table 3-Continued

\begin{tabular}{|c|c|c|c|c|c|}
\hline Categories & Belief Statements & $N$ & $M$ & $S D$ & $* \%$ \\
\hline \multirow[t]{6}{*}{ Teaching Strategies } & $\begin{array}{l}\text { It is necessary that teachers adjust instructional } \\
\text { methods to align with students' skills }\end{array}$ & 51 & 3.29 & 0.54 & 96.1 \\
\hline & $\begin{array}{l}\text { It is important that teachers adjust pacing to align } \\
\text { with students' learning rates }\end{array}$ & 52 & 3.27 & 0.66 & 88.5 \\
\hline & $\begin{array}{l}\text { Teachers should adjust instructional methods to } \\
\text { align with students' learning rate }\end{array}$ & 52 & 3.23 & 0.51 & 96.2 \\
\hline & $\begin{array}{l}\text { It is important that teachers adjust instructional } \\
\text { methods to align with students' prior knowledge }\end{array}$ & 53 & 3.21 & 0.57 & 92.5 \\
\hline & $\begin{array}{l}\text { It is important that teachers adjust pacing to align } \\
\text { with students' skills }\end{array}$ & 51 & 3.00 & 0.72 & 82.4 \\
\hline & $\begin{array}{l}\text { Teachers should adjust pacing to align with } \\
\text { students' prior knowledge }\end{array}$ & 51 & 2.96 & 0.49 & 86.3 \\
\hline Time & $\begin{array}{l}\text { Students should complete their assignments at the } \\
\text { same time }\end{array}$ & 52 & 1.96 & 0.74 & 17.3 \\
\hline
\end{tabular}

important to group students according to learning styles $(M=2.64, S D=0.65)$, and teachers should group students according to their interests $(M=2.58, S D=0.60)$.

In the introduction category, the survey results showed that the teachers agreed/strongly agreed with all four of the statements. They believe it is important that lesson introductions engage the students $(M=3.57, S D=0.60)$, communicate learning objectives $(M=3.37, S D=0.60)$, are relevant to the students $(M=3.36, S D=0.48)$, and should connect with students' prior knowledge $(M=3.17, S D=0.79)$.

All three of the statements in the learning activity category resulted in means of approximately 3.0 which indicates the teachers agree/strongly agree with them. These statements are critical thinking skills should be incorporated into learning activities $(M$ $=3.50, S D=0.61)$, learning activities should be adjusted to address students' learning 
rates $(M=3.10, S D=0.36)$, and learning objectives should be adjusted to address students' prior knowledge $(M=2.92, S D=0.56)$.

They also indicated they believed both of the statements concerning products and product choice. The first statement being that teachers should design assessments that result in products that vary in complexity $(\mathrm{M}=3.13, S D=0.53)$ and that teachers should provide opportunities for students to choose their learning activities $(M=3.17$, $S D=0.47)$

The majority of the teachers believed all six of the statements in the teaching strategy category. They believe that it is necessary to adjust instructional methods to align with students' skills $(\mathrm{M}=3.29, S D=0.54)$, as well as it is important to adjust pacing $(M=3.27, S D=0.66)$ and instructional methods $(M=3.23, S D=0.51)$ to align with students' learning rates. The teachers also believe it is important to adjust instructional methods to align with students' prior knowledge $(M=3.21, S D=0.57)$. They also reported that it is important teachers adjust pacing to align with students' skills $(M=3.00, S D=0.72)$ and they agree that teachers should adjust pacing to align with students' prior knowledge $(M=2.96, S D=0.49)$.

The final category is time. The statement students should complete their assignments at the same time $(M=1.96, S D=0.74)$ indicates that the majority of the teachers disagree with the statement and that they do not expect their students to complete their assignments at the same time. 
Qualitative findings

In conjunction with the beliefs of the teachers that agree/strongly agree with the survey process belief statements, the teachers who were interviewed shared their beliefs of the importance of adjusting teaching methods to align students' skills, learning rates, and prior knowledge. Marjorie said, "now that I have validation, I had proof that this is what we should be doing." She had been veering from the textbooks for some time, but when others (such as certain administrators and parents) found out, she would be questioned about her classroom practices. Other than her experience, she didn't have concrete support as to the effectiveness of her actions. The training gave Marjorie solid proof that her strategies and practice of adjusting teaching methods to her individual students were not only acceptable, but best practice. She felt the thoughts in her mind were now making sense and the training helped her to see clearly that differentiated instruction was indeed a practice to continue and to build on in her classroom.

Lynne said the training affirmed many things she was already doing in the classroom, such as projects, choices, and allowing students to be challenged on their own personal levels. In concurrence with the beliefs of the teachers overall on the surveys, Lynne also learned that not all children have to be doing the same thing at the same time and that "there are different doors" to allow children to arrive at the same destination. The training made this clear to her and she immediately started thinking of ways to change her classroom and her lessons to include differentiated instruction strategies and practices. 
Process belief summary

The teachers reported their strong belief of the majority of the statements in the process area. They agreed/strongly agreed with nineteen of the twenty-two process statements. The three statements with a lower percentage of belief, approximately onehalf to three-fourths of the teachers, were all in the grouping alternatives category.

In addition, the teachers who were interviewed, shared the belief that teachers should provide opportunities for students to choose their learning activities, they should adjust instructional methods, as well as pacing, to align with students' skills, learning rates, and prior knowledge.

\section{Assessment Beliefs}

This section discusses the findings in relationship to assessment beliefs. These beliefs may refer to pre-assessments or adjusting assessments to match content. The qualitative survey results are discussed followed by the qualitative results from the interviews.

Quantitative findings

Table 4 shows the assessment area survey belief statements. The survey participants responded that they agreed/strongly agreed with five of the six statements concerning their belief about the assessment of differentiated instruction.

The teachers who were trained in differentiated instruction reported they believed both statements in the Analysis of Pre-assessment category. They believe that it is important that pre-assessment data be analyzed $(M=3.21, S D=0.66)$ and that preassessments should be used to adapt lessons for individual students $(M=3.04, S D=$ $0.58)$. 
Table 4

Assessment Belief Statements

\begin{tabular}{llcccc}
\hline Categories & Belief Statements & $N$ & $M$ & $S D$ & $* \%$ \\
\hline $\begin{array}{l}\text { Analysis of Pre- } \\
\text { assessments }\end{array}$ & $\begin{array}{l}\text { It is important that pre-assessment } \\
\text { data be analyzed }\end{array}$ & 53 & 3.21 & 0.66 & 90.6 \\
& $\begin{array}{l}\text { Pre-assessments should be used to } \\
\text { adapt lessons for individual students }\end{array}$ & 53 & 3.04 & 0.58 & 88.7 \\
& $\begin{array}{l}\text { It is necessary to adjust assessments } \\
\text { to match the differentiated content }\end{array}$ & 53 & 3.00 & 0.71 & 83.1 \\
$\begin{array}{l}\text { Assessments } \\
\text { Formative/Summative) }\end{array}$ & $\begin{array}{l}\text { Pre-assessments should address } \\
\text { Pre-assessments }\end{array}$ & 53 & 3.08 & 0.47 & 92.5 \\
& $\begin{array}{l}\text { learning objectives } \\
\text { Teachers should use a variety of pre- } \\
\text { assessment processes }\end{array}$ & 53 & 3.02 & 0.50 & 88.7 \\
& $\begin{array}{l}\text { Pre-assessments should address } \\
\text { student learning profiles }\end{array}$ & 52 & 2.90 & 0.63 & 78.8 \\
\hline
\end{tabular}

*\% of respondents who agree/strongly agree

They also reported that it is necessary to adjust assessments to match the differentiated content $(M=3.00, S D=0.71)$. The teachers also believe that preassessments should address learning objectives $(M=3.08, S D=0.47)$ and that there should be a variety of pre-assessment processes $(M=3.02), S D=0.50)$. A lower percentage $(78.8 \%)$ of the teachers tended to disagree with the last statement, preassessments should address student learning profiles $(M=2.90, S D=0.63)$.

Qualitative findings

The beliefs of the teachers who were interviewed were consistent with the survey results concerning assessments. They believed that analyzing pre-assessments 
and using the results to adapt lessons for individual students were an important part of differentiating instruction.

The teachers who were interviewed also believed there should be a variety of pre-assessments used in the classroom. Anthony shared that the pre-assessment area was fairly new to him and he believed implementing these ideas would improve the effectiveness of his teaching practice. Julie believed that pre-assessment strategies were one of the biggest take-aways she had from the training. Both Kathy and Marjorie suggested that while they believed pre-assessments were an important part of understanding where individual students, as well as the whole class, were in understanding a topic, they didn't usually take the time to do pre-assessments, let alone analyze them for the purpose of differentiating instruction in any way prior to the training. The training gave them a renewed interest and desire in using pre-assessments in a routine manner in their classrooms.

\section{Assessment belief summary}

Both the surveys and the interviews were consistent in that the teachers believed five out of the six pre-assessment statements. They believed the data should be analyzed, used to adapt lessons and content for individual students, as well as that they should address learning objectives while using a variety of pre-assessment strategies. Fewer teachers $(78.8 \%)$ tended not to believe the statement regarding pre-assessments should address student-learning profiles.

\section{Practice}

Practice item statistics (mean, standard deviation, and frequency of practice) are reported in Table 5 for Content, Table 6 for Process, and Table 7 for Assessment. 
Practice items were scaled along a 5-point Likert scale (1- Never, 2- Less than once per month, 3- 1-2 times per month, 4- 1-2 times per week, and 5- 3-5 times per week).

Thus, for the purpose of this study, items with means of approximately 4.0 indicate that teachers practice those statements of differentiated instruction at least once a week. The percentage column designates the percentage of teachers who report practicing the statement at least once a week.

Table 5

Content Practice Statements

\begin{tabular}{|c|c|c|c|c|c|}
\hline Categories & Practice Statement & $N$ & $M$ & $S D$ & $* \%$ \\
\hline \multirow{2}{*}{$\begin{array}{l}\text { Alignment of } \\
\text { Content }\end{array}$} & Use clearly stated learning objectives & 46 & 4.61 & 0.65 & 91.3 \\
\hline & Objectives are aligned with NAD standards & 44 & 4.57 & 0.95 & 90.9 \\
\hline \multirow[t]{2}{*}{$\begin{array}{l}\text { Differentiation } \\
\text { of Content }\end{array}$} & $\begin{array}{l}\text { Match students to assignments appropriate } \\
\text { to their learning rates }\end{array}$ & 45 & 3.93 & 1.12 & 68.9 \\
\hline & $\begin{array}{l}\text { Adjust content to meet individual students' } \\
\text { level of prior knowledge }\end{array}$ & 45 & 3.93 & 0.96 & 71.1 \\
\hline \multirow[t]{2}{*}{$\begin{array}{l}\text { Product } \\
\text { Alternatives }\end{array}$} & $\begin{array}{l}\text { Provide alternative activities to } \\
\text { accommodate the range of student learning } \\
\text { styles }\end{array}$ & 45 & 3.67 & 1.13 & 55.6 \\
\hline & $\begin{array}{l}\text { Provide alternative activities to } \\
\text { accommodate the range of student interests }\end{array}$ & 45 & 3.49 & 1.12 & 46.7 \\
\hline \multirow[t]{3}{*}{ Resources } & Provide resources that vary in complexity & 46 & 4.00 & 0.76 & 76.1 \\
\hline & Provide resources that vary in familiarity & 45 & 3.64 & 0.83 & 64.4 \\
\hline & Provide resources that vary in abstractness & 45 & 3.58 & 1.08 & 53.3 \\
\hline \multirow[t]{2}{*}{$\begin{array}{l}\text { Resource } \\
\text { Alternatives }\end{array}$} & $\begin{array}{l}\text { Provide a variety of resources to meet } \\
\text { individual students' learning styles }\end{array}$ & 46 & 4.13 & 0.93 & 78.3 \\
\hline & $\begin{array}{l}\text { Provide a selection of resources that } \\
\text { address the full range of student interests }\end{array}$ & 44 & 3.59 & 1.09 & 47.7 \\
\hline
\end{tabular}


Out of the 54 surveys returned, eight of the participants were not currently teaching so they did not respond to the practice portion of the survey. There were also some questions that not all respondents answered. Therefore, the number of participants is between 44 and 46 in the practice tables.

The interview findings for areas related to content, process, and assessment are reported after each individual quantitative narrative.

\section{Content Practice}

This section discusses the findings in relationship to content practice. These teacher practices may refer to using materials at varying levels, providing a variety of resources which address both student interest and learning styles or modifying content to match learning rates. The survey practice results will be discussed, followed by the qualitative findings from the interviews.

\section{Quantitative findings}

Table 5 shows the reported practices of the teachers in the content area of differentiated instruction. Using the criteria state above, the participants responded that they practice six of the eleven statements at least once per week in the content area of differentiated instruction. These statements are in the alignment of content, differentiation of content, resources, and resource alternatives categories.

Teachers who have been trained in differentiated instruction report they use clearly stated learning objectives $(M=4.61, S D=0.65)$ and that they are aligned with NAD standards $(M=4.57, S D=0.95)$. 
In the differentiation of content category, the teachers report their practice of matching students to assignments appropriate to their learning rates $(M=3.93, S D=$ 1.12) and that they adjust content to meet individual students' level of prior knowledge $(M=3.93, S D=0.96)$.

In the resources and resource alternatives categories, the teachers report they provide resources that vary in complexity $(M=4.00, S D=0.76)$ as well as provide a variety of resources to meet individual students' learning styles $(M=4.13, S D=0.93)$.

The other statements teachers practice in table 5 have a lower mean and percentage of teachers who report regular practice. These results seem to imply that about half of the teachers practice less than once per week both of the product alternative statements- provide alternatives activities to accommodate the range of student learning styles $(M=3.67, S D=1.13)$ and provide alternative activities to accommodate the range of student interests $(M=3.49, S D=1.12)$. Again, about half of the teachers report a lower practice rate of the statements provide resources that vary in abstractness $(M=3.58, S D=1.08)$ in the resources category, as well as provide a selection of resources that address the full range of student interests $(M=3.59, S D=$ 1.09) in the resource alternatives category.

\section{Qualitative findings}

The teachers who were interviewed shared that their implementation of the content practice statements aligned consistently with the survey results. The teachers gave several examples of how they would differentiate content as well as provide resources to meet individual students' levels of prior knowledge, interest, and learning styles. 
Harold shared the training helped him to see that he didn't have to use day-today worksheets for everything just because they were there. He could skip pages in the workbook and use a variety of resources that met the learning styles and interests of his students. He shared he would look online at different websites, articles, and videos to help share information with his students. He would go to the bookstore to find resource books that would expand topics he was covering in class. These resources allowed him to give students the opportunity to use their learning strengths and preferences in ways he hadn't before.

Connie's eyes were "opened" and she saw bridges and connections she could take back to her classroom to meet her student's needs and interests. She was reminded she needed to use as "many of the senses and styles of learning as possible." She felt the training gave her "permission to toss out the textbook and use resource materials, including digital media, to spark interest and create a need in the students to know more." Connie regularly would use resources that matched her students learning styles and preferences. She says she was now more focused on being intentional about recognizing the individuality of her students. She said, "I really try to understand, and keep my antenna up when I work with them to watch for kids that need to be challenged, or kids that are overwhelmed, and find resources and content that will cater to them individually."

\section{Content practice summary}

The teachers reported their practice of six of the eleven content practice statements at least once per week. The five remaining statements in the product alternatives, resources, and resource alternatives categories had means less than 4 , 
meaning a lower percentage of teachers (between approximately 46\%-64\%) practiced these statements at least once per week.

In addition, the results from the teachers who were interviewed, shared they also regularly practiced differentiating assignment content based on learning rates and prior knowledge. They also use a variety of resources that vary in complexity to meet the students at their personal learning styles.

\section{Process Practice}

This section discusses the findings in relationship to process practice. These practices of the teachers may refer to how they group students, how they present a concept or skill taught to an individual student based on learning profiles, rates or readiness levels, or how they pace assignments. Once again, the quantitative results from the surveys will be discussed first, followed by the findings from the interviews.

Quantitative findings

Table 6 shows the reported practices of the teachers in the process area of differentiated instruction. The participants responded they practice fifteen of the twentytwo statements at least once per week in the process area of differentiated instruction. These statements are discussed below. 
Table 6

Process Practice Statements

\begin{tabular}{|c|c|c|c|c|c|}
\hline Categories & Practice Statements & $N$ & $M$ & $S D$ & $* \%$ \\
\hline \multirow[t]{6}{*}{$\begin{array}{l}\text { Grouping } \\
\text { Alternatives }\end{array}$} & $\begin{array}{l}\text { It is important to use a variety of grouping } \\
\text { strategies }\end{array}$ & 46 & 4.02 & 0.95 & 71.7 \\
\hline & $\begin{array}{l}\text { Group students randomly to increase social } \\
\text { skills }\end{array}$ & 46 & 3.63 & 0.97 & 56.5 \\
\hline & $\begin{array}{l}\text { Group students heterogeneously to increase } \\
\text { achievement and social skills }\end{array}$ & 43 & 3.37 & 1.11 & 41.9 \\
\hline & $\begin{array}{l}\text { Group students homogeneously by interest to } \\
\text { increase motivation }\end{array}$ & 46 & 3.30 & 1.03 & 50.0 \\
\hline & Group students according to learning styles & 45 & 3.04 & 1.35 & 44.4 \\
\hline & Group students according to their interests & 45 & 2.98 & 1.12 & 35.6 \\
\hline \multirow[t]{4}{*}{ Introduction } & $\begin{array}{l}\text { Lesson introductions communicate learning } \\
\text { objectives }\end{array}$ & 46 & 4.63 & 0.61 & 93.5 \\
\hline & $\begin{array}{l}\text { Makes lesson introductions relevant to } \\
\text { students }\end{array}$ & 46 & 4.57 & 0.78 & 93.5 \\
\hline & Lesson introductions engage the students & 44 & 4.36 & 0.69 & 88.6 \\
\hline & $\begin{array}{l}\text { Connect lesson introductions with students' } \\
\text { prior knowledge }\end{array}$ & 46 & 4.33 & 0.87 & 84.8 \\
\hline \multirow[t]{3}{*}{$\begin{array}{l}\text { Learning } \\
\text { Activities }\end{array}$} & $\begin{array}{l}\text { Design learning activities that incorporate } \\
\text { critical thinking skills }\end{array}$ & 46 & 4.48 & 0.66 & 95.7 \\
\hline & $\begin{array}{l}\text { Adjust learning activities to address students' } \\
\text { learning rates }\end{array}$ & 46 & 4.20 & 1.00 & 78.3 \\
\hline & $\begin{array}{l}\text { Adjust learning activities to address students' } \\
\text { prior knowledge }\end{array}$ & 44 & 3.89 & 1.06 & 70.5 \\
\hline Products & $\begin{array}{l}\text { Design assignments that result in products } \\
\text { that vary in complexity }\end{array}$ & 46 & 3.57 & 1.09 & 50.0 \\
\hline
\end{tabular}


Table 6-Continued

\begin{tabular}{llcccc}
\hline Categories & Practice Statements & $N$ & $M$ & $S D$ & $* \%$ \\
\hline $\begin{array}{l}\text { Teaching } \\
\text { Strategies }\end{array}$ & $\begin{array}{l}\text { Adjust instructional methods to align with } \\
\text { students' learning rates }\end{array}$ & 45 & 4.27 & 0.94 & 82.2 \\
& $\begin{array}{l}\text { Product Choice } \\
\text { Provide opportunities for students to choose } \\
\text { their learning activities. }\end{array}$ & 45 & 3.29 & 1.16 & 44.4 \\
& $\begin{array}{l}\text { Adjust instructional methods to align with } \\
\text { students' skills }\end{array}$ & 44 & 4.20 & 0.93 & 77.3 \\
& $\begin{array}{l}\text { Adjust pacing to align with students' skills } \\
\text { Adjust pacing to align with students' prior }\end{array}$ & 45 & 4.20 & 1.01 & 82.2 \\
& $\begin{array}{l}\text { knowledge } \\
\text { Adjust pacing to align with students' learning } \\
\text { rates }\end{array}$ & 45 & 3.98 & 1.01 & 73.3 \\
& $\begin{array}{l}\text { Adjust instructional methods to align with } \\
\text { students' prior knowledge }\end{array}$ & 45 & 3.98 & 0.97 & 68.9 \\
\hline $\begin{array}{l}\text { Expect students to complete assignments at } \\
\text { the same time }\end{array}$ & 47 & 3.34 & 1.59 & 61.7 \\
\hline Time & & & & & \\
\hline * of respondents who practice the statement 1-5 times per week & & & \\
\hline
\end{tabular}

In the grouping strategy category, the teachers reported practicing using a variety of grouping strategies $(M=4.02, S D=0.95)$ at least once per week. Four of the five highest means were statements, which were connected to the introductions category. The statement with the highest mean was lesson introductions communicate learning objectives $(M=4.63, S D=0.61)$. The other process statements connected to lesson introductions were make lesson introductions relevant to students $(M=4.57, S D$ $=0.78)$, lesson introductions engage the students $(M=4.36, S D=0.69)$, and connect lesson introductions with students' prior knowledge $(M=4.33, S D=0.87)$. 
The learning activities and teaching strategies categories had all of the nine statements with means approximately 4.0 suggesting the teachers practice these statements in both of these categories at least once per week.

In the learning activities category, design learning activities that incorporate critical thinking skills $(M=4.48, S D=0.66)$ was the highest reported statement indicating practice at least three to five times per week followed by adjusting learning activities to address students' learning rates $(M=4.20, S D=1.00)$, and adjust learning activities to address students' prior knowledge $(M=3.89, S D=1.06)$.

In the teaching strategies category, the teachers reported practicing the statements adjusting instructional methods to align with students' learning rates $(M=$ $4.27, S D=0.94)$ and students' skills $(M=4.20, S D=0.93)$. They also report practicing adjusting pacing to align with students' skills $(M=4.20, S D=1.01)$, prior knowledge $(M=4.20, S D=0.97)$, and students' learning rates $(M=3.98, S D=1.01)$. They also adjust instructional methods to align with students' prior knowledge $(M=3.98, S D=$ 0.97) at least once per week.

Fewer teachers, between $35 \%$ and $56.5 \%$, reported practicing five of the six statement in the grouping categories at least one time per week. These statements are group students randomly to increase social skills $(M=3.63, S D=0.97)$, group students heterogeneously to increase achievement and social skills $(M=3.37, S D=1.11)$, group students homogeneously by interest to increase motivation $(M=3.30, S D=1.03)$, group students according to learning styles $(M=3.04, S D=1.35)$ and group students according to their interests $(M=2.98, S D=1.12)$. 
With means less than 4 in the products and product choice categories, only about half of the teachers practice these statements at least once per week- design assignments which result in products that vary in complexity $(M=3.57, S D=1.09)$ and providing opportunities for students to choose their learning activities $(M=3.29, S D=1.16)$.

The last category in the process area is concerning time. The majority of the teachers reported they do not expect their students to complete assignments at the same time $(M=3.34, S D=1.59)$.

Qualitative findings

In line with the survey results, the teachers who were interviewed shared their practice of the process statements. The teachers share they design learning activities that incorporate critical thinking skills and adjust learning activities to address students' learning rates. Their teaching strategies include adjusting instructional methods to align with students' learning rates and skills, as well as adjusting pacing to align with students' skills and prior knowledge.

Mark talked about the training giving lots of practical ideas he stated, "the training gave me a lot of strategies for real things that I can do that can turn into habits." He discussed how he could see immediately while at the training how these strategies could be implemented into his high-school Math classroom. The thought of one group being able to keep up with another group just by differentiating the notes and review sheets was a new idea for him. Some of the students had a stronger math background and didn't necessarily need everything that others in the classroom did. He was able to use strategies learned at the training to help him adjust for prior knowledge, learning rates, and overall skill in this subject. Mark was happy to learn multiple strategies which 
would reach all of the students in his room at one time and give him immediate feedback that would assist him in helping all of his students regardless of what level they were working on.

Lynne agreed the strategies learned at the training would be beneficial. She states "It (the training) gave me tools to reach my students." She realizes her students are different, but intentionally watching out for ways to differentiate for them was eyeopening and gave her a lot to think about. Because Lynne taught in a small school and had multiple grades in her classroom, she appreciated the strategies that helped her give her students choices on their personal level, not necessarily their grade level. Lynne shared she learned strategies to give her students more choices that were appropriate for their skills, prior knowledge, and learning rates. The assignments she started giving after the training, reflected varied critical thinking skills from her students as well as aligned more closely to their personal skills, prior knowledge, and learning rates.

Teachers found themselves being more purposeful and using these strategies in their classrooms after experiencing them at the training. Connie says, "I found myself being more intentional about implementing strategies" and Julie stated, "Once I knew about some of these tools and had the chance to experience them myself, they were super easy to use and to take back to my classroom immediately."

Connie also reports trying to move away from paper and pencil activities and vary the learning activities with group discovery activities as well as learning using movement around the classroom. The differentiated instruction training helped her "understand how students learn differently." She shares this knowledge allows her to plan for different learning needs at the beginning of lessons instead of trying to figure 
out what went wrong at the end. Connie states "I find that even as young as middle schoolers are, there are many that have already developed an attitude or expectation of failure, and differentiated instruction gives me some different angles to look at their attitudes." She goes on to say she is not likely to see their attitude as laziness, but "rather as a challenge to find a way to engage their learning style so they can experience success.”

Process practice summary

The survey results showed the teachers practiced fifteen of the twenty-two statements at least once per week. While they practiced the statements in the introductions, learning activities, and teaching strategy categories at least once per week, fewer teachers (between 35.6\% and 56.5\%) practiced the majority of the grouping strategy statements, and both of the statements in the products, and product choice categories.

In addition, regarding teaching strategies, the teachers who were interviewed, reported they also adjust instructional methods and pacing to align with the skills, learning rates, and prior knowledge of the students.

\section{Assessment Practice}

Quantitative findings

Table 7 shows the reported practices of the teachers in the assessment area of differentiated instruction. This table shows all six assessment practice statements have means less than 4.00 showing that approximately $34 \%$ to $60 \%$ of the teachers practiced each of these statements less than once per week. 
The statement with the highest mean was use pre-assessments to adapt lessons for individual students $(M=3.58, S D=1.12)$. The statement with the lowest mean was pre-assessments address learning profiles $(M=2.80, S D=1.23)$.

\section{Table 7}

Assessment Practice Statements

\begin{tabular}{|c|c|c|c|c|c|}
\hline Categories & Practice Statements & $N$ & $M$ & $S D$ & $* \%$ \\
\hline \multirow[t]{2}{*}{$\begin{array}{l}\text { Analysis of Pre- } \\
\text { assessments }\end{array}$} & $\begin{array}{l}\text { Use pre-assessments to adapt lessons for } \\
\text { individual students }\end{array}$ & 45 & 3.58 & 1.12 & 51.1 \\
\hline & Analyze pre-assessment data & 46 & 3.50 & 0.98 & 52.2 \\
\hline $\begin{array}{l}\text { Assessments } \\
\text { (Formative \& } \\
\text { Summative) }\end{array}$ & $\begin{array}{l}\text { Adjust assessments to match differentiated } \\
\text { content }\end{array}$ & 43 & 3.28 & 0.96 & 44.2 \\
\hline \multirow[t]{3}{*}{ Pre-assessment } & Pre-assessments address learning objectives & 45 & 3.51 & 1.20 & 60.0 \\
\hline & Use a variety of pre-assessment processes & 48 & 3.46 & 1.05 & 43.8 \\
\hline & Pre-assessments address learning profiles & 44 & 2.80 & 1.23 & 34.1 \\
\hline
\end{tabular}

Qualitative findings

The teachers who were interviewed shared they went back to their classrooms and implemented pre-assessments and pre-assessment strategies at a higher rate than the overall survey results show from the entire group of survey respondents.

Out of all of the strategies and practices learned and discussed at the training, pre-assessments, a major component of differentiating, was at the top of the list for immediate implementation after the training for several of the interview participants. 
Julie was brand-new to differentiated instruction and stated that after the training "preassessments were probably the easiest component to implement.” There were many ideas for pre-assessments that were easy to take back to the classroom and use across the curriculum. Julie now consistently uses pre-assessments prior to lessons and units, as well as quick-check assessments throughout the units, to ensure her students are with her and achieving the standards being taught.

Marjorie also discussed the pre-assessments, as a part of the training was very useful. The pre-assessment ideas presented, as well as understanding the importance of them, was very beneficial. She makes it a regular practice in her classroom to use preassessments with the intent to differentiate the instruction for her students after she has the pre-assessment data. Mark \& Anthony both found the pre-assessment strategies presented at the training were helpful and very easy to implement in their classrooms. It gave them an instant look at where their students were as well as information to help them be on the right track for instruction.

\section{Assessment practice summary}

The survey results indicate that $60 \%$ or fewer of the teachers practice the assessment statements at least one time per week. The teachers who were interviewed shared one of the biggest take-aways from the training was in the area of assessments, and several of them reported they began incorporating these strategies in their classrooms on a regular basis after training.

\section{Research Question 1 Summary}

The teachers who attended the differentiated instruction workshop indicated they believed the majority of the content, process, and assessment statements. Out of the 
thirty-nine combined statements in all categories, the majority of the teachers indicated they agreed/strongly agreed with thirty-three of the thirty-nine statements. Out of the thirty-nine combined practice statements, the majority of the teachers indicated they practiced twenty-one of the process, content and assessment statements one to five times per week.

Several of the teachers who were interviewed stated they had been using some sort of differentiated instruction already in their classrooms, and now felt more confident in their practice as they felt their actions were validated. They also stated they were already familiar with some of the strategies and practices, and this new method they were being trained to use, wasn't going to be something completely different than they had already been doing.

The teachers who were interviewed also indicated many of the strategies presented at the workshop were useful and easy to take back to their classroom to begin using right away. Several shared the pre-assessment strategies were most useful, not only in ease of use, but also to help springboard their over-all use of the differentiated instruction teaching method. Several of the teachers who were interviewed reported they were already using some differentiated instruction strategies in their classroom prior to the training. The training boosted their knowledge as well as their confidence. Research question 2 will look at how the beliefs of the teachers compare to the reported practice of the differentiated instruction statements in each different area of content, process, and assessment. 


\section{Research Question 2}

How do their beliefs of differentiated instruction compare with their classroom practices?

\section{Content Belief and Practice Statement Pairs}

Table 8 shows the content beliefs and practices statement pairs of the content segment of differentiated instruction. The differentiated instruction categories, according to the innovation configuration, are listed in the left-hand column alphabetically.

There were three statements the teachers believed, and also reported their regular practice of, at least one time per week. The percentage sub-column in the belief columns indicates the percentage of teachers that agree or disagree with the statement. The sub-column, "at least one time per week" in the practice frequency column indicates from the teachers who agreed with the statement, the percentage that practiced the statement at least one time per week. The statements with agreeance over $80 \%$ and practice percentages over $70 \%$ will be discussed first. These statements are in the categories of alignment of content, differentiation of content, resources, and resource alternatives.

In the alignment of content category, $100 \%$ of the teachers believe and $91.3 \%$ of these teachers practice the statement there should be/are clearly stated learning objectives. They also believe $(97.7 \%)$ and practice $(93.0 \%)$ the statement learning objectives should be/are aligned with NAD standards. 
Table 8

Content Belief/Practice Statement Pairs

\begin{tabular}{|c|c|c|c|c|c|c|c|c|c|c|c|}
\hline \multirow[b]{4}{*}{ Category } & \multirow[b]{4}{*}{ Content Belief/Practice Statement Pairs } & \multicolumn{3}{|c|}{ Belief } & \multirow{2}{*}{\multicolumn{4}{|c|}{$\begin{array}{l}\text { Practice } \\
\text { Frequency }\end{array}$}} & \multirow[b]{4}{*}{$X^{2}$} & \multirow[b]{4}{*}{$P$} & \multirow[b]{4}{*}{$V$} \\
\hline & & & & & & & & & & & \\
\hline & & \multirow[t]{2}{*}{$\begin{array}{c}\text { Disagree } \\
\text { Agree }\end{array}$} & \multirow[b]{2}{*}{$N$} & \multirow[b]{2}{*}{$\%$} & \multicolumn{2}{|c|}{$\begin{array}{l}\text { Less than } 2 \mathrm{x} \\
\text { per month }\end{array}$} & \multicolumn{2}{|c|}{$\begin{array}{l}\text { At least } 1 \mathrm{x} \\
\text { per week }\end{array}$} & & & \\
\hline & & & & & \# & $\%$ & \# & $\%$ & & & \\
\hline \multirow{4}{*}{$\begin{array}{l}\text { Alignment of } \\
\text { Content }\end{array}$} & & $\mathrm{D}$ & - & - & - & - & - & - & - & - & - \\
\hline & There should be/are clearly stated learning objectives & A & 46 & 100.0 & 4 & 8.7 & 42 & 91.3 & - & - & - \\
\hline & Learning objectives should be/are be aligned with & $\mathrm{D}$ & 1 & 2.3 & 1 & 100.0 & - & - & - & - & - \\
\hline & NAD standards & A & 43 & 97.7 & 3 & 7.0 & 40 & 93.0 & 10.23 & .001 & .48 \\
\hline \multirow{4}{*}{$\begin{array}{l}\text { Differentiation } \\
\text { of Content }\end{array}$} & It is important to adjust/I adjust content to meet each & $\mathrm{D}$ & 18 & 40.0 & 7 & 38.9 & 11 & 61.1 & - & - & - \\
\hline & individual students' prior knowledge & A & 27 & 60.0 & 6 & 22.2 & 21 & 77.8 & 1.46 & .23 & .18 \\
\hline & It is important to match/I match students to & $\mathrm{D}$ & 1 & 2.2 & 1 & 100.0 & - & - & - & - & - \\
\hline & assignments appropriate to their learning rates & A & 44 & 97.8 & 13 & 29.5 & 31 & 70.5 & 2.26 & .13 & .22 \\
\hline \multirow{4}{*}{$\begin{array}{l}\text { Product } \\
\text { Alternatives }\end{array}$} & There should be/I provide alternative activities to & $\mathrm{D}$ & 4 & 8.9 & 2 & 50.0 & 2 & 50.0 & - & - & - \\
\hline & accommodate the range of student interests & A & 41 & 91.1 & 22 & 53.7 & 19 & 46.3 & .02 & .89 & .02 \\
\hline & There should be/I provide alternate activities to & $\mathrm{D}$ & - & - & - & - & - & - & - & - & - \\
\hline & accommodate the range of student learning styles & A & 45 & 100.0 & 20 & 44.4 & 25 & 55.6 & - & - & - \\
\hline \multirow{6}{*}{ Resources } & Teachers should use/I use resources that vary in & $\mathrm{D}$ & - & - & - & - & - & - & - & - & - \\
\hline & complexity & A & 46 & 100.0 & 11 & 23.9 & 35 & 76.1 & - & - & - \\
\hline & It is imperative that teachers provide/I provide & $\mathrm{D}$ & 12 & 26.7 & 8 & 66.7 & 4 & 33.3 & - & - & - \\
\hline & resources that vary in abstractness & A & 33 & 73.3 & 13 & 39.4 & 20 & 60.6 & 2.63 & .105 & .24 \\
\hline & Teachers should provide resources/I provide that vary & $\mathrm{D}$ & - & - & - & - & - & - & - & - & - \\
\hline & in familiarity & A & 45 & 100.0 & 16 & 35.6 & 29 & 64.4 & - & - & - \\
\hline \multirow{4}{*}{$\begin{array}{l}\text { Resource } \\
\text { Alternatives }\end{array}$} & It is important to provide/I provide a variety of & $\mathrm{D}$ & 3 & 6.8 & 1 & 33.3 & 2 & 66.7 & - & - & - \\
\hline & interests & A & 41 & 93.2 & 22 & 53.7 & 19 & 46.3 & .46 & .49 & .10 \\
\hline & It is important to provide/I provide a variety of & D & 2 & 4.4 & 2 & 100.0 & 0.0 & 0.0 & - & - & - \\
\hline & learning styles & A & 43 & 95.6 & 8 & 18.6 & 35 & 81.4 & 7.33 & .007 & .40 \\
\hline
\end{tabular}


The statement in the differentiation of content category, it is important to match students to assignments appropriate to their learning rates, had $97.8 \%$ of the teachers in agreeance, and $70.5 \%$ of these teachers report practicing this statement at least once per week.

In the resource category, $100 \%$ of the teachers agreed they should use resources that vary in complexity, and $76.1 \%$ of these teachers reported this practice at least one time per week.

In the resource alternative category, $95.6 \%$ of the teachers believed that it is important to provide a variety of resources that address the full range of student learning styles, and $81.4 \%$ of the teachers report practicing this statement at least one time per week.

There were also a number of statements in which the teachers believed the statement, yet the reported practice showed that the teachers tended not to practice these statements on a regular basis. These statements are in the categories of product alternatives, resources, and resource alternatives. Statements with agreeance percentages over $80 \%$ and practice reports of less than $70 \%$ will be reviewed. These statements are in the categories product alternatives, resources and resource alternatives.

In the category of product alternatives, $91 \%$ of the teachers reported they believed they should provide alternatives to accommodate the range of student interests, however, only $46.3 \%$ reported that they practice this at least one time per week. Regarding providing alternatives to accommodate the range of student learning styles, $100 \%$ of the teachers reported believing this, while only $55.6 \%$ of them reported practicing at least one time per week. 
The category of resources had $100 \%$ of teachers reporting they believe that resources should vary in familiarity. However, only $64.4 \%$ of them reported practicing these statements at least one time per week.

In the category of resource alternatives, $93.2 \%$ of the survey respondents reported their belief that teachers should provide a variety of resources that address the full range of student interest, but only $46.3 \%$ of them reported practicing this at least one time per week.

\section{Content Belief/Practice Summary}

Overall, the teachers agreed and practiced five content statements. The first category was alignment of content. The teachers agreed and practiced both statements at least one time per week. They also agreed and practiced the statement in the differentiation of content category that it is important to match students to assignments appropriate to their learning rate. The statement in the resource category, 'it is important to provide a variety of resources that vary in complexity', and the statement in the resource alternatives category, "provide a variety of resources that address the full range of student learning styles', the teachers who agreed with, also practiced these statements at least one time per week.

There were teachers who agreed with four other statements in the content area but only about half of them tended to practice these items at least one time per week. These items are in the product alternatives, resources, and resource alternative categories. Only $46 \%$ - $64.4 \%$ of the teachers practice on a regular basis, providing alternatives or resources that vary in familiarity to accommodate or address the full range of student interest. 


\section{Process Beliefs and Practice Statement Pairs}

Table 9 shows the process area beliefs and practices statement pairs of the process segment of differentiated instruction. The differentiated instruction categories according to the innovation configuration are listed alphabetically in the left-hand column.

There were some statements that approximately $80 \%$ or more of the teachers believed and more than $70 \%$ practiced at least one time per week. These statements were in the grouping alternatives, introductions, learning activities, and the teaching strategies categories.

Out of five statements in the grouping alternatives category, $97.7 \%$ of the teachers agreed they should use a variety of grouping strategies, and $72.7 \%$ of these teachers practiced this statement at least once per week.

In the introduction category, all four statements were both believed and practiced by the teachers. The statement, lesson introductions should be/are relevant to the students, had a report of $100 \%$ of the teachers believing the statement, with $93.5 \%$ of them reporting practice. $97.7 \%$ of the teachers believed that lesson introductions should engage the students and $88.4 \%$ of the teachers report that their lesson introductions do engage the students. The statement, lesson introductions should/do communicate learning objectives, had $93.3 \%$ of the teachers report their belief and $95.2 \%$ indicated their practice of this statement. Finally, $84.4 \%$ of the teachers agreed that lesson introductions should connect with students' prior knowledge, and $86.8 \%$ of these teachers practice this at least one time per week. 
Table 9

\section{Process Belief/Practice Statement Pair}

\begin{tabular}{|c|c|c|c|c|c|c|c|c|c|c|c|}
\hline \multirow[t]{3}{*}{ Category } & \multirow[t]{3}{*}{ Process Belief/Practice Statement Pairs } & \multicolumn{3}{|c|}{ Beliefs } & \multicolumn{4}{|c|}{ Practice } & \multirow{3}{*}{$\mathrm{X}^{2}$} & \multirow{3}{*}{$p$} & \multirow{3}{*}{$\bar{V}$} \\
\hline & & \multicolumn{3}{|c|}{$\begin{array}{l}\text { Disagree } \\
\text { Agree }\end{array}$} & \multicolumn{2}{|c|}{$\begin{array}{l}\text { Less than } 2 \mathrm{x} \\
\text { Per month }\end{array}$} & \multicolumn{2}{|c|}{$\begin{array}{l}\text { At least } 1 \mathrm{x} \\
\text { Per week }\end{array}$} & & & \\
\hline & & & $N$ & $\%$ & \# & $\%$ & \# & $\%$ & & & \\
\hline \multirow{12}{*}{$\begin{array}{l}\text { Grouping } \\
\text { Alternatives }\end{array}$} & Students should be/are grouped according to learning styles & $\mathrm{D}$ & 21 & 46.7 & 15 & 71.4 & 6 & 28.6 & - & - & - \\
\hline & & A & 24 & 53.3 & 10 & 41.7 & 14 & 58.3 & 4.01 & .05 & .30 \\
\hline & Teachers should /I do group students according to their interests & $\mathrm{D}$ & 20 & 44.4 & 16 & 80.0 & 4 & 20.0 & - & - & - \\
\hline & & A & 25 & 55.6 & 13 & 52.0 & 12 & 48.0 & 3.80 & .05 & .29 \\
\hline & Teachers should/I use a variety of grouping strategies & $\mathrm{D}$ & 1 & 2.2 & 1 & 100.0 & 0 & 0.0 & - & - & - \\
\hline & & $\mathrm{A}$ & 44 & 97.8 & 12 & 27.3 & 32 & 72.7 & 2.52 & .11 & .24 \\
\hline & Grouping students heterogeneously may/to increase achievement & $\mathrm{D}$ & 7 & 16.7 & 6 & 85.7 & 1 & 14.3 & - & - & - \\
\hline & and social skills & A & 35 & 83.3 & 18 & 51.4 & 17 & 48.6 & 2.80 & .09 & .23 \\
\hline & Grouping students homogeneously by interest may/to increase & $\mathrm{D}$ & 5 & 10.9 & 5 & 100.0 & - & - & - & - & - \\
\hline & motivation & A & 41 & 89.1 & 18 & 43.9 & 23 & 56.1 & 5.61 & .02 & .35 \\
\hline & Grouping students randomly may/to increase social skills & $\mathrm{D}$ & 6 & 13.0 & 4 & 66.7 & 2 & 33.3 & - & - & - \\
\hline & & A & 40 & 87.0 & 16 & 40.0 & 24 & 60.0 & 1.21 & .22 & .18 \\
\hline \multirow[t]{8}{*}{ Introductions } & Lesson introductions should be/are relevant to the students & $\mathrm{D}$ & - & - & - & - & - & - & - & - & - \\
\hline & & A & 46 & 100.0 & 3 & 6.5 & 43 & 93.5 & - & - & - \\
\hline & Lesson introductions should engage/do engage the students & $\mathrm{D}$ & 1 & 2.3 & - & - & 1 & 100.0 & - & - & - \\
\hline & & A & 43 & 97.7 & 5 & 11.6 & 38 & 88.4 & .13 & .72 & .05 \\
\hline & Lesson introductions should/do communicate learning objectives & $\mathrm{D}$ & 3 & 6.7 & 1 & 33.3 & 2 & 66.7 & - & - & - \\
\hline & & A & 42 & 93.3 & 2 & 4.8 & 40 & 95.2 & 3.67 & .06 & .29 \\
\hline & Lesson introductions should/do connect with students' prior & $\mathrm{D}$ & 7 & 15.6 & 2 & 28.6 & 5 & 71.4 & - & - & - \\
\hline & knowledge & A & 38 & 84.4 & 5 & 13.2 & 33 & 86.8 & 1.01 & .30 & .15 \\
\hline \multirow{6}{*}{$\begin{array}{l}\text { Learning } \\
\text { Activities }\end{array}$} & Learning activities should be/are adjusted to address students' & $\mathrm{D}$ & 7 & 16.3 & 4 & 57.1 & 3 & 42.9 & & & \\
\hline & prior knowledge & A & 36 & 83.7 & 8 & 22.2 & 28 & 77.8 & 3.55 & .06 & .29 \\
\hline & Learning activities should be/are adjusted to address students' & $\mathrm{D}$ & 1 & 2.2 & 1 & 100.0 & 0 & 0.0 & - & - & - \\
\hline & learning rates & A & 44 & 97.8 & 9 & 20.5 & 35 & 79.5 & 3.58 & .06 & .28 \\
\hline & Critical thinking skills should be/are incorporated into learning & $\mathrm{D}$ & 1 & 2.2 & 0 & 0.0 & 1 & 100.0 & - & - & - \\
\hline & activities & A & 44 & 97.8 & 2 & 4.5 & 42 & 95.5 & .05 & .83 & .03 \\
\hline
\end{tabular}


Table 9-Continued

\begin{tabular}{|c|c|c|c|c|c|c|c|c|c|c|c|}
\hline \multirow[t]{3}{*}{ Category } & \multirow[t]{3}{*}{ Process Belief/Practice Statement Pairs } & \multicolumn{3}{|c|}{ Beliefs } & \multicolumn{4}{|c|}{ Practice } & \multirow{3}{*}{$\mathrm{X}^{2}$} & \multirow{3}{*}{$p$} & \multirow{3}{*}{ 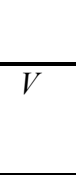 } \\
\hline & & \multirow[t]{2}{*}{$\begin{array}{l}\text { Disagree } \\
\text { Agree }\end{array}$} & \multirow{2}{*}{$N$} & \multirow[b]{2}{*}{$\%$} & \multicolumn{2}{|c|}{$\begin{array}{l}\text { Less than } 2 \mathrm{x} \\
\text { Per month }\end{array}$} & \multicolumn{2}{|c|}{$\begin{array}{l}\text { At least } 1 \mathrm{x} \\
\text { Per week }\end{array}$} & & & \\
\hline & & & & & \# & $\%$ & \# & $\%$ & & & \\
\hline Products & Teachers should/do design assignments that result in products & $\mathrm{D}$ & 4 & 8.9 & 2 & 50.0 & 2 & 50.0 & - & - & - \\
\hline & that vary in complexity & A & 41 & 91.1 & 21 & 51.2 & 20 & 48.8 & .002 & .96 & .001 \\
\hline Product & Teachers should provide/I provide opportunities for students to & $\mathrm{D}$ & 2 & 4.5 & 2 & 100.0 & - & - & - & - & - \\
\hline Choice & choose their learning activities & A & 42 & 95.5 & 22 & 52.4 & 20 & 47.6 & 1.75 & .19 & .20 \\
\hline Teaching & Teachers should/do adjust pacing to align with students' prior & $\mathrm{D}$ & 6 & 13.6 & 3 & 50.0 & 3 & 50.0 & & & \\
\hline \multirow[t]{11}{*}{ Strategies } & knowledge & A & 38 & 86.4 & 5 & 13.2 & 33 & 86.8 & 4.73 & .03 & .33 \\
\hline & $\begin{array}{l}\text { It is not important that teachers adjust pacing to align with } \\
\text { students' skills }\end{array}$ & $\mathrm{D}$ & 8 & 18.2 & 3 & 37.5 & 8 & 62.5 & - & - & - \\
\hline & Adjust pacing to align with students' skills & A & 36 & 81.8 & 4 & 11.1 & 32 & 88.9 & 3.41 & .07 & .28 \\
\hline & Teachers should/do adjust pacing to align with students' learning & $\mathrm{D}$ & 4 & 8.9 & 4 & 100.0 & 0 & 0.0 & - & - & - \\
\hline & rate & A & 41 & 91.1 & 8 & 19.5 & 33 & 80.5 & 12.1 & .00 & .52 \\
\hline & Teachers should/do adjust instructional methods to align with & $\mathrm{D}$ & 4 & 8.9 & 2 & 50.0 & 2 & 50.0 & & & \\
\hline & students' prior knowledge & A & 41 & 91.1 & 12 & 29.3 & 29 & 70.7 & .73 & .39 & .13 \\
\hline & Teachers should/do adjust instructional methods to align with & $\mathrm{D}$ & 2 & 4.7 & 1 & 50.0 & 1 & 50.1 & - & - & - \\
\hline & students' skills & A & 41 & 95.3 & 9 & 22.0 & 32 & 78.0 & .84 & .36 & .14 \\
\hline & Teachers should/do adjust instructional methods to align with & $\mathrm{D}$ & 2 & 4.4 & 1 & 50.0 & 1 & 50.0 & - & - & - \\
\hline & students' learning rate & A & 43 & 95.6 & 7 & 16.3 & 36 & 83.7 & 1.49 & .22 & .18 \\
\hline \multirow[t]{2}{*}{ Time } & \multirow{2}{*}{$\begin{array}{l}\text { Students should/expect students to complete their assignments at } \\
\text { the same time }\end{array}$} & $\mathrm{D}$ & 38 & 82.6 & 17 & 44.7 & 21 & 55.3 & - & - & - \\
\hline & & A & 8 & 17.4 & 1 & 12.5 & 7 & 87.5 & 2.88 & .09 & .25 \\
\hline
\end{tabular}


In the learning activities category, all three of the statements had both belief and reported practice by the teachers. $97.8 \%$ of the teachers strongly agreed that critical thinking skills should be incorporated into learning activities, and 95.5\% practiced this at least one time per week. The statement learning activities should be/are adjusted to address students' learning rates has an agreeance percentage of $97.8 \%$ and $79.5 \%$ of teachers reported using this practice at least one time per week in their classroom. The final statement in the learning activities category, states that learning activities should be/are adjusted to address students' prior knowledge with $83.7 \%$ of teachers reporting agreeance, and $77.8 \%$ of these teachers reporting their practice at least one time per week.

In the teaching strategies category, the teachers both believed and practiced all six of the statements. The teachers believe and practice the statements at least one time per week concerning adjust pacing to align with students' prior knowledge $(86.4 \%$ believe, $86.8 \%$ practice), to align with students' skills ( $81.8 \%$ believe, $88.9 \%$ practice), and to align with students' learning rate $(91.1 \%$ believe, $80.5 \%$ practice $)$. They also believe and practice the statements regarding instructional methods to align with students' prior knowledge (91.1\% believe, 70.7 practice), students' skills $(95.3 \%$ believe, $78.0 \%$ practice), and students' learning rates ( $95.6 \%$ believe, $83.7 \%$ practice).

There were several statements with a large discrepancy of the teachers who reported their belief, yet they did not report practicing these statements on a regular basis. These statements are in the grouping alternative, products, and product choice categories. 
The grouping alternative category shows $83.3 \%$ of teachers believe grouping students heterogeneously may increase achievement and social skills, but only $48.6 \%$ practice this technique at least one time per week. Grouping students homogeneously by interest to increase motivation was reported as a belief by $89.1 \%$ of the survey respondents, yet only $56.1 \%$ reported practicing this statement. Grouping students randomly to increase social skills was reported by $87.0 \%$ as a belief, however, only $60 \%$ reported practicing this strategy at least one time per week.

In the area of products there were $91.1 \%$ of the teachers who agreed assignments should be designed so that the product result will vary in complexity, but only $48.8 \%$ of them report this practice at least 1 time per week.

In product choice, the statement teachers should provide opportunities for students to choose their learning activities had $95.5 \%$ of the teachers agreeing, but only $47.6 \%$ of them actually provided opportunities for their students to choose their learning activities at least one time per week.

In the category of time, $17.4 \%$ of teachers reported they believed students should complete their assignments at the same time with $87.5 \%$ of these teachers expecting this at least one time per week. Most teachers $(82.6 \%)$ believe that students should not complete their assignments at the same time.

\section{Process Belief/Practice Summary}

In the process area, the teachers both believed and practiced fourteen statements. In the introduction category, they both believed and practiced all four of the statements regarding lesson introductions being relevant, engaging, communicating learning objectives and connect with students' prior knowledge. In the learning activities 
category, they believed and practiced all three statements that critical thinking skills should be incorporated into learning activities and that learning activities should be adjusted to address students' prior knowledge and learning rates. And in the teaching strategies category, they agreed and practiced adjusting pacing and instructional methods to align with the prior knowledge, students' skills, and learning rates of their students.

There were other statements the teachers believed, but fewer than $60 \%$ of the teachers reported their practice of these statements, at least one time per week. These statements are in the grouping alternatives, products, and product choice categories. The teachers who believe they should design assignments that result in products that vary in complexity, provide opportunities for students to choose learning activities, do not practice these statements at least one time per week.

\section{Assessment Practice and Belief Statement Pairs}

Table 10 shows the assessment beliefs and practices statement pairs of the assessment area of differentiated instruction. The differentiated instruction categories according to the innovation configuration are listed in the left-hand column alphabetically. 
Table 10

Assessment Belief/Practice Statement Pairs

\begin{tabular}{|c|c|c|c|c|c|c|c|c|c|c|c|}
\hline \multirow[t]{3}{*}{ Category } & \multirow[t]{3}{*}{ Belief/Practice Statement Pairs } & \multicolumn{3}{|c|}{ Belief } & \multicolumn{4}{|c|}{ Practice } & \multirow[b]{3}{*}{$\mathrm{X}^{2}$} & \multirow[b]{3}{*}{$p$} & \multirow[b]{3}{*}{$V$} \\
\hline & & \multirow[b]{2}{*}{ A-D } & \multirow[b]{2}{*}{$N$} & \multirow[b]{2}{*}{$\%$} & \multicolumn{2}{|c|}{$\begin{array}{l}\text { Less than } \\
2 \mathrm{x} \text { per } \\
\text { month }\end{array}$} & \multicolumn{2}{|c|}{$\begin{array}{l}\text { At least } 1 \mathrm{x} \\
\text { per week }\end{array}$} & & & \\
\hline & & & & & $\#$ & $\%$ & $\#$ & $\%$ & & & \\
\hline \multirow[t]{4}{*}{$\begin{array}{l}\text { Analysis of Pre- } \\
\text { assessment Data }\end{array}$} & $\begin{array}{l}\text { It is important that pre-assessment data should be/is } \\
\text { analyzed }\end{array}$ & $\mathrm{D}$ & 3 & 6.5 & 1 & 33.3 & 2 & 66.7 & & & \\
\hline & & $\mathrm{A}$ & 43 & 93.5 & 21 & 48.8 & 22 & 51.2 & .27 & .60 & .08 \\
\hline & $\begin{array}{l}\text { Pre-assessments should be used/are used to adapt } \\
\text { lessons for individual students }\end{array}$ & $\mathrm{D}$ & 6 & 13.3 & 6 & 100.0 & - & - & & & \\
\hline & & A & 39 & 86.7 & 16 & 41.0 & 23 & 59.0 & 7.24 & .01 & .40 \\
\hline Assessments & Adjust assessments to match the differentiated content & $\mathrm{D}$ & 7 & 16.3 & 3 & 42.9 & 4 & 57.1 & & & \\
\hline (Formative/Summative) & & A & 36 & 83.7 & 21 & 58.3 & 15 & 41.7 & .57 & .45 & .12 \\
\hline \multirow[t]{6}{*}{ Pre-assessments } & $\begin{array}{l}\text { Teachers should use/use a variety of pre-assessment } \\
\text { processes }\end{array}$ & $\mathrm{D}$ & 6 & 12.8 & 6 & 100.0 & - & - & & & \\
\hline & & A & 41 & 87.2 & 21 & 51.2 & 20 & 48.8 & 5.11 & .024 & .33 \\
\hline & $\begin{array}{l}\text { Pre-assessments should address/address student learning } \\
\text { profiles }\end{array}$ & $\mathrm{D}$ & 10 & 22.7 & 9 & 90.0 & 1 & 10.0 & & & \\
\hline & & A & 34 & 77.3 & 20 & 58.8 & 14 & 41.2 & 3.34 & .07 & .28 \\
\hline & $\begin{array}{l}\text { Pre-assessments should address/address learning } \\
\text { objectives }\end{array}$ & $\mathrm{D}$ & 3 & 6.7 & 2 & 66.7 & 1 & 33.3 & & & \\
\hline & & A & 42 & 93.3 & 16 & 38.1 & 26 & 61.9 & .95 & .33 & .15 \\
\hline
\end{tabular}


Out of the six statements, there were two statements in the assessment area the teachers reported they strongly believed (at least 90\%) in. However, only $51.2 \%$ and $61.9 \%$ of the teachers reported practicing these statements at least one time per week.

In the category of analyzing pre-assessment data, $93.5 \%$ of the teachers report they believe pre-assessment data should be analyzed, but only $51.2 \%$ analyze their preassessment data at least one time per week. And in the pre-assessment category, $93.3 \%$ of teachers strongly agree that pre-assessments should address learning objectives, yet only $61.9 \%$ of these teachers practice this statement at least one time per week.

There were an additional three statements the teachers agreed (between $80 \%$ and $90 \%$ ) with in the assessment area but fewer than $60 \%$ of the teachers practiced these statements at least once per week. These statements were pre-assessments should be used to adapt lessons for individual students $(86.7 \%$ agreed with $59.0 \%$ reported practicing), assessments should be adjusted to match the differentiated content $(83.7 \%$ agreed with $41.7 \%$ practicing), and teachers should use a variety of pre-assessments (87.2\% agreed with $48.8 \%$ practicing).

\section{Assessment Belief/Practice Summary}

In the assessment area, the teachers strongly agreed with two of the six statements, yet only $51.2 \%$ and $61.9 \%$ of the teachers practiced those statements at least once per week. They also agreed with the additional four statements, but again, fewer teachers $(59 \%$ or less) practiced those statements at least once per week. Over-all, the teachers agreed/strongly agreed with all six assessment statements, but approximately only $60 \%$ or fewer of the teachers tended to practice these statements at least one time per week. 
Table 11 reports the results of the Wilcoxon Signed Rank Test for comparing overall percentages of beliefs and practices in each of the three areas of differentiated instruction: process, content, and assessment.

Table 11

Wilcox on Signed Rank Test for Comparing Overall Beliefs and Practices $(n=47)$

\begin{tabular}{llllll}
\hline Variables & & Beliefs $^{\mathrm{a}}$ & Practice $^{\mathrm{b}}$ & $Z$ & $p$ \\
\hline Content & Mean & 91.03 & 68.88 & 4.12 & $<.001$ \\
& $S D$ & 10.31 & 30.28 & & \\
Process & Mean & 83.90 & 71.14 & 3.84 & $<.001$ \\
& $S D$ & 11.66 & 23.52 & & \\
Assessment & Mean & 88.74 & 46.45 & 5.32 & $<.001$ \\
& $S D$ & 12.11 & 38.84 & & \\
\hline
\end{tabular}

${ }^{a}$ Overall percent and standard deviation of agree/strongly agree.

${ }^{\mathrm{b}}$ Overall percent and standard deviation of practice 1 or more times per week

About $91 \%$ believed the content area statements of differentiated instruction. However, only $69 \%$ reported practicing these items. This discrepancy in beliefs and practice is also statistically significant $(Z=4.12, p<.001)$. Overall, approximately $84 \%$ of teachers believed the process area of differentiated instruction statements, while only $70 \%$ practiced these processes. This difference is statistically significant $(Z=3.84, p<$ $.001)$. In the area of assessment, about $89 \%$ of the teachers in this study believed in the statements concerning different types of assessments in differentiated instruction. However, only $46.4 \%$ practiced the statements. This difference is statistically significant $(Z=5.32, p<.001)$. These results suggest that overall; teachers practiced differentiated instruction significantly less than their level of beliefs about it. 
The results shown in Table 11 also denote that there are large variances in the practice of differentiated instruction with standard deviations ranging from 30.28 for each area of content, 23.52 process, and 38.84 for assessment. In contrast, the variation in the beliefs are quite small (10.31 for content,11.66 for process, and 12.11 for assessment).

The levels of practice across the content, process, and assessment areas are also statistically significant $\left(\chi^{2}=8.81, d f=2, p=.011\right)$. More teachers practiced content area statements than they did assessments $(Z=3.63, p<.001)$. There were also more teachers who practiced differentiated instruction processes than they did assessments $(Z$ $=4.10, p<.001)$. No statistically significant differences were found between levels of practice in the process and content areas.

\section{Research Question 2 Summary}

Tables 8, $9 \& 10$ examine the beliefs and practice comparisons by item. Table 11 gives an overview of those comparisons of each of the content, process, and assessment areas. The tables show there are categories and statements that the teachers both believe and practice, as well as categories and statements that the teachers believe, yet do not practice.

Table 8, the content table, suggests the teachers believe and practice both of the statements in alignment of content as well as the statement that they provide a variety of resources that address student learning styles in the resource alternatives category. The teachers also believe in both of the product alternative statements as well as two of the resource/resource alternatives statements, yet only about half $(46 \%-64 \%)$ of the teachers practice these statements at least one time per week. 
The process table, Table 9, indicates the teachers believe and practice all four of the introduction category statements as well as the statement critical thinking skills should be/are incorporated into learning activities in the learning activities category. The table also shows the teachers believe, yet fewer than $60 \%$ of the teachers practice, two of the grouping strategy statements, as well as both of the statements in the products and product choice categories.

Table 10, the assessment table, shows the teachers believe the six statements. However, only approximately $60 \%$ or fewer of the teachers practice these statements at least one time per week.

Table 11 gives an overall look at the three categories showing the teachers practice the content and process statements more than the assessment statements, however their level of belief was higher than their practice in all three areas of content, process, and assessment.

Research question 3 will look at how teachers report and describe support methods of their implementation of differentiated instruction.

\section{Research Question 3}

How do teachers report and describe various methods of support on their implementation of differentiated instruction?

\section{Quantitative}

Table 12 shows the "Yes" and "No" responses for 38 or 39 teachers who selfreported support methods in their implementation of differentiated instruction in their classrooms after the training. 
Table 12

\begin{tabular}{lrr} 
Support Statements & Yes & No \\
\hline $\begin{array}{l}\text { I have shared ideas with another teacher concerning differentiated } \\
\text { instruction. }\end{array}$ & 37 & 2 \\
$\begin{array}{l}\text { I received ideas from another teacher concerning differentiated } \\
\text { instruction. }\end{array}$ & 33 & 5 \\
I self-reflect on the implementation of differentiated instruction. & 30 & 8 \\
I have observed another teacher implement differentiated instruction. & 25 & 13 \\
I discuss the process of differentiated instruction with another teacher. & 24 & 14 \\
Another teacher observed me teaching with differentiated instruction. & 20 & 18 \\
$\begin{array}{l}\text { I had a mentor who coached me while beginning to implement } \\
\text { differentiated instruction. }\end{array}$ & 10 & 29 \\
$\begin{array}{l}\text { I participated with another classroom teacher for planning my } \\
\text { differentiated instruction activities. }\end{array}$ & 7 & 31 \\
I keep a journal of my implementation of differentiated instruction. & 0 & 38
\end{tabular}

The majority of teachers responded they have either shared ideas with another teacher or received ideas from another teacher concerning the practice of differentiated instruction. The majority also report they have done self-reflection on the practice of the implementation of differentiated instruction. About two-thirds of participants who answered the support statements on the survey reported they discussed the process of differentiated instruction or shared an observation experience either in their classroom or visiting another classroom. Less than half also reported they had a mentor, coach, or participated with another classroom teacher for planning differentiated instruction activities for their classroom. None of the teachers who answered the survey reported keeping a journal of their implementation. 


\section{Qualitative}

When asked about support methods the teachers had used when implementing differentiated instruction, several topics surfaced. Colleague interaction and feedback was a strong theme that emerged from the interviews. When asked about what they would share with an administrator or supervisor about their experience at the training, and implementing differentiated instruction into their classroom, both Kathy and Julie said their advice would be to tell the administrators to support them by giving them resources and time to learn, plan, and prepare. Anthony also wanted the administrators to be aware of giving their teachers time to prepare differentiated lessons. They also were very adamant about giving the teachers support. Marjorie said, "please, please give the teachers resources, continued training, a mentor, or another teacher to talk with." Anthony suggested that all teachers implementing differentiated instruction have someone they can bounce ideas off, and Lynne said "it is important to have feedback and to be able to ask questions." It was very apparent the teachers wanted to have colleague interactions, and those who did felt much more comfortable and confident in their implementation of differentiated instruction whether they were implementing just a few strategies in one class, or across their curriculum.

All of the teachers interviewed discussed in some way colleague collaboration was instrumental in their implementation of differentiated instruction. Mark, Connie, Harold, Julie, Marjorie, and Anthony all discussed the importance of other teachers in their buildings who had attended the training and that they bounced ideas off of each other, gave each other feedback, observed each other, etc. This gave them ideas, 
reminded them of strategies presented at the training, and gave them confidence. Julie said talking to a colleague through the beginning of implementing differentiated instruction was most helpful to her. Anthony said he had a teacher proficient already in differentiated instruction helping him and coaching him through new ideas when he began to implement differentiated instruction into his classroom. Kathy and Lynne both said that collaborating with other teachers outside of their building who had attended the training was very helpful. Lynne appreciated input on someone outside of her building observing her and giving her feedback, while Kathy, who was working in a one-teacher school at the time of her initial implementation, said that talking to other teachers who had attended the training was very helpful and she learned a lot from their discussions.

\section{Research Question \#3 Summary}

Most of the teachers who took the survey reported they did share ideas with another teacher regarding implementation of differentiated instruction. Most teachers also reported they either visited another classroom for observation or had someone visit their classroom for observation. Most of the teachers reported they did not have a mentor or a coach to assist them through the implantation of differentiated instruction, nor did they participate with another teacher when it came to planning for differentiated instruction in their classroom.

In the interviews, teachers indicated that colleague interaction regarding the planning and implementation of differentiated instruction would be desirable to assist in increased effectiveness. They also suggested more feedback from administrators would help improve their practice and keep them focused on applying differentiated instruction methods intentionally in their classrooms on a regular basis. 


\section{Summary of Major Findings}

In analyzing both the quantitative and qualitative data, there were several key findings concerning the beliefs and practices of the teachers of the Columbia Union Conference of Seventh-day Adventists who participated in the training of differentiated instruction.

The first two key findings are related to research question 1 regarding the beliefs and practices of the teachers.

\section{Key Finding \#1}

The sample of teachers agree or strongly agree with the majority of the content, process, and assessment statements of differentiated instruction. The exceptions are two statements in the content area, adjusting content to meet each individual students' prior knowledge and providing resources that vary in abstractness, in the process area, three of the six grouping statements, and in the assessment area the statement that preassessments should address student learning profiles.

\section{Key Finding \#2}

The teachers practice at least once per week the statements in the categories of alignment of content and differentiation of content in the content area, and in the process area, they practice the introduction, learning activities, and teaching strategies at least once per week.

About half of the teachers report they do not practice the content statements in the product alternative category or the process statements in the grouping alternatives, products, or product choice categories. Approximately $60 \%$ or fewer of the teachers practice the statements in the assessment category. 
Key findings 3, 4, 5 and 6 are in relation to research question 2 comparing the beliefs and practices of the teachers. Table 13 shows an overview of the categories the teachers believe and practice.

\section{Table 13}

Key Finding Overview of Categories Teachers Believe/Practice

\begin{tabular}{lll}
\hline Finding & Areas & Categories \\
\hline Teachers believe and practice the statements & $\begin{array}{l}\text { Content } \\
\text { Process }\end{array}$ & $\begin{array}{l}\text { Alignment of content } \\
\text { Introductions } \\
\text { Teaching strategies } \\
\text { Learning activities }\end{array}$ \\
& & $\begin{array}{l}\text { Product alternatives } \\
\text { Products } \\
\text { Teachers believe and don't practice the statements } \\
\text { Analysis of pre-assessments } \\
\text { Content } \\
\text { Process } \\
\text { (formative/summative) }\end{array}$ \\
& Assessment & Pre-assessments \\
& & Grouping Alternatives \\
Teachers don't believe and don't practice the & Process & \\
statements & & \\
\hline
\end{tabular}

Key Finding \#3

There were four categories in which the teachers agreed and practiced all of the statements. The teachers agreed and reported the practice of the statements at least one time per week in the alignment of content category in the content area. They also agreed and practiced the process area statements in the introductions, teaching strategies, and learning activities categories. 


\section{Key Finding \#4}

The teachers believed yet did not practice the statements in several categories. In the content area the teachers believe, yet only about one-half to two-thirds practice the statements in the product alternatives category. Less than $60 \%$ of the teachers practice the product and product choice categories in the process area. In the assessment area, they believe all of the statements, yet only $60 \%$ or fewer report they practice these statements at least one time per week.

\section{Key Finding \#5}

There was a low belief (between 53\% and $89 \%$ ) of the teachers, and a low practice $(60 \%$ or less $)$ of the majority of the statements in the grouping alternatives category in the process area of differentiated instruction. The statement with the exception is it is important to use a variety of grouping strategies.

\section{Key Finding \#6}

There were mixed results with the statements in two of the categories in the content area. These categories are resources and resource alternatives. The statements are about providing resources that vary in complexity, familiarity, and abstractness, as well as providing resources that meet individual students' learning styles and interests.

Key finding 7 addresses research question 3 and support methods the teachers may have had when implementing differentiated instruction. 


\section{Key Finding \#7}

The surveys and interviews indicate the majority of the teachers have interacted with other teachers in some way to assist in their implementation of differentiated instruction. 


\section{CHAPTER 5}

\section{KEY FINDINGS, DISCUSSION AND FUTURE CONSIDERATIONS}

The purpose of this chapter is to summarize the study, highlight the major findings with a discussion, give recommendations for practice and possible future research, as well as a conclusion.

\section{Description of the Study}

In the summer of 2013, the Columbia Union of Seventh-day Adventists began an initiative to train their teachers in the differentiated instruction teaching method. There were three cohorts for a two-year, three-day per summer training, for a combined total of 6 days of training for each participant. This mixed-methods research study was conducted to explore the beliefs, practices, and support methods of teachers of the Columbia Union of Seventh-day Adventists concerning differentiated instruction after completion of the training.

Data was collected through a questionnaire based on the Connecticut Study by Kirner \& Bennett (See Appendix C). This innovation configuration model of differentiated instruction guided the survey questions for the beliefs and corresponding practice sections of the questionnaire. There were also eight interviews with teachers discussing their personal experiences. 
The purpose of this study was to describe how teachers implemented the differentiated instruction method after completing the training. It also looked at what type of on-going support they may have used in the process.

The participants of this research study were the ninety-three teachers that completed the differentiated instruction training. Fifty-four teachers returned the survey giving a 58\% return rate. There were eight volunteers who agreed to be interviewed for the purpose of this research study. All classrooms have a wide range of student interest, academic levels, learning styles, and preferences, making it impossible to teach all concepts in one way and have all students master each concept. Many Seventh-day Adventist schools also have multi-grade classrooms, lending a teaching method, such as differentiated instruction, as a preferred method of instruction.

\section{Findings and Discussion}

In analyzing both the quantitative and qualitative data, there were several key findings concerning the beliefs and practices of the teachers of the Columbia Union Conference of Seventh-day Adventists who participated in the training of differentiated instruction. Below are the research questions, the key findings that relate to them and discussion of each key finding.

Research question one states, "How do teachers who have attended differentiated instruction workshops describe their beliefs and practices concerning the use of differentiated instruction in their classrooms?" The first two key findings are related to this question. 


\section{Key Finding \#1}

The sample of teachers in this study agree or strongly agree with the content, process, and assessment statements of differentiated instruction. The exceptions are three statements in the content area, adjusting content to meet each individual students' prior knowledge and providing resources that vary in abstractness, in the process area, three of the six grouping alternative statements, and in the assessment area the statement that pre-assessments should address student learning profiles.

Previous research suggests that teachers' beliefs are influential forces in decisions teachers make and are linked to student performance (Good, 1987). Smylie (1988) says that "teacher's perceptions and beliefs are the most significant predictors of individual change" (p. 3).

It may be possible the teachers may have believed the majority of the differentiated instruction content statements because they have been practicing them since they began teaching. For example, in the content area the statement "there should be clearly stated learning objectives." Likewise, in the process area in the introduction category, stems such as "it is important that lesson introductions engage students." These are obviously good teaching practices, and regardless of implementation methods, teachers most likely are applying these types of statements in their teaching prior to the training.

\section{Key Finding \#2}

The teachers practice at least once per week the statements in the categories of alignment of content and differentiation of content in the content area, and in the 
process area, they practice the introduction, learning activities, and teaching strategies at least once per week.

About half of the teachers report they do not practice the content statements in the product alternative category or the process statements in the grouping alternatives, products, or product choice categories. Approximately $60 \%$ or fewer of the teachers practice the statements in the assessment area.

In this finding, the teachers are practicing good teaching in regard to introductions and following the guiding standards set forth. The statements in these categories, while important to differentiated instruction, however, are not exclusive or unique to this method of teaching. These practices are standard for teaching regardless of instructional method, subject matter, or grade levels being taught.

They are also practicing good teaching strategies and learning activities in their classrooms. The teachers who took the survey report they are comfortable with, and are, adjusting instructional methods and learning activities to align with students' prior knowledge, students' skills and students' learning rates. Over $70 \%$ of these teachers also reported they practice this in their classrooms at least one time per week. According to Hall (2009), these teachers are allowing for diversity in assignments and pacing, are giving their students the opportunity to work at their own level of challenge and be successful in their learning.

Good teacher practice happens when teachers are equipped and have a good knowledge of the subject matter as well as their ability "to implement new strategies, to develop effective performance tasks, to plan appropriate assessment tools, and to address different student learning styles" (Stafford, 2006, p. 1). The training provided 
not only knowledge, but looking back at the first key finding, the teachers also held the belief of the majority of the statements of differentiated instruction.

However, there is discrepancy among the teachers' beliefs and practices in the classroom of some fundamental statements of differentiated instruction. The next four key findings will look further at the beliefs and reported practices of the teachers.

Key findings 3, 4, 5 and 6 are in relation to research question two, "How do their beliefs of differentiated instruction compare with their classroom practices?" According to Pajares (1992) beliefs are difficult to measure as they are not observable, nor are the individuals consciously aware of their beliefs. However, the "formulation and change of teacher educators' beliefs can lead to the improvement of their teaching" (Shagrir, 2015, as cited in Yuan, 2017, p. 260). Some studies have indicated that teachers may not always "practice what they preach" (Lunenberg \& Korthagen, 2003, p. 29). This would account for some discrepancies between a teacher's beliefs and their practices. These discrepancies may be attributed to "lack of professional competence", "limited opportunities for critical reflection and continuous learning in their work environment", as well as other factors such as limited time or understanding (Yuan, 2017, p. 261).

\section{Key Finding \#3}

The teachers agreed and practiced all of the statements in four categories. The teachers agreed and reported the practice of the statements at least one time per week in the alignment of content category in the content area. They also agreed and practiced the process area statements in the introductions, teaching strategies, and learning activities categories. 
In this finding, the teachers both believe and are practicing good teaching in providing the alignment category by providing clearly stated learning objectives that are aligned with NAD standards. It is likely that the teachers were practicing these processes prior to attending the training. Regardless of the instructional method, this is a standard procedure for teaching and not limited to differentiated instruction.

When teachers provide a range of learning opportunities that cater to the individual needs and interests of the students, it will both challenge and give academic success to the students (Lawrence-Brown, 2004). This practice of differentiation provides a framework for planning and teaching to the differences in the student's levels of readiness, learning profiles, as well as their interests. The data in my study revealed that the respondents of the survey both believed and practiced in varying and adjusting learning activities, teaching strategies and pacing to address individual student learning rates. The data also showed that the teachers believed and practiced varying and adjusting learning activities and teaching strategies to address individual students' skills and prior knowledge.

The Iris Center (2010) at Vanderbilt states that "when teachers differentiated process, they teach the same concept or skill to each student; however, the manner in which each student makes sense of the topic or skill can vary" (p. 6). Therefore, when teachers vary the activities the students use, they take into account "their students' readiness levels, interests, or learning profiles" (p. 6). Tomlinson \& McTighe (2006) share that teachers who practice differentiated instruction are "attuned to students' varied learning needs....and will make modifications to how students get access to important ideas and skills (p. 18). 
During the interviews, the teachers shared they felt it was important to adjust instructional methods and learning activities. They felt the training gave them "strategies for real things....that can turn to habits" and gave "tools to reach my low students and my average students and then my gifted students." Another teacher stated that the training "allowed me to further develop my teaching repertoire and allowed me to reach kids on different levels." And yet another teacher said, "I could develop a program with the curriculum that would help with the thought process of all students at different levels." As I was talking to the teachers, it was very clear they felt comfortable using the strategies learned at the differentiated instruction training. Most of them shared they were already using some sort of differentiated instruction strategies in their classrooms, but they didn't really know it was considered differentiated instruction.

Some of these strategies and learning activities included adjusting assignments to make them either more or less challenging, giving some students more information or assistance than others, creating assignments that used the intelligence strengths of their students, and building lessons on prior knowledge that their students already had obtained. One teacher stated the training "really opened my eyes and made me aware of what I was already doing”, while another said, "I was already doing so much DI, I just wasn't aware of it and now I have validation."

After the training they felt their choices in the classroom were confirmed and justified. The training enhanced their knowledge and gave them more ideas and avenues to reach their children to continue implementing strategies and activities that would engage and raise the academic achievement of their students. 


\section{Key Finding \#4}

There were several categories in which the teachers believed yet did not practice the statements. In the content area the teachers believe, yet only about one-half to twothirds practice the statements in the product alternatives category. Less than $60 \%$ of the teachers practice the product and product choice categories in the process area. In the assessment area, they believe all of the statements, yet only $60 \%$ or fewer report they practice these statements at least one time per week.

Findings from this study indicate there is a gap that exists between what was believed and what was actually implemented by the teachers. Cross (2010) says "the disparities between teachers' stated beliefs and their actual classroom practices can be attributed to a range of cognitive and contextual factors" (p. 414). This suggests that the teachers' belief-practice relationship might be looked at within the influence of individual school settings, classroom size, as well as range of grade-levels in a specific classroom.

There are some statements in each area of content, process, and assessment that the teachers believe, yet don't practice. It may be that while they believe these statements, the teachers find it difficult to practice these statements for numerous reasons. Many of the teachers are in small schools which have multiple grade levels with smaller numbers of students in one classroom. Teachers who were interviewed stated time was a huge factor in their implementation of differentiated instruction. It takes a lot of time to plan assorted lessons as well as time to train the students in a variety of ways of responding appropriately to assignments. As one interviewee responded the planning can be "overwhelming." One teacher also stated that "changing the culture" of the classroom is difficult. When some students are completing a different 
assignment, it may seem "unfair" to others. Creating a classroom where it is acceptable to both students and parents when there are a variety of assignments and expectations may not be an easy feat.

Students should be given a choice of their learning activities so they can demonstrate their learning in different ways (Chein, 2012). Following this type of instruction would enable the students to choose an activity, resources, or product and show what they have learned according to their preferred learning style and personal interest. The survey respondents shared they believed the students should have a choice of what their learning activities were, however less than half of the teachers actually allowed their students to choose their learning activities at least one time per week. Giving students choices or alternative activities could be difficult for some teachers as they may feel they would lose control, not have enough time to plan or to carry out lessons, or they may feel they may not be able to manage the students doing different activities.

One of the teachers that I interviewed shared how she began giving choices to her students after the training. She gave an example regarding choices in a Bible assignment. She had a multi-grade classroom and gave several options for her students to show how the Bible lesson applied to them. She was a bit skeptical at first, thinking they would just choose the "easiest" and not give their best, but after giving them the choice of drawing a picture, creating a project or doing some sort of writing activity (poem, reader's theatre, etc.) she was quite pleased with the outcome of all of her grade K-4 students. They were happy to have a choice, spent adequate time and the product was meaningful and portrayed the knowledge that her students had. The needs of her 
diverse students were met by being provided with choices so that her students could demonstrate their learning in different ways.

Although the teachers believed in all of the assessment statements in all of the categories in the survey, the results indicated that approximately $60 \%$ or fewer of the teachers do not use preassessments, nor do they adjust formative/summative assessments in their classroom. The literature reveals that pre-assessments and assessments are a major component of differentiated instruction.

Meaningful pre-assessments of students will automatically lead to an effective and successful differentiation (Hall, et al., 2004). They also argue that using both pre and on-going assessments informs teachers to that they can provide choices and can scaffold for the varying needs of "interests and abilities that exists in classrooms of diverse student" (p. 7). The teachers who completed the survey shared they believe they should use, analyze and adjust assessments. However, approximately $60 \%$ or less of them reported that they do not use pre-assessments, nor do they adjust formative/summative assessments in their classrooms at least once per week.

Torgenson (2008) emphasizes a key practice of conducting timely and valid assessments. The data from these assessments should be used to improve differentiated instructional planning. When it relates to pre-assessments, some teachers may not understand their value. They recognize that it was discussed and shared at the training and know that it is something they believe would be advantageous, yet they may still be cautious to try something new back in their classrooms for a myriad of reasons. They may not feel like they have the time, or they may feel like they wouldn't know what to do if some of the children already knew the content area to be covered. 
According to Tomlinson (2001) the assessment portion can be differentiated by giving students different opportunities to show what they have learned, rubrics which extend the varied skill levels of the students and allowing students to create their own assessments which contain required components (p. 13). It can be a daunting task to be constantly adjusting content as well as assessments. Some teachers may feel that regardless of how their students obtained and learned information they should be able to show their knowledge in the same way as other students. It is also a possibility that some teachers may not adjust assessments for fear they will not include pertinent content areas that need to be assessed.

In discussing pre-assessments with the teachers I interviewed, all of the them mentioned pre-assessments in a positive way. They appreciated and took back the preassessment portion of differentiated instruction back to their classrooms. One stated that she now did more intentional pre-assessments and that they were probably the easiest component of differentiated instruction to implement without "much thought or preparation.”

I believe the teachers I interviewed may have possibly been more open to change and trying new things than some of the other survey respondents. The survey results show that most of the teachers who took the training believed in the statements that make up the different instruction method of teaching. The survey showed that they understood what differentiated instruction is, yet the survey revealed that most did not take those components back to their classrooms to practice. The teachers that were willing to be interviewed seemed to not only believe in differentiated instruction, but they shared they were also already performing some of these strategies in their 
respective classrooms. These teachers were clearly willing to go back and continue to try new things and share their findings with me for the purpose of this study.

\section{Key Finding \#5}

There was a low belief (between 53\% and $89 \%$ ) of the teachers, and a low practice $(60 \%$ or less) of the majority of the statements in the grouping alternatives category in the process area of differentiated instruction. The statement with the exception 'it is important to use a variety of grouping strategies'.

Grouping students is an important part of the process segment of differentiated instruction (Tomlinson, 1999). She suggested that teachers plan their instruction so that all of the students would work with a variety of groups within their classroom. She suggested they work with mixed-readiness groups, similar interest groups, randomly, with the class as a whole and sometimes with those who learn in a similar style to the way they learn. Using a variety of grouping strategies allows students to see themselves "in a variety of contexts" and aides the teacher in "auditioning" students in different settings with different peers and different types of work (Tomlinson, 1999).

The data revealed that approximately half of the teachers did not believe in or practice three of the six statements in the process grouping alternatives category. Understanding that many of the teachers taking this survey teach in small school settings, it's likely they may not have enough students in their classroom to group students homogenously, or with students that function at similar levels. Instead, they may without choice, have students grouped heterogeneously, or with students that are diverse in their academic, social and emotional levels. As most Seventh-day Adventist 
schools have multiple grade levels within the same classroom, teachers group students heterogeneously; possibly without even realizing this is their constant grouping strategy.

However, the data showed that the teachers did believe and practice the statement "provide a variety of grouping strategies" in the grouping alternatives category. Strategies such as “pick a partner", "grade groups”, a grouping rotation or alphabetical rotation could be combined to ability and interest grouping strategies. The interviewees shared that they found that the training provided a variety of grouping strategies, such as "appointment clocks", "postcard puzzles", and "four corners" that were helpful and easy to implement when they returned to their classroom. The majority of the teachers taking the survey, and all of the teachers that were interviewed, shared that the training was very helpful in showing a variety of effective grouping strategies to use in their classrooms.

\section{Key Finding \#6}

There were mixed results with the statements in two of the categories in the content area. These categories are resources and resource alternatives. The statements are in regard to providing resources that vary in complexity, familiarity, and abstractness, as well as providing resources that meet individual students' learning styles and interests.

This key finding indicates there was a strong belief of four of the five statements in the resources and resource alternatives categories of the content area. Two of the statements, teachers should provide resources that vary in complexity, and it is important to provide a variety of resources that address the full range of student learning styles both had a high belief of the teachers. The data also revealed that the teachers 
practiced these statements at least one time per week. It may be that teachers both believe and practice these statements as they are wanting to give their students experiences that will enhance and grow their learning and academic achievement. They are providing resources that teach to the strengths and styles of their individual students. In smaller schools and classrooms, the teachers are able to "step out of the norm" and provide experiences that aren't possible with larger classrooms or schools with more restrictions.

While the teachers may be able to provide some variety of resources and experiences, they may not be able to cover all areas. The teachers believed the statements provide resources that vary in familiarity, and it is important to provide a variety of resources that address the full range of student interest; however, they do not practice these statements at least one time per week. When teachers are choosing resources and activities for their students, sometimes they have to use what is available. Time, money and certain other logistics may be factors for not implementing these statements. Most of the teachers work in schools that have limited funds and resources and they may not have a choice to provide a wide range of resources that vary in familiarity and individual interests of the students.

As indicated in Key Finding 1, the teachers had a lower belief in the statement providing resources that vary in abstractness, and subsequently only $60.6 \%$ of them indicated they practice this statement at least one time per week.

Key finding 7 addresses research question 3 and support methods the teachers may have had when implementing differentiated instruction. 


\section{Key Finding \#7}

The surveys and interviews indicate the majority of the teachers have interacted with other teachers in some way to assist in their implementation of differentiated instruction.

The teachers of the Columbia Union were given the opportunity for professional development in the differentiated instruction method of teaching. The purpose of the training was to give the teachers tools and knowledge to go back to their classrooms and implement this method of teaching. When professional development experiences are taken back and practiced, professional learning evolves. Professional learning develops into professional growth, which increases student achievement.

The literature and research on support methods backs that teachers who interact and collaborate with each other have increased professional growth as well as student achievement (Kennedy \& Shiel, 2010). Most of the teachers who took this survey indicated that they shared ideas, or received ideas, in some form with another teacher. Most have also looked at their own implementation of differentiated instruction and performed self-reflection on their practice. About two-thirds of the teachers discussed differentiated instruction and/or shared an observation experience, and less than half reported they had a mentor, coach, or participated with another classroom teacher planning for implementation in their classroom.

The interviews indicated that while teachers felt supported and were highly satisfied with their training and new knowledge in the differentiated instruction teaching methods, they would like more communication and interaction with other teachers. Additionally, they were interested in different levels of administration giving them 
feedback to ensure they are growing in their professional practice and doing the best they can for their students' learning.

\section{Recommendations for Practice}

Possible recommendations for practice could include:

1. Administrators at the union, conference, and school levels explore ways to provide opportunity for professional learning communities within, and beyond, school communities.

2. Teachers to be paired together with someone who teaches a similar grade to share observation and feedback with each other.

3. Formal evaluations and conferencing become routine to ensure professional growth.

\section{Suggestions for Future Research}

Based on the results of this mixed methods study, it is recommended that further qualitative and quantitative studies be performed on the understanding and implementation of differentiated instruction and the support methods that can be used to enhance and give confidence to this teaching practice. The studies could:

1. Include teacher observations and other artifacts (such as testing results) in addition to a survey and interviews for triangulation of data.

1. Be broadened by including additional teachers outside of the Columbia Union, possibly a North American Division-wide sample.

2. Look at what types of ongoing professional development that would assist teachers and administrators in creating professional learning communities to give support on differentiated instruction. 
3. Include teachers broken down into grade-groups to look at similarities and differences that they are experiencing based on the age of the students that they teach.

4. Involve interviewing administrators, both principals and superintendents, as to their view of the implementation of differentiated instruction, and/or other teaching methods and what type of on-going support they feel is most beneficial to their teachers.

5. Compare the results of this research using a sample of Seventh-day Adventist teachers who have not completed the differentiated training to learn if their understanding and practice have any similarities or differences.

\section{Conclusion}

The overall drive for this mixed methods study was to determine the beliefs and practices of teachers in the implementation of differentiated instruction. The qualitative data revealed that the teachers found differentiated instruction to be a useful method of classroom practice. Many were already implementing segments of differentiated instruction without realizing their practice was a specific method of teaching. The training validated their current practices. Teachers also shared that they saw the effectiveness of this method and were motivated to continue implementing additional areas of differentiated instruction into their classroom routines.

They also indicated that while they felt supported and were highly satisfied with their training and new knowledge in the differentiated instruction implementation method, they would appreciate more communication and interaction with other 
teachers, as well as different levels of administration, to give them feedback to ensure they are growing in their professional practice.

The quantitative data supported the fact that the teachers who took the training overall understood what differentiated instruction was and how it should be implemented. However, the data also showed that they were not practicing all areas of differentiated instruction in content, process, and assessment. 


\section{APPENDIX A}

\section{Differentiated Instruction Beliefs/Practice Survey}

\begin{tabular}{|c|c|c|}
\hline \multicolumn{3}{|c|}{ Part I: Beliefs } \\
\hline \multicolumn{3}{|c|}{ Please indicate your belief using the following scale: } \\
\hline \multicolumn{3}{|c|}{1 - Strongly Disagree } \\
\hline \multicolumn{3}{|c|}{2 - Disagree } \\
\hline \multicolumn{3}{|c|}{3 - Agree } \\
\hline \multicolumn{3}{|c|}{4 - Strongly Agree } \\
\hline 1 & $\begin{array}{l}\text { There should be alternative activities to accommodate the } \\
\text { range of student interest in a classroom }\end{array}$ & 1234 \\
\hline 2 & It is important that lesson introductions engage the students & 1234 \\
\hline 3 & It is important to group students according to learning styles & 1234 \\
\hline 4 & $\begin{array}{l}\text { It is not necessary to adjust assessments to match the } \\
\text { differentiated content }\end{array}$ & 1234 \\
\hline 5 & There should be clearly stated learning objectives & 1234 \\
\hline 6 & It is important that pre-assessment data be analyzed & 1234 \\
\hline 7 & Lesson introductions should communicate learning objectives & 1234 \\
\hline 8 & Teachers should group students according to their interests & 1234 \\
\hline 9 & Lesson introductions should be relevant to the students & 1234 \\
\hline 10 & Teachers should provide resources that vary in familiarity & 1234 \\
\hline 11 & Pre-assessments should address student learning profiles & 1234 \\
\hline 12 & It is important to use a variety of grouping strategies & 1234 \\
\hline 13 & $\begin{array}{l}\text { There should be alternative activities to accommodate the } \\
\text { range of student learning styles in a classroom }\end{array}$ & 1234 \\
\hline 14 & $\begin{array}{l}\text { Pre-assessments should be used to adapt lessons for individual } \\
\text { students }\end{array}$ & 1234 \\
\hline 15 & $\begin{array}{l}\text { Teachers should provide opportunities for students to choose } \\
\text { their learning activities }\end{array}$ & 1234 \\
\hline 16 & $\begin{array}{l}\text { It is important that learning objectives be aligned with NAD } \\
\text { standards }\end{array}$ & 1234 \\
\hline 17 & $\begin{array}{l}\text { It is important that teachers adjust instructional methods to } \\
\text { align with students' prior knowledge }\end{array}$ & 1234 \\
\hline 18 & $\begin{array}{l}\text { Critical thinking skills should be incorporated into learning } \\
\text { activities }\end{array}$ & 1234 \\
\hline 19 & Pre-assessments should address learning objectives & 1234 \\
\hline
\end{tabular}




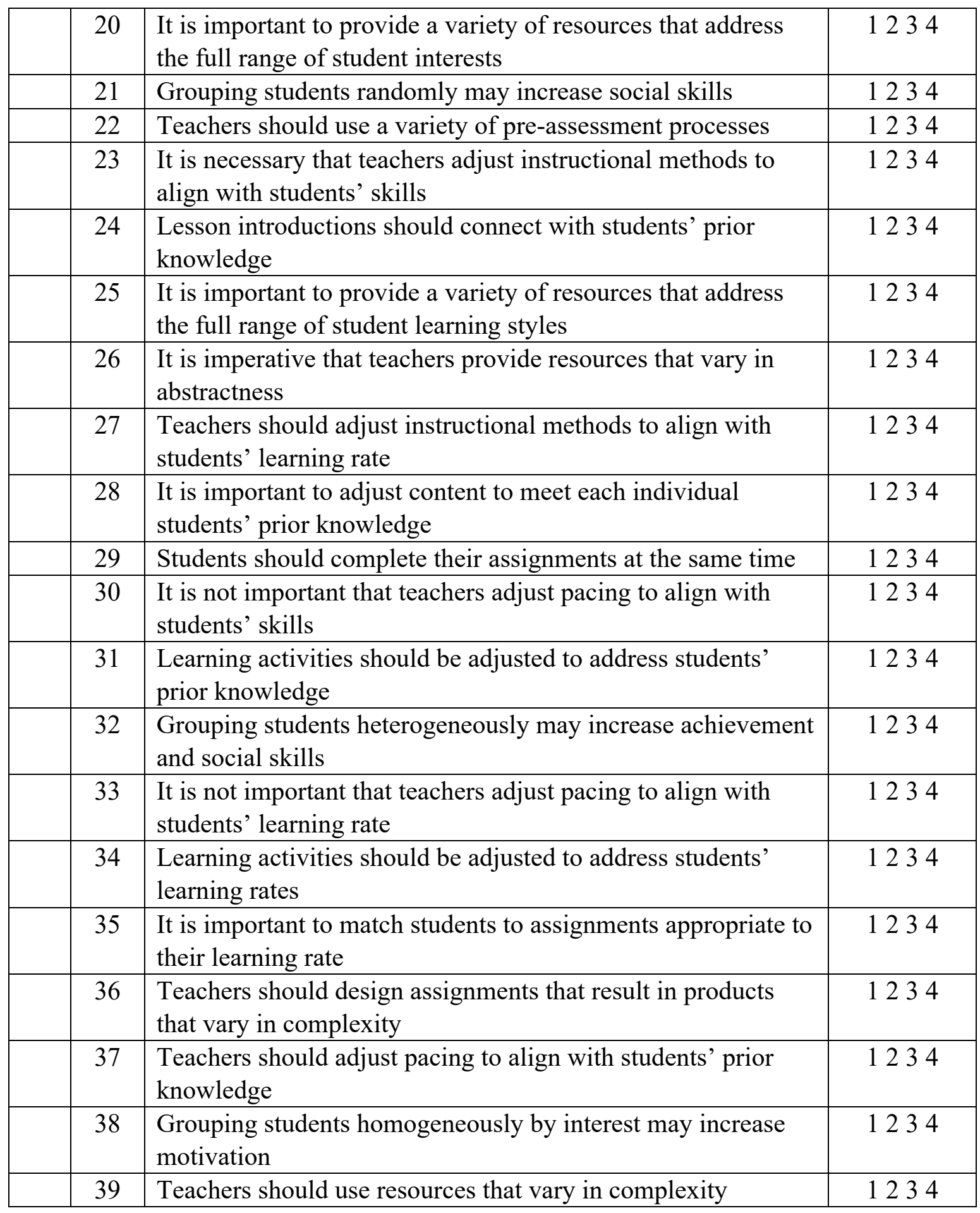


Part II: Practice

Please indicate your personal practice using the following scale:

$1-$ Never

2 - Less than once a month

$3-1-2$ times per month

$4-1-2$ times per week

$5-3-5$ times per week

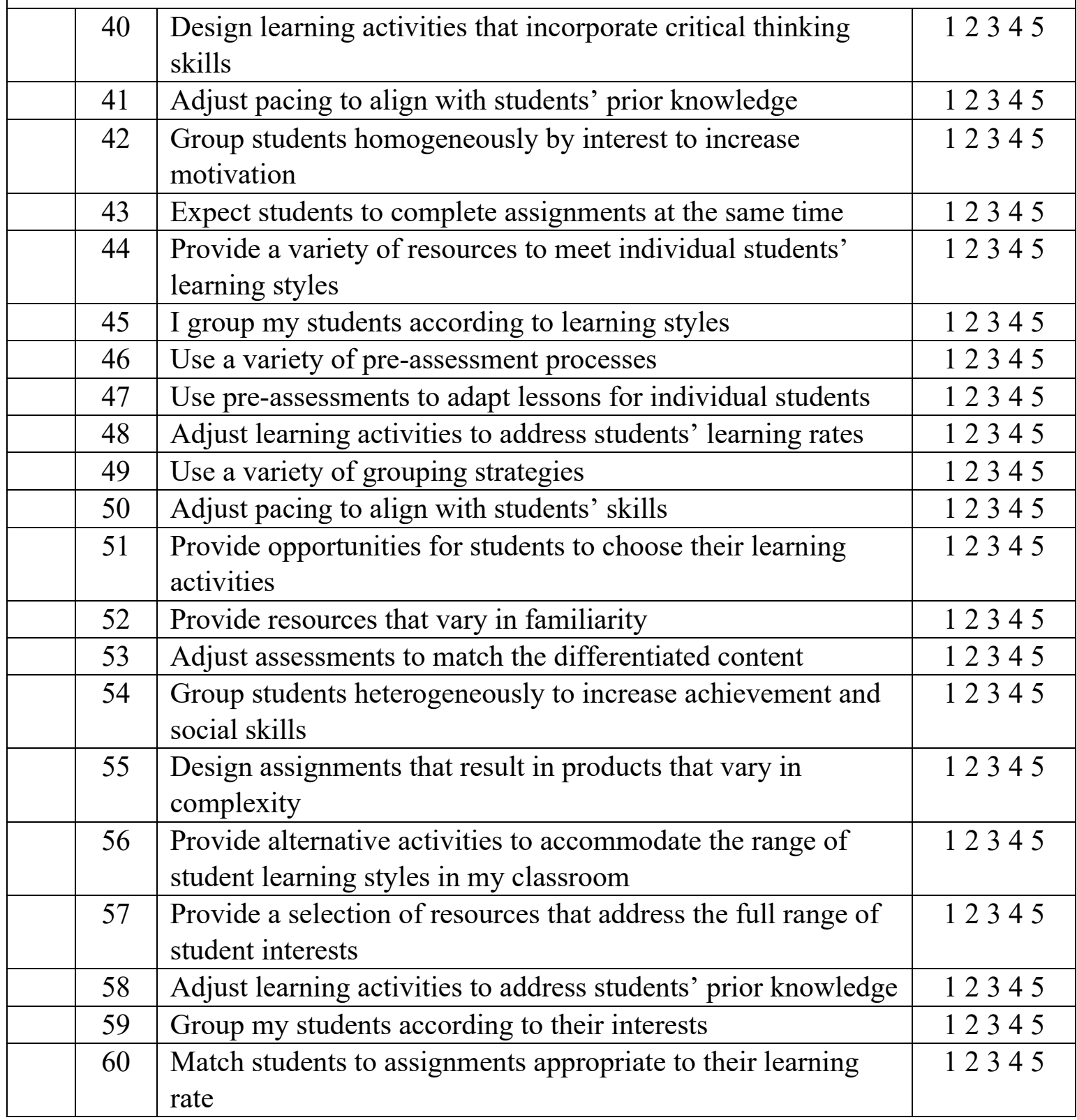




\begin{tabular}{|c|c|c|}
\hline 61 & $\begin{array}{l}\text { Provide alternative activities to accommodate the range of } \\
\text { student interests in my classroom }\end{array}$ & 12345 \\
\hline 62 & Adjust pacing to align with students' learning rate & 12345 \\
\hline 63 & Lesson introductions connect with students' prior knowledge & 12345 \\
\hline 64 & Adjust instructional methods to align with students' skills & 12345 \\
\hline 65 & Pre-assessments address learning objectives & 12345 \\
\hline 66 & Provide resources that vary in abstractness & 12345 \\
\hline 67 & Learning objectives are aligned with the NAD standards & 12345 \\
\hline 68 & I analyze pre-assessments & 12345 \\
\hline 69 & $\begin{array}{l}\text { Adjust instructional methods to align with students' prior } \\
\text { knowledge }\end{array}$ & 12345 \\
\hline 70 & $\begin{array}{l}\text { Adjust instructional methods to align with students' learning } \\
\text { rate }\end{array}$ & 12345 \\
\hline 71 & Pre-assessments address student learning profiles & 12345 \\
\hline 72 & Group students randomly to increase social skills & 12345 \\
\hline 73 & Lesson introductions engage the students & 12345 \\
\hline 74 & Provide resources that vary in complexity & 12345 \\
\hline 75 & Lesson introductions communicate learning objectives & 12345 \\
\hline 76 & Use clearly stated learning objectives & 12345 \\
\hline 77 & $\begin{array}{l}\text { Adjust content to meet each individual students' level of prior } \\
\text { knowledge }\end{array}$ & 12345 \\
\hline 78 & Lesson introductions are relevant to the students & 12345 \\
\hline 79 & $\begin{array}{l}\text { I participated with another classroom teacher for planning my } \\
\text { differentiated instruction activities }\end{array}$ & Yes No \\
\hline 80 & $\begin{array}{l}\text { I have observed another teacher implement differentiated } \\
\text { instruction }\end{array}$ & Yes No \\
\hline 81 & $\begin{array}{l}\text { Another teacher observed me teaching with differentiated } \\
\text { instruction }\end{array}$ & Yes No \\
\hline 82 & $\begin{array}{l}\text { I have shared ideas with another teacher concerning } \\
\text { differentiated instruction }\end{array}$ & Yes No \\
\hline 83 & $\begin{array}{l}\text { I received ideas from another teacher concerning } \\
\text { differentiated instruction }\end{array}$ & Yes No \\
\hline 84 & $\begin{array}{l}\text { I had a mentor who coached me while beginning to implement } \\
\text { differentiated instruction }\end{array}$ & Yes No \\
\hline 85 & $\begin{array}{l}\text { I keep a journal of my implementation of differentiated } \\
\text { instruction }\end{array}$ & Yes No \\
\hline 86 & $\begin{array}{l}\text { I self-reflect on the implementation of differentiated } \\
\text { instruction }\end{array}$ & Yes No \\
\hline 87 & $\begin{array}{l}\text { I discuss the process of differentiated instruction with another } \\
\text { teacher }\end{array}$ & Yes No \\
\hline 88 & $\begin{array}{l}\text { I would be willing to be interviewed concerning my } \\
\text { knowledge and practice of differentiated instruction to assist }\end{array}$ & Yes No \\
\hline
\end{tabular}




\begin{tabular}{|l|l|l|l|}
\hline & $\begin{array}{l}\text { in this study. (all information obtained will be kept } \\
\text { confidential) }\end{array}$ & \\
\hline 89 & $\begin{array}{l}\text { If answered "YES" to question 49, please provide name and } \\
\text { contact information: (Name, school, grades taught, e-mail, } \\
\text { phone number) }\end{array}$ & \\
\hline
\end{tabular}




\section{APPENDIX B}

\section{Interview Questions}

1. What is your name?

2. Tell me about your teaching experience.

3. What grades do you currently teach?

4. What is your current classroom size?

5. Describe an ideal classroom.

6. How does differentiated instruction fit into an ideal classroom?

7. How did the differentiated instruction training at the Columbia Union office prepare you for implementing this teaching method into your classroom?

8. Following the training, how did you go about implementing differentiated instruction in your classroom?

9. What was easiest about implementing differentiated instruction?

10. What was the hardest part of the implementation?

11. What helped you most in your implementation?

12. How have these tools been useful?

13. Have you used any support methods during your implementation?

14. If yes, how have these methods helped you?

15. If no, why not? How would it have helped you more if support methods were available?

16. What barriers have you experienced in implementing differentiated instruction?

17. How has differentiated instruction changed your teaching practice?

18. Has differentiated instruction changed your classroom?

19. If yes, how?

20. If no, why do you think it hasn't?

21. What preparation was needed in the implementation of differentiated instruction?

22. How did your students respond to your implementation of differentiated instruction?

23. What have you learned from your implementation that you would recommend to other teachers who might be trying to implement differentiated instruction?

24. If you were to give advice to another teacher wanting to implement differentiated instruction, what would you say to them and to their supervisors? 


\section{APPENDIX C}

\section{The Innovation Configuration (IC) Map for Differentiated Instruction}

(Draft 1, 2008)

The IC Map is used for collecting and analyzing student and school-wide data to assess schools' fidelity in implementing DI. This model uses a 3-point or 4-point scale to measure the level of fidelity in teacher practices, though schools may adopt their own model as needed. For an electronic copy of the IC Map, contact Alice Henley, Assistant Director, State Education Resource Center (SERC), (860) 632-1485, ext.311, or henley@ctserc.org.

[Note: Items marked $(*)$ to be defined in a glossary by the participating teams, for use in their schools]

\begin{tabular}{|l|l|l|l|l|}
\hline \multicolumn{5}{|c|}{ Curriculum Components That May Be Differentiated } \\
\hline CATEGORY & \multicolumn{1}{|c|}{$\mathbf{4}$} & \multicolumn{1}{|c|}{$\mathbf{3}$} & \multicolumn{1}{|c|}{$\mathbf{2}$} \\
\hline $\begin{array}{l}\text { Alignment } \\
\text { of } \\
\text { Content* }\end{array}$ & $\begin{array}{l}\text { The teacher provides learning } \\
\text { objectives that are consistently clear } \\
\text { and aligned with state/national } \\
\text { standards, the district's priority } \\
\text { standards, and scope and sequence. }\end{array}$ & $\begin{array}{l}\text { The teacher provides learning } \\
\text { objectives that are sometimes clear } \\
\text { and aligned with state/national } \\
\text { standards, the district's priority } \\
\text { standards, and scope and sequence. }\end{array}$ & $\begin{array}{l}\text { The teacher provides learning } \\
\text { objectives that are often } \\
\text { unclear and poorly aligned } \\
\text { with state/national standards. }\end{array}$ & $\begin{array}{l}\text { The teacher provides } \\
\text { learning objectives that } \\
\text { are unclear and not } \\
\text { aligned with state/national } \\
\text { standards. }\end{array}$ \\
\hline Introduction* & $\begin{array}{l}\text { The teacher provides an introduction } \\
\text { that consistently establishes relevance, } \\
\text { includes an engaging scenario, } \\
\text { communicates learning objectives, and } \\
\text { connects with students' prior }\end{array}$ & $\begin{array}{l}\text { The teacher provides an introduction } \\
\text { that includes an engaging scenario } \\
\text { and communicates learning } \\
\text { objectives but does not either connect } \\
\text { with prior knowledge or establish }\end{array}$ & $\begin{array}{l}\text { The teacher provides an } \\
\text { introduction that } \\
\text { communicates the objective } \\
\text { but is either not engaging or } \\
\text { does not establish relevance. }\end{array}$ & $\begin{array}{l}\text { The teacher provides no } \\
\text { introduction. }\end{array}$ \\
\hline Preassessment* & $\begin{array}{l}\text { The teacher consistently uses a variety } \\
\text { of preassessments that address students, } \\
\text { learning profiles* and the learning } \\
\text { objectives for units of instruction* }\end{array}$ & $\begin{array}{l}\text { The teacher sometimes uses } \\
\text { preassessments that address the } \\
\text { students' learning profiles* and the } \\
\text { learning objectives for units of } \\
\text { instruction. }\end{array}$ & $\begin{array}{l}\text { The teacher uses } \\
\text { preassessments that either do } \\
\text { not address the students' } \\
\text { learning profiles or learning } \\
\text { objectives for units of } \\
\text { instruction. }\end{array}$ & $\begin{array}{l}\text { The teacher does not use } \\
\text { preassessments. }\end{array}$ \\
\hline
\end{tabular}




\begin{tabular}{|l|l|l|l|l|}
\hline \multicolumn{2}{|l|}{ Adjusting the Breadth: Differentiating by Providing Alternatives and Choice } \\
\hline Curriculum Components That May Be Differentiated \\
\hline CATEGORY & \multicolumn{1}{|c|}{$\mathbf{4}$} & \multicolumn{2}{|l|}{$\mathbf{3}$} \\
\hline $\begin{array}{l}\text { Analysis of } \\
\text { Preassessment } \\
\text { Data }\end{array}$ & $\begin{array}{l}\text { The teacher consistently analyzes } \\
\text { preassessment data, identifies the } \\
\text { most critical student learning } \\
\text { difference, and plans to adjust the } \\
\text { breadth or depth of components } \\
\text { accordingly. }\end{array}$ & $\begin{array}{l}\text { The teacher analyzes preassessment } \\
\text { data and identifies the most critical } \\
\text { student learning difference but does } \\
\text { not plan to adjust the breadth or } \\
\text { depth accordingly. }\end{array}$ & $\begin{array}{l}\text { The teacher analyzes } \\
\text { preassessment data but is } \\
\text { unable to identify the most } \\
\text { critical student learning } \\
\text { difference and plan to } \\
\text { adjust the breadth or depth } \\
\text { accordingly. }\end{array}$ & $\begin{array}{l}\text { The teacher does not } \\
\text { analyze preassessment } \\
\text { data. }\end{array}$ \\
\hline $\begin{array}{l}\text { Product } \\
\text { Alternatives* }\end{array}$ & $\begin{array}{l}\text { The teacher provides alternative } \\
\text { products that are aligned with the } \\
\text { learning objectives to address the } \\
\text { range of student interest and } \\
\text { learning styles. }\end{array}$ & $\begin{array}{l}\text { The teacher provides alternative } \\
\text { products that are aligned with the } \\
\text { learning objectives but do not address } \\
\text { the full range of student interest and } \\
\text { learning styles. }\end{array}$ & $\begin{array}{l}\text { The teacher provides } \\
\text { alternative products that do } \\
\text { not align with the learning } \\
\text { objectives or do not address } \\
\text { the full range of student } \\
\text { interests and learning styles. }\end{array}$ & $\begin{array}{l}\text { The teacher does not } \\
\text { provide a selection of } \\
\text { products. }\end{array}$ \\
\hline $\begin{array}{l}\text { Product } \\
\text { Choice }\end{array}$ & $\begin{array}{l}\text { The teacher consistently provides } \\
\text { opportunities for students to choose } \\
\text { their products. }\end{array}$ & $\begin{array}{l}\text { The teacher sometimes provides } \\
\text { opportunities for students to choose } \\
\text { their products. }\end{array}$ & $\begin{array}{l}\text { The teacher seldom } \\
\text { provides opportunities for } \\
\text { students to choose their } \\
\text { products. }\end{array}$ & $\begin{array}{l}\text { The teacher does not } \\
\text { provide opportunities to } \\
\text { choose their products. }\end{array}$ \\
\hline
\end{tabular}




\begin{tabular}{|l|l|l|l|}
\hline \multicolumn{2}{|c|}{$\mathbf{|}$} & \multicolumn{1}{|c|}{$\mathbf{2}$} & \multicolumn{1}{|c|}{$\mathbf{1}$} \\
\hline $\begin{array}{l}\text { Resteurce } \\
\text { Alternatives* }\end{array}$ & $\begin{array}{l}\text { The teacher provides a selection of resources that } \\
\text { are aligned with the learning objectives to } \\
\text { address the full range of student interests and } \\
\text { learning styles. }\end{array}$ & $\begin{array}{l}\text { The teacher provides a selection of } \\
\text { resources that may not be aligned with } \\
\text { the learning objectives or may not } \\
\text { address the full range of student interests } \\
\text { and learning styles. }\end{array}$ & $\begin{array}{l}\text { The teacher provides a single resource } \\
\text { that may or may not address students' } \\
\text { learning needs. }\end{array}$ \\
\hline $\begin{array}{l}\text { Grouping } \\
\text { Alternatives }\end{array}$ & $\begin{array}{l}\text { The teacher uses a variety of grouping strategies } \\
\text { that are aligned with the learning objectives and } \\
\text { address the full range of student interests and } \\
\text { learning styles. }\end{array}$ & $\begin{array}{l}\text { The teacher uses a variety of grouping } \\
\text { strategies that may not be aligned with } \\
\text { the learning objectives or may not } \\
\text { address the full range of student interests } \\
\text { and learning styles. }\end{array}$ & $\begin{array}{l}\text { The teacher does not vary grouping } \\
\text { strategies. }\end{array}$ \\
\hline
\end{tabular}

\begin{tabular}{|l|l|l|l|}
\hline \multicolumn{1}{|c|}{ Adjusting the Depth: Differentiating by Providing Tiering* } \\
\hline Curriculum Components that May Be Differentiated \\
\hline \multicolumn{1}{|c|}{$\mathbf{3}$} & & \multicolumn{1}{|c|}{$\mathbf{2}$} \\
\hline $\begin{array}{l}\text { Differentiation } \\
\text { of Content* }\end{array}$ & $\begin{array}{l}\text { The teacher adjusts the content to increase or } \\
\text { decrease its complexity*, abstractness*, } \\
\text { familiarity*, or opportunity for application* to } \\
\text { address the full range of students' prior }\end{array}$ & $\begin{array}{l}\text { The teacher adjusts the content, but the } \\
\text { adjustment does not address the full range } \\
\text { of students' prior knowledge/skills or } \\
\text { learning rates. }\end{array}$ & $\begin{array}{l}\text { The teacher does not make } \\
\text { adjustments to the content. }\end{array}$ \\
\hline $\begin{array}{l}\text { Assessments* } \\
\text { (formative } \\
\text { and } \\
\text { summative) }\end{array}$ & $\begin{array}{l}\text { The teacher adjusts assessments to address the } \\
\text { differentiated content. }\end{array}$ & $\begin{array}{l}\text { The teacher adjusts assessments, but } \\
\text { they do not address the differentiated } \\
\text { content. }\end{array}$ & $\begin{array}{l}\text { The teacher does not adjust } \\
\text { assessments. }\end{array}$ \\
\hline
\end{tabular}




\begin{tabular}{|c|c|c|c|c|}
\hline & 4 & 3 & 2 & 1 \\
\hline $\begin{array}{l}\text { Grouping } \\
\text { Strategies }\end{array}$ & $\begin{array}{l}\text { The teacher uses a } \\
\text { variety of grouping } \\
\text { strategies that are } \\
\text { aligned with the } \\
\text { learning objectives } \\
\text { and address the full }\end{array}$ & $\begin{array}{l}\text { The teacher uses a variety of grouping } \\
\text { strategies that may not be aligned with the } \\
\text { learning objectives or may not address the } \\
\text { full range of students' prior knowledge/skills } \\
\text { or learning rates. }\end{array}$ & $\begin{array}{l}\text { The teacher randomly uses } \\
\text { grouping strategies. }\end{array}$ & $\begin{array}{l}\text { The teacher does not vary } \\
\text { grouping strategies. }\end{array}$ \\
\hline
\end{tabular}




\begin{tabular}{|c|c|c|c|c|c|}
\hline Products & $\begin{array}{l}\text { The teacher designs } \\
\text { assignments that result } \\
\text { in products that vary } \\
\text { in complexity, critical } \\
\text { thinking, or } \\
\text { independence, and the } \\
\text { teacher matches } \\
\text { students to particular } \\
\text { assignments } \\
\text { appropriate to their } \\
\text { prior knowledge/skills } \\
\text { and learning rate. }\end{array}$ & $\begin{array}{l}\text { The teacher designs assignments that result } \\
\text { in products that vary in complexity, critical } \\
\text { thinking, or independence, but does not } \\
\text { match all students to particular assignments } \\
\text { appropriate to their prior knowledge/skills } \\
\text { and learning rate. }\end{array}$ & \multicolumn{2}{|c|}{$\begin{array}{l}\text { The teacher designs } \\
\text { assignments that result in } \\
\text { products that vary in } \\
\text { complexity, critical thinking, } \\
\text { or independence, but the } \\
\text { assignments are not matched to } \\
\text { students' prior } \\
\text { knowledge/skills and learning } \\
\text { rate. }\end{array}$} & $\begin{array}{l}\text { The teacher does not } \\
\text { design differentiated } \\
\text { products. }\end{array}$ \\
\hline & 3 & \multicolumn{2}{|l|}{2} & & 1 \\
\hline Time & $\begin{array}{l}\text { The teacher consistently } \\
\text { provides an opportunity } \\
\text { for subgroups of } \\
\text { students to learn at } \\
\text { varied paces. }\end{array}$ & \multicolumn{2}{|c|}{$\begin{array}{l}\text { The teacher inconsistently provides opportunities for } \\
\text { subgroups of students to learn at varied paces. }\end{array}$} & \multicolumn{2}{|c|}{$\begin{array}{l}\text { The teacher does not provide opportunities for } \\
\text { subgroups of students to learn at varied paces. }\end{array}$} \\
\hline
\end{tabular}




\section{APPENDIX D}

Innovation Configuration/Beliefs/Practice Relationship Chart

\begin{tabular}{|c|c|c|c|c|}
\hline Innovation Configuration Reference & Beliefs \# & Belief Question/s & Practice \# & Practice Question/s \\
\hline $\begin{array}{l}\text { Alignment of Content } \\
\text { The teacher provides learning } \\
\text { objectives that are consistently clear } \\
\text { and aligned with state/national } \\
\text { standards, the district's priority } \\
\text { standards, and scope and sequence }\end{array}$ & $\begin{array}{l}\mathrm{C} \\
\# 5 \\
\# 16\end{array}$ & $\begin{array}{l}\text { *There should be clearly stated } \\
\text { objectives. } \\
\text { *It is important that learning } \\
\text { objectives be aligned with NAD } \\
\text { standards. }\end{array}$ & $\begin{array}{l}\# 76 \\
\# 67\end{array}$ & $\begin{array}{l}\text { *I use clearly stated learning } \\
\text { objectives. } \\
\text { * My learning objectives are } \\
\text { aligned with the NAD } \\
\text { standards. }\end{array}$ \\
\hline $\begin{array}{l}\text { Introduction } \\
\text { The teacher provides an introduction } \\
\text { that consistently establishes } \\
\text { relevance, includes an engaging } \\
\text { scenario, communicates learning } \\
\text { objectives, and connects with } \\
\text { students' prior knowledge. }\end{array}$ & $\begin{array}{l}\mathrm{P} \\
\# 9 \\
\# 2 \\
\# 7 \\
\# 24\end{array}$ & $\begin{array}{l}\text { *Lesson introductions should be } \\
\text { relevant to the students. } \\
\text { *It is important that lesson } \\
\text { introductions engage the students. } \\
\text { *Lesson introductions should } \\
\text { communicate learning objectives. } \\
\text { *Lesson introductions should } \\
\text { connect with students' prior } \\
\text { knowledge. }\end{array}$ & $\begin{array}{l}778 \\
\# 73 \\
\# 75 \\
\# 63\end{array}$ & $\begin{array}{l}\text { *My lesson introductions are } \\
\text { relevant to the students. } \\
\text { *My lesson introductions } \\
\text { engage the students. } \\
\text { *My lesson introductions } \\
\text { communicate learning } \\
\text { objectives. } \\
\text { *My lesson introductions } \\
\text { connect with students' prior } \\
\text { knowledge. }\end{array}$ \\
\hline $\begin{array}{l}\text { Preassessment } \\
\text { The teacher consistently uses a } \\
\text { variety of pre-assessments that } \\
\text { address students' learning profiles } \\
\text { and the learning objectives for units } \\
\text { of instruction }\end{array}$ & $\begin{array}{l}\text { A } \\
\# 22 \\
\# 11 \\
\# 19\end{array}$ & $\begin{array}{l}\text { *Teachers should use a variety of } \\
\text { pre-assessment processes. } \\
\text { * Pre-assessments should address } \\
\text { student learning profiles. } \\
\text { *Pre-assessments should address } \\
\text { learning objectives. }\end{array}$ & $\begin{array}{l}\# 46 \\
\# 71 \\
\# 65\end{array}$ & $\begin{array}{l}\text { *I use a variety of pre- } \\
\text { assessments processes. } \\
\text { *My pre-assessments address } \\
\text { student learning profiles. } \\
\text { *My pre-assessments address } \\
\text { learning objectives. }\end{array}$ \\
\hline Analysis of Preassessment Data & $\begin{array}{l}\mathrm{A} \\
\# 6\end{array}$ & $\begin{array}{l}\text { *It is important that pre- } \\
\text { assessment data be analyzed. }\end{array}$ & $\begin{array}{l}\# 68 \\
\# 47\end{array}$ & $*$ I analyze pre-assessments. \\
\hline
\end{tabular}




\begin{tabular}{|c|c|c|c|c|}
\hline Innovation Configuration Reference & Beliefs \# & Belief Question/s & Practice \# & Practice Question/s \\
\hline $\begin{array}{l}\text { The teacher consistently analyzes } \\
\text { preassessment data, identifies the } \\
\text { most critical student learning } \\
\text { difference, and plans to adjust the } \\
\text { breadth or depth of components } \\
\text { accordingly }\end{array}$ & $\# 14$ & $\begin{array}{l}\text { *Pre-assessments should be used } \\
\text { to adapt lessons for individual } \\
\text { students. }\end{array}$ & & $\begin{array}{l}\text { *I use pre-assessments to } \\
\text { adapt lessons for individual } \\
\text { students. }\end{array}$ \\
\hline $\begin{array}{l}\text { Product Alternatives } \\
\text { The teacher provides alternative } \\
\text { products that are aligned with the } \\
\text { learning objectives to address the } \\
\text { range of student interest and } \\
\text { learning styles }\end{array}$ & $\begin{array}{l}\mathrm{C} \\
\# 1 \\
\# 13\end{array}$ & $\begin{array}{l}* \text { There should be alternative } \\
\text { activities to accommodate the } \\
\text { range of student interests in a } \\
\text { classroom. } \\
\text { * There should be alternative } \\
\text { activities to accommodate the } \\
\text { range of student learning styles in } \\
\text { a classroom. }\end{array}$ & $\begin{array}{l}\# 61 \\
\# 56\end{array}$ & $\begin{array}{l}\text { *I provide alternative } \\
\text { activities to accommodate the } \\
\text { range of student interests in } \\
\text { my classroom. } \\
\text { *I provide alternative } \\
\text { activities to accommodate the } \\
\text { range of student learning } \\
\text { styles in my classroom. }\end{array}$ \\
\hline $\begin{array}{l}\text { Product Choice } \\
\text { The teacher consistently provides } \\
\text { opportunities for students to choose } \\
\text { their products }\end{array}$ & $\begin{array}{l}\mathrm{P} \\
\# 15\end{array}$ & $\begin{array}{l}\text { *Teachers should provide } \\
\text { opportunities for students to } \\
\text { choose their learning activities. }\end{array}$ & $\# 51$ & $\begin{array}{l}\text { *I provide opportunities for } \\
\text { students to choose their } \\
\text { learning activities. }\end{array}$ \\
\hline $\begin{array}{l}\text { Resource Alternatives } \\
\text { The teacher provides a selection of } \\
\text { resources that are aligned with the } \\
\text { learning objectives to address the } \\
\text { full range of student interests and } \\
\text { learning styles }\end{array}$ & $\begin{array}{l}\mathrm{C} \\
\# 20 \\
\# 25\end{array}$ & $\begin{array}{l}\text { *It is important to provide a } \\
\text { variety of resources that address } \\
\text { the full range of student interests. } \\
\text { *It is important to provide a } \\
\text { variety of resources that address } \\
\text { the full range of student learning } \\
\text { styles. }\end{array}$ & $\begin{array}{l}\# 57 \\
\# 44\end{array}$ & $\begin{array}{l}\text { *I provide a selection of } \\
\text { resources that address the full } \\
\text { range of student interests. } \\
\text { *I provide a variety of } \\
\text { resources to meet individual } \\
\text { students' learning styles. }\end{array}$ \\
\hline $\begin{array}{l}\text { Grouping Alternatives } \\
\text { The teacher uses a variety of } \\
\text { grouping strategies that are aligned }\end{array}$ & $\begin{array}{l}\mathrm{P} \\
\# 3 \\
\# 8\end{array}$ & $\begin{array}{l}* \text { It is important to group students } \\
\text { according to learning styles. }\end{array}$ & $\begin{array}{l}\# 45 \\
\# 59 \\
\# 49 \\
\end{array}$ & $\begin{array}{l}\text { *I group my students } \\
\text { according to learning styles. }\end{array}$ \\
\hline
\end{tabular}




\begin{tabular}{|c|c|c|c|c|}
\hline Innovation Configuration Reference & Beliefs \# & Belief Question/s & Practice \# & Practice Question/s \\
\hline $\begin{array}{l}\text { with the learning objectives and } \\
\text { address the full range of student } \\
\text { interests and learning styles }\end{array}$ & $\begin{array}{l}\# 12 \\
\# 32 \\
\# 38 \\
\# 21\end{array}$ & $\begin{array}{l}\text { *Teachers should group students } \\
\text { according to their interests. } \\
\text { *It is important to use a variety of } \\
\text { grouping strategies. } \\
\text { *Grouping students } \\
\text { heterogeneously may increase } \\
\text { achievement and social skills. } \\
\text { *Grouping students } \\
\text { homogeneously by interest may } \\
\text { increase motivation. } \\
\text { *Grouping students randomly may } \\
\text { increase social skills. }\end{array}$ & $\begin{array}{l}\# 54 \\
\# 42 \\
\# 72\end{array}$ & $\begin{array}{l}\text { *I group my students } \\
\text { according to their interests. } \\
\text { *I use a variety of grouping } \\
\text { strategies. } \\
\text { *I group students } \\
\text { heterogeneously to increase } \\
\text { achievement and social skills. } \\
\text { *I group students } \\
\text { homogeneously by interest to } \\
\text { increase motivation. } \\
\text { *I group students randomly to } \\
\text { increase social skills. }\end{array}$ \\
\hline $\begin{array}{l}\text { Differentiation of Content } \\
\text { The teacher adjusts the content to } \\
\text { increase or decrease the complexity, } \\
\text { abstractness, familiarity or } \\
\text { opportunity for application to } \\
\text { address the full range of students' } \\
\text { prior knowledge/skills or learning } \\
\text { rates }\end{array}$ & $\begin{array}{l}\mathrm{C} \\
\# 28 \\
\# 35\end{array}$ & $\begin{array}{l}\text { *It is important to adjust content to } \\
\text { meet each individual students' } \\
\text { prior knowledge. } \\
\text { *It is important to match students } \\
\text { to assignments appropriate to their } \\
\text { learning rate. }\end{array}$ & $\begin{array}{l}\# 77 \\
\# 60\end{array}$ & $\begin{array}{l}\text { *I adjust content to meet each } \\
\text { individual students' level of } \\
\text { prior knowledge. } \\
\text { *I match students to } \\
\text { assignments appropriate to } \\
\text { their learning rate. }\end{array}$ \\
\hline $\begin{array}{l}\text { Assessments (Formative and } \\
\text { Summative) } \\
\text { The teacher adjusts assessments to } \\
\text { address the differentiated content }\end{array}$ & $\begin{array}{l}\mathrm{A} \\
\# 4\end{array}$ & $\begin{array}{l}\text { *It is not necessary to adjust } \\
\text { assessments to match the } \\
\text { differentiated content. }\end{array}$ & $\# 53$ & $\begin{array}{l}\text { *I do not adjust assessments } \\
\text { to match the differentiated } \\
\text { content. }\end{array}$ \\
\hline $\begin{array}{l}\text { Teaching Strategies } \\
\text { The teacher adjusts instructional } \\
\text { methods, pacing, and scaffolding to } \\
\text { align with the learning objectives } \\
\text { and to address the full range of }\end{array}$ & $\begin{array}{l}\mathrm{P} \\
\# 37 \\
\# 30 \\
\# 33 \\
\# 17\end{array}$ & $\begin{array}{l}\text { *Teachers should adjust pacing to } \\
\text { align with students' prior } \\
\text { knowledge. }\end{array}$ & $\begin{array}{l}\# 41 \\
\# 50 \\
\# 62 \\
\# 69 \\
\# 64\end{array}$ & $\begin{array}{l}\text { *I adjust pacing to align with } \\
\text { students' prior knowledge. } \\
\text { *I don't adjust pacing to align } \\
\text { with students' skill. }\end{array}$ \\
\hline
\end{tabular}




\begin{tabular}{|c|c|c|c|c|}
\hline Innovation Configuration Reference & Beliefs \# & Belief Question/s & Practice \# & Practice Question/s \\
\hline $\begin{array}{l}\text { students' prior knowledge/skills or } \\
\text { learning rates }\end{array}$ & $\begin{array}{l}\# 23 \\
\# 27\end{array}$ & $\begin{array}{l}\text { *It is not important that teachers } \\
\text { adjust pacing to align with } \\
\text { students' skills. } \\
\text { *It is not important that teachers } \\
\text { adjust pacing to align with } \\
\text { students' learning rate. } \\
\text { *It is important that teachers adjust } \\
\text { instructional methods to align with } \\
\text { students' prior knowledge. } \\
\text { *It is necessary that teachers adjust } \\
\text { instructional methods to align with } \\
\text { students' skills. } \\
\text { *Teachers should adjust } \\
\text { instructional methods to align with } \\
\text { students' learning rate. }\end{array}$ & $\# 70$ & $\begin{array}{l}\text { *I don't adjust pacing to align } \\
\text { with students' learning rate. } \\
\text { *I adjust instructional } \\
\text { methods to align with } \\
\text { students' prior knowledge } \\
\text { *I adjust instructional } \\
\text { methods to align with } \\
\text { students' skills. } \\
\text { *I adjust instructional } \\
\text { methods to align with } \\
\text { students' learning rate. }\end{array}$ \\
\hline $\begin{array}{l}\text { Learning Activities } \\
\text { The teacher designs learning } \\
\text { activities to help students develop } \\
\text { and apply critical thinking skills. } \\
\text { The learning activities are adjusted } \\
\text { to address the full range of students' } \\
\text { prior knowledge/skills or learning } \\
\text { rates. }\end{array}$ & $\begin{array}{l}\mathrm{P} \\
\# 31 \\
\# 34 \\
\# 18\end{array}$ & $\begin{array}{l}\text { *Learning activities should be } \\
\text { adjusted to address students' prior } \\
\text { knowledge. } \\
\text { *Learning activities should be } \\
\text { adjusted to address students' } \\
\text { learning rates. } \\
\text { *Critical thinking skills should be } \\
\text { incorporated into learning } \\
\text { activities. }\end{array}$ & $\begin{array}{l}\# 58 \\
\# 48 \\
\# 40\end{array}$ & $\begin{array}{l}\text { *I adjust learning activities to } \\
\text { address students' prior } \\
\text { knowledge. } \\
\text { *I adjust learning activities to } \\
\text { address students' learning } \\
\text { rates. } \\
\text { *I design learning activities } \\
\text { that incorporate critical } \\
\text { thinking skills. }\end{array}$ \\
\hline $\begin{array}{l}\text { Products } \\
\text { The teacher designs assignments that } \\
\text { result in products that vary in } \\
\text { complexity, critical thinking, or }\end{array}$ & $\begin{array}{l}\mathrm{P} \\
\# 36\end{array}$ & $\begin{array}{l}\text { *Teachers should design } \\
\text { assignments that result in products } \\
\text { that vary in complexity. }\end{array}$ & $\# 55$ & $\begin{array}{l}\text { *I design assignments that } \\
\text { result in products that vary in } \\
\text { complexity. }\end{array}$ \\
\hline
\end{tabular}




\begin{tabular}{|c|c|c|c|c|}
\hline \multirow[b]{2}{*}{$\begin{array}{l}\text { Innovation Configuration Reference } \\
\text { independence, and the teacher } \\
\text { matches students to particular } \\
\text { assignments appropriate to their } \\
\text { prior knowledge/skills and learning } \\
\text { rate }\end{array}$} & Beliefs \# & Belief Question/s & Practice \# & Practice Question/s \\
\hline & & & & \\
\hline $\begin{array}{l}\text { Resources } \\
\text { The teacher provides resources that } \\
\text { vary in complexity, abstractness } \\
\text { and/or familiarity to address the full } \\
\text { range of students' prior } \\
\text { knowledge/skills or learning rates }\end{array}$ & $\begin{array}{l}\mathrm{C} \\
\# 39 \\
\# 26 \\
\# 10\end{array}$ & $\begin{array}{l}\text { *Teachers should use resources } \\
\text { that vary in complexity. } \\
\text { *It is imperative that teachers } \\
\text { provide resources that vary in } \\
\text { abstractness. } \\
\text { *Teachers should provide } \\
\text { resources that vary in familiarity. }\end{array}$ & $\begin{array}{l}\# 74 \\
\# 66 \\
\# 52\end{array}$ & $\begin{array}{l}\text { *I provide resources that vary } \\
\text { in complexity. } \\
\text { *I provide resources that vary } \\
\text { in abstractness. } \\
\text { *I provide resources that vary } \\
\text { in familiarity. }\end{array}$ \\
\hline $\begin{array}{l}\text { Time } \\
\text { The teacher consistently provides } \\
\text { opportunity for subgroups of } \\
\text { students to learn at varied paces }\end{array}$ & $\begin{array}{l}P \\
\# 29\end{array}$ & $\begin{array}{l}\text { *Students should complete their } \\
\text { assignments at the same time. }\end{array}$ & \#43 & $\begin{array}{l}\text { *I expect students to complete } \\
\text { assignments at the same time. }\end{array}$ \\
\hline & & & & \\
\hline
\end{tabular}

*The original innovation configuration map had another section entitled "grouping strategies." It was worded identically to the "grouping alternatives" section in this chart. For my purposes, it would be redundant to use both segments, therefore I omitted the "grouping strategies" section. 


\section{REFERENCE LIST}

Adventist Archives-Educational Program. (N.D.). https://www.adventistarchives.org/ quick-statistics-on-the-seventh-day-adventist-church

Adventist Education-About. (N.D.). https://education.eud.adventist.org/en/about/ philosophy/a-statement-of-seventh-day-adventist-educational-philosophy/

Adventist Education-Statistics. (N.D.). https://adventisteducation.org/stat.html

Anderson, S. E. (1977). Understanding teacher change: Revisiting the concerns based adoption model. Curriculum Inquiry, 27, 331-367.

Appalachia Regional Educational Laboratory. (2016, August 3,). What is an Innovation Configuration Map? [Video file]. Retrieved from https://youtu.be/D1vwFxw85wI

Astuto, T., Clark, D., Read, A., McGree, K., \& Fernandez, L. (1993). Challenges to dominant assumptions controlling educational reform. Andover, MA: Regional Laboratory for the Educational Improvement of the Northeast and Islands.

Attard, K. (2012). Public reflection within learning dommunities: An incessant type of professional development. European Journal of Teacher Education, 35(2), 199211.

Avalos, B. (2011). Teacher professional development in teaching and teacher education over ten years.Teaching and Teacher Education, 27(1), 10-20.

Bean, R. M., Belcastro, B., Hathaway, J., Risko, V., Rosemary, C., \& Roskos, K. (2008, March). A review of the research on instructional coaching. Paper presented at the American Educational Research Association Conference, New York.

Berliner, D. C., \& Biddle, B. J. (1995). The manufactured crisis. New York, NY: Addison-Wesley.

Birman, B. F., Desimone, L., Porter, A. C., \& Garet, M. S. (2000). Designing professional development that works. Educational leadership, 57(8), 28-33.

Brualdi Timmins, Amy C. (1996). Multiple intelligences: Gardner's theory. Practical Assessment, Research, and Evaluation, 5(10). doi.org/10.7275/7251-ea02

Busher, L. A. (1994). The effects of peer coaching on elementary school teachers. Paper presented at the Annual meeting of the Eastern Educational Research Association, Sarasota, FL. 
Buxton, C. A., Allexsaht-Snider, M., Kayumova, S., Aghasaleh, R., Choi, Y. J., \& Cohen, A. (2015). Teacher agency and professional learning: Rethinking fidelity of implementation as multiplicities of enactment. Journal of Research in Science Teaching, 52(4), 489-502.

Cash, R., Heacox, D., Hollas, B., \& Elliot, L. (2009). Differentiated Instruction for the 21 st Century Classroom Trainer's Guide. Peterborough, NH: Staff Development for Educators.

Ceedar Center. (2011). Innovation configurations: Guidelines for use in institutions of higher education and professional development evaluation. National Comprehensive Center for Teacher Quality. Retrieved from http://ceedar.education.ufl.edu/wp-content/uploads/2013/07/IC_Guidelines.pdf

Chien, C. W. (2012). Differentiated instruction in an elementary school EFL classroom. TESOL Journal, 3(2), 280-291.

Clark, D., \& Hollingsworth, H. (2002). Elaborating a model of teacher professional growth. Teaching and teaching education, 18(8), 947-967.

Cochran-Smith, M., \& Lytle, S. L. (1999). The teacher research movement: A decade later. Educational Researcher, 28(7), 15-25.

Creswell, J. W. (2003). Research design: Qualitative, quantitative, and mixed methods approaches (2nd ed.). Thousand Oaks, CA: Sage.

Creswell, J. W. (2012). Educational research: Planning, conducting, and evaluating quantitative and qualitative research (4th ed.). Boston, MA: Pearson Education.

Creswell, J. W. (2013). Qualitative Inquiry \& Research Design Choosing among Five Approaches (3rd ed.). Thousand Oaks, CA: Sage.

Cross, R. (2010). Language teaching as a sociocultural activity: Rethinking language teacher practice. The Modern Lanugage Journal, 94(3), 434-452.

Desimone, L. (2009). Improving impact studies of teachers' professional development: toward better conceptualizations and measures. American Educational Research Association, 38(3), 181-199. Retrieved from http://edr.sagepub.com/content/ 38/3/181.abstract

Desimone, L. M., Porter, A. C., Garet, M. S., Yoon, K. S., \& Birman, B. F. (2002). Effects of professional development on teachers' instruction: Results from a three-year longitudinal study. Educational evaluation and policy analysis, 24(2), 81-112.

Dixon, F. A., Yssel, N., McConnell, J. M., \& Hardin, T. (2014). Differentiated instruction, professional development, and teacher efficacy. Journal for the Education of the Gifted, 37(2), 111-127. 
DuFour, R. (2004). What is a professional learning community? Educational Leadership, 61(8), 6-11.

DuFour, R., DuFour, R., Eaker, R., \& Many, T. (2006). Learning by doing: A handbook for professional learning communities at work. Bloomington, IN: Solution Tree.

DuFour, R., DuFour, R., \& Eaker, R. (2006). Professional learning communities at work plan book. Bloomington, IN: Solution Tree.

Eaker, R. (2002). Cultural shifts: Transforming schools into professional learning communities. In R. Eaker, R. DuFour, and R. DuFour (Eds.), Getting started: Reculturing schools to become professional learning communities, (p. 9-29). Bloomington, IN: National Educational Service.

Eisner, E. W. (1991). The enlightened eye: Qualitative inquiry and the enhancement of educational practice. New York, NY: MacMillan.

Ertmer, P. A. (2005). Teacher pedagogical beliefs: The final frontier in our quest for technology integration? Educational Technology Research and Development, 53(4), 25-39.

Fattig, M. L., \& Taylor, M. T. (2008). Co-teaching in the differentiated classroom: Successful collaboration, lesson design, and classroom management. San Francisco, CA: Jossey-Bass.

Fuller, F. F., \& Case, C. (1969). Concerns of teachers. A manual for teacher educators: Increasing teacher satisfaction with professional preparation by considering teachers' concerns when planning preservice and inservice education. Austin, TX: University of Texas, Research and Development Center for Teacher Education.

Fullan, M. (2007). Change the terms for teacher learning. Journal of Staff Development, 28(3), 35-36.

Fullan, M., Hill, P., \& Crevola, C. (2006). Breakthrough. Thousand Oaks, CA: Corwin Press.

Furry, A., Silverstein, J. \& Van Vieck, S. (2010). What positive effects does differentiated instruction have on student success? National Reading Technical Assistance Center (NRTAC).

Gardner, H. (1983). Multiple Intelligences. New York, NY: Basic Books.

Garet, M. S., Porter, A. C., Desimone, L., Birman, B. F., \& Yoon, K. S. (2001). What makes professional development effective? Results from a national sample of teachers. American educational research journal, 38(4), 915-945.

Good, T. L. (1987). Teacher Expectations. New York: Random House. 
Greenleaf, F. (2005). In passion for the world: A history of Seventh-day Adventist education. Nampa, ID: Pacific Press.

Grierson, A. L. (2011). Walking the talk: Supporting teachers growth with differentiated professional learning. Paper presented at the American Educational Research Association, New Orleans, LA.

Gusky, T. R. (1986). Staff development and the process of teacher change. Educational Researcher, 15(5), 5-12.

Gusky, T. R. (1994). Professional development in education: In search of the optimal mix. Paper presented at the American Educational Research Association, New Orleans, LA.

Hall, B. 2009. Differentiated instruction: Reaching all students. Research into practice mathematics. Retrieved from http://www.pearsonschool.com/live/assets/200916/ Matmon092625HS2011Hall_20703_1.pdf

Hall, G. E. (1974). The concerns-based adoption model: A developmental conceptualization of the adoption process within educational institutions (ERIC Document Reproduction Service No. ED111791).

Hall, G. E., Dirksen, D. J., \& George, A. A. (2013). Measuring implementation in schools: Levels of use: Southwest Educational Development Laboratory.

Hall, G. E., \& George, A. A. (2000). The use of nnovation configuration maps in assessing implementation: The bridge between development and student outcomes. Paper presented at the American Educational Research Association, New Orleans, LA.

Hall, G. E., \& Hord, S. M. (2011). Implementing change: Patterns, principles, and potholes, (3rd ed.). Upper Saddle River, NJ: Pearson.

Hall, G. E., \& Loucks, S. (1978). Teacher concerns as a basis for facilitating and personalizing staff development. Teachers College Record, 80(1), 36-53.

Hall, G. E., Wallace, R. D., Jr., \& Dossett, W. A. (1973). A developmental conceptualization of the adoption process within educational institutions. Austin, TX: Research and Development Center for Teacher Education, University of Texas, (ERIC Document Reproduction Service No. ED 095126).

Hall, T. (2002). Differentiated instruction. Effective classroom practices report. National Center on Accessing the General Curriculum, CAST, U.S. Office of Special Education Programs.[Online] http://www.cast.org/ncac/classroompractice/ cpractice02.doc 
Hall, T., Vue, G., Strangman, N., \& Meyer, A. (2004). Differentiated instruction and implications for UDL implementation. Wakefield, MA: National Center on Accessing the General Curriculum. Retrieved from http://aem.cast.org/about/ publications/2003/ncac-differentiated-instruction-udl.html

Hargreaves, A. (2014). Handbook of professional development in education: Successful models and practices, PreK-12. Guilford Publications.

Heacox, D. (2002). Differentiating instruction in the regular classroom: how to reach and teach all learners, grades 3-12, (Updated anniversary edition). Minneapolis, MN: Free Spirit.

Henry, G. T., \& Opfer, D. (2004). The impact of high stakes accountability on teachers efforts to improve instruction: Andrew Young School of Policy Studies, Georgia State University.

Hiebert, J. (1999). Relationships between research and the NCTM standards. Journal for research in mathematics education, $30(1), 3$.

Hord, S. M. (1997). Professional learning communities: Communities of continuous inquiry and improvement. Austin, TX: Research and Development Center for Teacher Education, University of Texas, (ERIC Document Reproduction Service No. ED 410659.

Hord, S. M. (2004). Learning together leading together: Changing schools through professional learning communities. New York: Teachers College Press.

Hord, S., Stiegelbauer, S., Hall, G., \& George, A. (2006). Measuring implementation in schools: Innovation configurations. Retrieved from Austin Texas: Southwest Educational Development Laboratory

Immel, S. (1992). Reflective practice in adult education (pp. 1992-3). (ERIC Document Reproduction Service No. ED 346319).

Ismaji, H., \& Imami-Morina, I. (2018). Differentiated Instruction: Understanding and Applying Interactive Strategies to Meet the Needs of All the Students. International Journal of Instruction, 11(3), 207-218.

IRIS Center. (2010). Differentiated instruction: Maximizing the learning of all students. Retrieved from https://iris.peabody.vanderbilt.edu/module/di/

Jewett, P., \& MacPhee, D. (2012). Adding collaborative peer coaching to our teaching identities. The Reading Teacher, 66(2), 105-110.

Joyce, B., \& Showers, B. (2002). Designing training and peer coaching: Our need for learning. VA: ASCD. National College for School Leadership, 1-5.

Kauchak, D. P., \& Eggen, P. D. (1993). Learning and teaching. New York: Allyn Bacon. 
Kennedy, E., \& Sheil, G. (2010). Raising literacy levels with collaborative on-site professional development in an urban disadvantaged school. The Reading Teacher, 63(5), 372-383

Kirner, M. (2009). Differentiated instruction data report \& summary: A look at Connecticut. Middletown, CT: State Education Resource Center Retrieved from https://ctserc.org/documents/resources/differentiated-instruction-data-report-andsummary-2010.pdf

Knapp, M. S. (2003). Professional development as a policy pathway. Review of Research in Education, 27(1), 109-157.

Kohler, F. W., Good, G., Crilley, K. M., \& Shearer, D. D. (2001). Effects of peer coaching on teacher and student outcomes. The Journal of Educational Research, 90(4), 240-250.

Latz, A. O., Speirs Neumeister, K. L., Adams, C. M., \& Pierce, R. L. (2008). Peer coaching to improve classroom differentiation: Perspectives from Project CLUE. Roeper Review, 31(1), 27-39.

Lawrence-Brown, D. (2004). Differentiated instruction: Inclusive strategies for standards based learning that benefitvs the whole class. American Secondary Education, $32(3), 34-62$.

Little, C. A., Paul, K. A. (2011). Professional development to support successful curriculum implementation. In J. VanTassel-Baska \& C.A. Little content-based curriculum for high-ability learners, 413-436. Waco, TX: Prufrock Press.

Loucks-Horsley, S. (1996). Professional development for science education: A critical and immediate challenge. Biological Sciences Curriculum Study. Dubuque, IA: Kendall/Hunt.

Lunenberg, M., \& Korthagen, F. A. (2003). Teacher Educators and Student-directed learning. Teaching and teaching education, 19(1), 29-44.

Mack, N. (2005). Qualitative research methods: A data collector's field guide.

McCarthy, B. (1996). About Learning. Barrington, IL: Excel.

McCarthy, B., \& Morris, S. (1998). A Comprehensive guide to the study \& presentation of the 4MAT instructional method. Barrington, IL: Excel.

McLesky, J., \& Waldron, N. L. (2002). Professional development and inclusive schools: reflections on effective practice. The Teacher Educator, 37(3), 159-172. 
Mitchell, T. F. (2013). An exploration of teachers' perception of the influence of professional learning communities on their professional practices and on teacher retention. (Doctoral dissertation). Available from ProQuest Dissertations \& Theses Global (UMI No. 3586169).

Mizell, H., Hord, S., Killion, J., \& Hirsh, S. (2011). New standards put the spotlight on professional learning. The Learning Professional, 32(4), 41.

Mraz, M., Algozzine, B., \& Kissel, B. (2009). The literacy coach's companion: Pre-K-3. Thousand Oaks, CA: Internal Reading Association.

Nishimura, T. (2014). Effective professional development of teachers: a guide to actualizing inclusive schooling. International Journal of Whole Schooling, 10(1), $21-42$.

Pajares, M. F. (1992). Teachers' beliefs and educational research: Cleaning up a messy construct. Review of Educational Research, 62, 307-332.

Ritchie, J., Lewis, J., Nicholls, C. M., \& Ormston, R. (2013). Qualitative research practice: A guide for social science students and researchers: sage.

Roach, A. T., Kratochwill, T. R., \& Frank, J. L. (2009). School-based consultants as change facilitators: Adaptation of the concerns-based adoption model (CBAM) to support the implementation of research-based practices. Journal of Educational and Psychological Consultation, 19(4), 300-320.

Roach, V. (1996). Overcoming barriers to creating inclusive schools. Impact, 6-7.

Robbins, P. (1991). How to plan and implement a peer-coaching program. Association for Supervision and Curriculum Development, Alexandria, VA:

Schmoker, M. (2006). Results now. Alexandria, VA: Association for Supervision and Curriculum Development. Connections, 9.

Shields, S. L. (2007). A cross-case analysis of peer coaching in two elementary schools. . (Doctoral dissertation). Available from ProQuest Dissertations \& Theses Global (UMI No. DP20060).

Showers, B., \& Joyce, B. (1996). The evolution of peer coaching. Educational Leadership, 53, 12-16.

Smylie, M. (1988). The enhancement function of staff development: Organizational and psychological antecedents to individual teacher change. American Educational Research, 25(1), 1-30.

Stafford, J. T. (2006). The importance of educational research in the teaching of history. Canadian Social Studies, 40(1). 
Sternberg, R. J. (2011). The Cambridge Handbook of Intelligence. New York: Cambridge University Press.

Sternberg, R. J., \& Williams, W. M. (1998). You proved our point better than we did: A reply to our critics. A merican Psychologist, 53(5), 576-577.

Stewart, C. (2014). Transforming professional development to professional learning. Journal of Adult Education, 43(1), 28.

Stiggins, R. (2005). Assessment for learning: Building a culture of confident learners. In R. DuFour, R. Eaker, \& R. DuFour (Eds.), On common ground: The power of professional learning communities (pp. 209-223). Bloomington, IN: Solution Tree.

Stover, K., Kissel, B., Haag, K., \& Shoniker, R. (2011). Differentiated coaching: fostering reflection with teachers. The Reading Teacher, 64(7), 498-509.

Taton, J. A. (2015). Much more than it's cooked-up to be: reflections on doing math and teachers' professional learning. The University of Pennsylvania Graduate School of Education's online Urban Education Journal, 12(1).

Teddlie, C. \& Tashakkori, A. (2003). Major issues and controversies in the use of mixedmethods in the social \& behavioral sciences. In A. Tashakkori \& C. Teddlie (Eds.), Handbook of mixed-methods in social \& behavioral research, (3-50). Thousand Oaks, CA: Sage.

Tomlinson, C. A. (1999). The differentiated classroom: Responding to the needs of all learners. Alexandria, VA: Association for Supervision and Curriculum Development. (ERIC Document Reproduction Service No. ED 429944).

Tomlinson, C. A. (2001). How to differentiate instruction in mixed-ability classrooms. Alexandria, Virginia: ASCD.

Tomlinson, C. A., \& Jarvis, J. (2009). Differentiation: Making curriculum work for all students through responsive planning and instruction. In J. S. Renzulli, E. J. Gubbins, K. S. McMillen, R. D. Eckert, \& C. A. Little (Eds.), Systems and models for developing programs for the gifted and talented (pp. 599-628). Storrs, CT: Creative Learning Press.

Tomlinson, C. A., \& McTighe, J. (2006). Integrating differentiated instruction and understanding by design: Connecting content and kids. Alexandria, VA: Association for Supervision \& Curriculum Development.

Torgenson, J. (November, 2008). Teaching all students to read: Is it really possible? Presented at the meeting of the International Dyslexia Association, Seattle, WA.

Tschannen-Moran, B., \& Tschannen-Moran, M. (2010). Evocative coaching: transforming schools one conversation at a time. San Francisco, CA: Jossey-Bass. 
Tschannen-Moran, B., \& Tschannen-Moran, M. (2011). Coaching, the new leadership skill: The coach and the evaluator. Educational Leadership, 69(2), 10-16.

Tunks, J., \& Weller, K. (2009). Changing practice, changing minds, from arithmetical to algebraic thinking: An application of the concerns-based adoption model (CBAM). Educational Studies in Mathematics, 72(2), 161.

Van Harpen, G. (2015). Connecting to Learn: A Mixed Methods Study of Professional Learning for Secondary School Leaders in Small Districts and Rural Areas: Cardinal Stritch University.

Vygotsky, L. S. (1980). Mind in society: The development of higher psychological processes. Harvard University Press.

Yin, R. K. (2014). Case study research design and methods (5 $5^{\text {th }}$ ed.) Thousand Oaks, CA: Sage.

Yuan, E. R. (2017). Exploring university-based teacher educators' teaching beliefs and practice: a Hong Kong study. Teaching in Higher Education, 22(3), 259-273.

Zeichner, K. M., \& Liston, D. P. (1996). Reflective teaching: An introduction. Mahwah, NJ: Lawrence Erlbaum. 
VITA

\section{Jennifer J. Bianco \\ 552 Wildlife Court -- Fairborn, OH 45324 -- 484.459 .3508}

\section{Philosophv:}

Educating children not only for success in this world, but also for living a life of mission and ultimately for eternity with Jesus Christ, by building relationships, developing leadership and excellence among colleagues and students, and creating a school environment where a bright future is cultivated.

\section{Professional Experience:}

$1^{\text {st }} / 2^{\text {nd }}$ grade Teacher, Spring Valley Academy

2017-Present

Dayton, $\mathrm{OH}$

Principal/6-8 Teacher Lehigh Valley SDA School

2015-2017

Allentown, PA

$1^{\text {st }}-2^{\text {nd }}$ Grade Teacher Huntingdon Valley Christian Academy

2006-2015

Huntingdon Valley, PA

$5^{\text {th }}-8^{\text {th }}$ Grade Teacher West Chester Seventh-day Adventist School

$1996-2006$

West Chester, PA

K- $4^{\text {th }}$ Grade Teacher Apison Seventh-day Adventist School

1993-1996

Apison, TN

\section{Education:}

BS Elementary Education, Southern Adventist College

M.Ed., West Chester University (emphasis on creative teaching in the multiage/multigrade classroom)

Ph.D. Candidate, dissertation topic- "Differentiated Instruction, Beliefs/Perceptions \&

Support Methods", projected graduation date- Summer 2019

\section{Qualifications \& Awards}

Columbia Union Outstanding Educator Award

Who's Who in American Colleges and Universities

Lead Teacher/Trainer Pennsylvania Conference Pathways Program 2007-2009

Lead Teacher/Trainer Columbia Union Encounters Bible Program 2014-Present

Gessell Developmental Assessment Evaluator

Working with, mentoring, coaching, and training teachers in curricula and classroom strategies 2007-Present

Summer Camp Experience includes counselor, craft director, food service director, nature director

Day-Care Experience

\section{Committees/Boards}

Spring Valley Academy Strategic Planning Committee, 2018-present

Pennsylvania Conference Executive Committee, 2012-2016 
Columbia Union Board of Education, 2013-2016

Pennsylvania Principal's Council 2015-2017

\section{References:}

**Dr. Jeff Bovee, PhD., Supervisor, Nebraska Conference Superintendent -610.927.7744

**Dr. Janet Ledesma, PhD., Academic Advisor, Andrews University -269.363.0045

**Darren Wilkins, MBA, Principal, Current Supervisor, Spring Valley Academy 406.570 .9258 